Aus der Klinik für Psychiatrie und Psychotherapie

(Prof. Dr. med. J. Wiltfang)

der Medizinischen Fakultät der Universität Göttingen

\title{
Die Wirkung von postnataler Hypoxie auf die neuronale Zellproliferation im Rattenhirn und ihre Relevanz für die Schizophrenie
}

\author{
INAUGURAL - DISSERTATION \\ zur Erlangung des Doktorgrades \\ der Medizinischen Fakultät der \\ Georg-August-Universität zu Göttingen
}

vorgelegt von

Franziska Kühn

aus

Weimar

Göttingen 2015 
Dekan:

Prof. Dr. rer. nat. H. Kroemer

I. Berichterstatter/ in: Prof. Dr. A. Schmitt

II. Berichterstatter/ in: Prof. Dr. T. Dresbach

III. Berichterstatter/ in:

IV. Tag der mündlichen Prüfung: $\quad$ 15.03.2016 
Teile dieser Arbeit wurden veröffentlicht:

Schaeffer EL, Kühn F, Schmitt A, Gattaz WF, Gruber O, Schneider-Axmann T, Falkai P, Schmitt A (2013):

Increased cell proliferation in the rat anterior cingulate cortex following neonatal hypoxia:

relevance to schizophrenia. J Neural Transm $\underline{120}(1), 187-95$ 


\section{Inhaltsverzeichnis}

- Tabellenverzeichnis.............................................................VI

- Abbildungsverzeichnis........................................................... II

• Abkürzungsverzeichnis..............................................................III

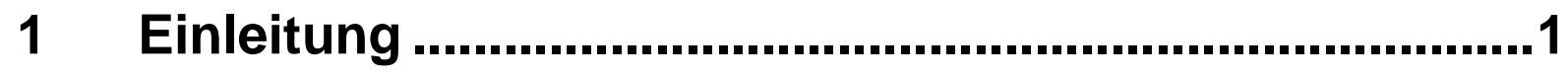

1.1 Symptome und klinische Aspekte....................................... 2

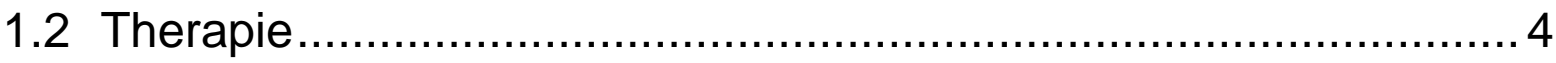

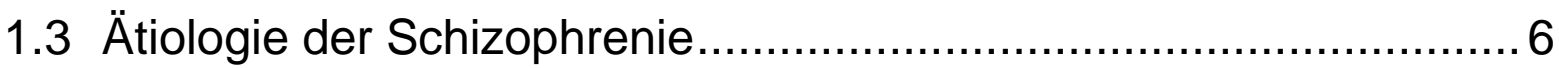

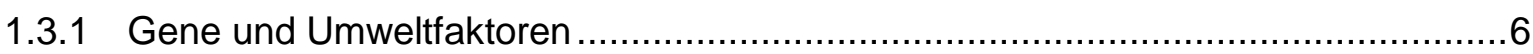

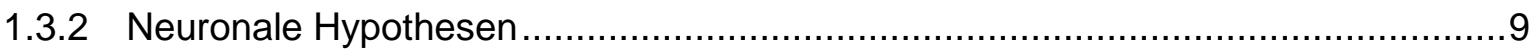

1.4 Hypoxie: Ein Umweltfaktor in der Ätiologie der Schizophrenie ..... 11

1.4.1 Auswirkungen von Hypoxie auf das Gehirn ......................................................11

1.4.2 Tiermodelle in der Schizophrenie: Untersuchungen des Verhaltens und Auswirkungen postnataler Hypoxie ...........................................12

1.5 Neurogenese und Stammzellproliferation................................. 14

1.5.1 Neurogenese und Schizophrenie.................................................................15

1.5.2 Einfluss von Clozapin und Haloperidol auf die Neurogenese ..............................16

1.5.3 Einfluss von Stress auf die Neurogenese ......................................................17

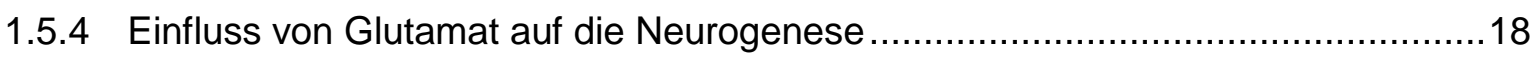

1.5.5 Einfluss von Hypoxie-Ischämie auf die Neurogenese ......................................19

1.6 Zielsetzung und Fragestellung .......................................... 20

2 Material und Methoden ................................................21

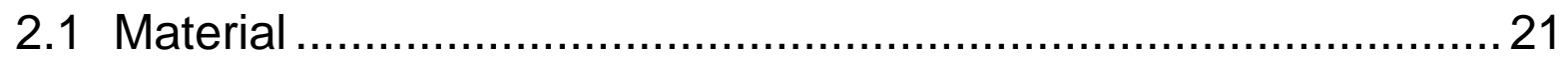

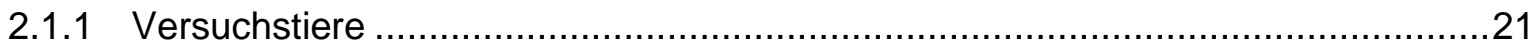

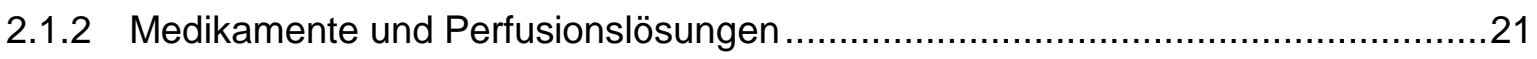

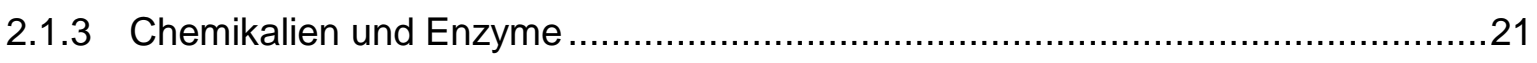

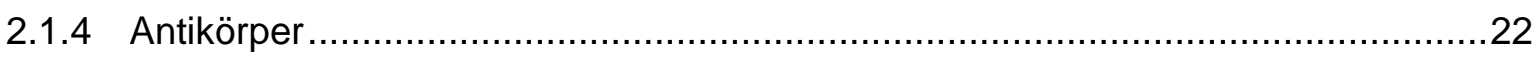

2.1.5 Geräte und Materialien ..............................................................................22

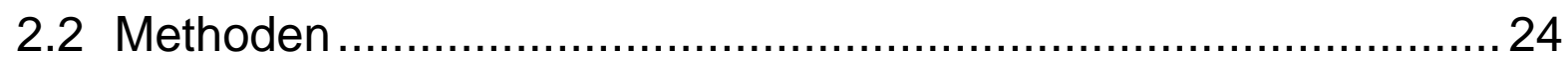

2.2.1 Einteilung der Versuchstiere ..................................................................24 


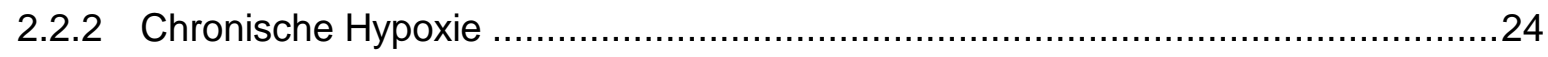

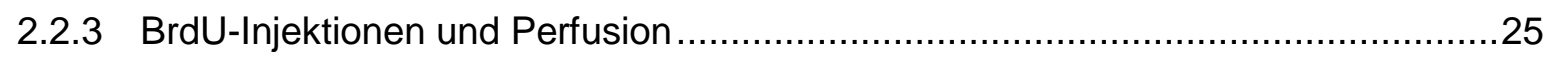

2.2.4 Anfertigung von Dünnschnitten am Gefriermikrotom.....................................28

2.2.5 Immunhistochemische BrdU-Peroxidasefärbung ........................................29

2.2.6 Bestimmung der Zellzahl mit dem Stereologiemikroskop..................................30

2.2.7 Tabellarische Zusammenfassung zur Zellzahlbestimmung mit der Optical Fractionator-Methode ............................................................ 39

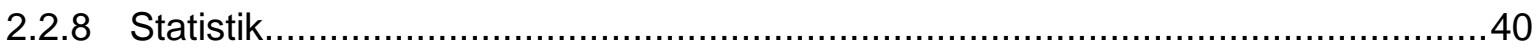

3 Ergebnisse ..............................................................41

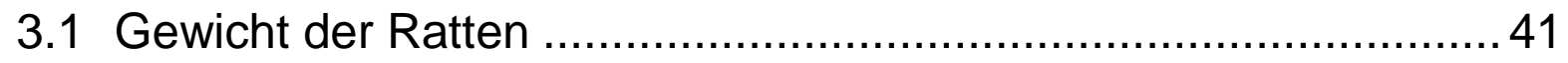

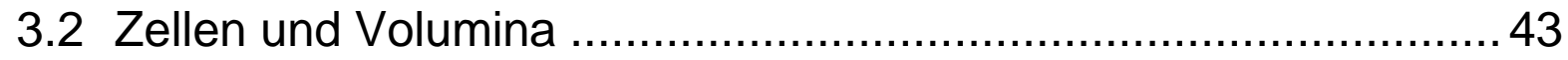

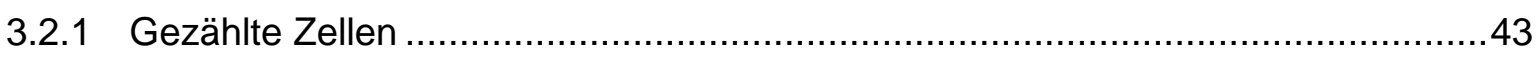

3.2.2 Absolute Zellzahlen und Volumina............................................................... 46

3.3 Korrelationen zwischen Gewicht/Gewichtszunahme und absoluter Zellzahl/Zellvolumina ................................... 52

4 Diskussion ...................................................................54

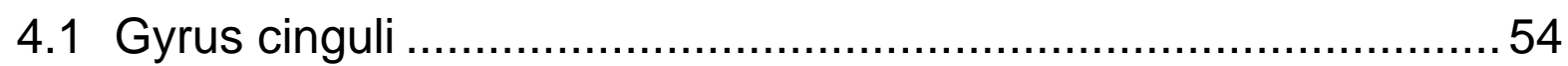

4.2 Subventrikuläre Zone .................................................. 58

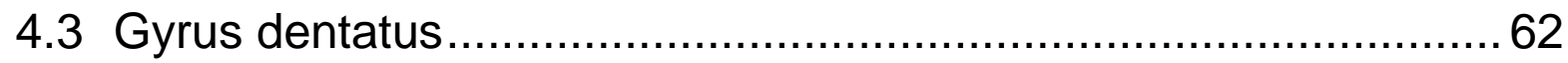

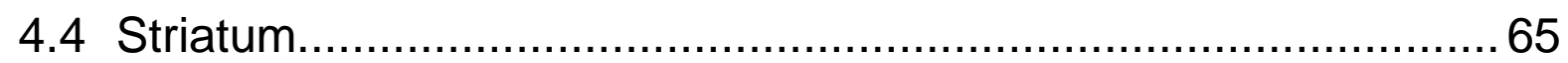

4.5 Weitere hypoxieassoziierte Tiermodelle und deren

Auswirkungen auf die Zellproliferation

und Neurogenese ....................................................... 70

4.6 Neurobiologische Tiermodelle der Gen-Hypoxie-Interaktion und ihre Relevanz für die Schizophrenie ............................ 71

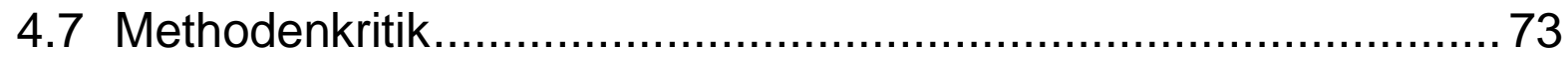

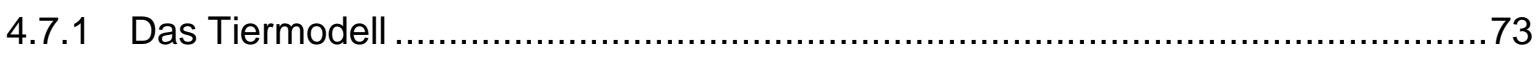

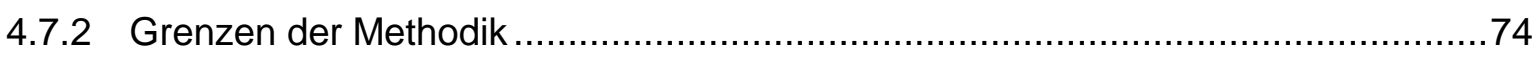

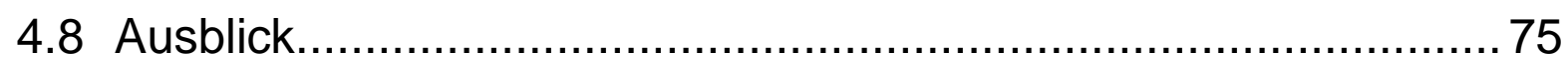

$5 \quad$ Zusammenfassung......................................................77 
6 Anhang

6.1 Systematik der Symptome ersten und zweiten Ranges

nach Kurt Schneider (1938)

6.2 Anzahl (n) der ausgewerteten Schnitte je Hirnregion und Gehirn

7 Literaturverzeichnis .82 


\section{Tabellenverzeichnis}

Tab. 1: $\quad$ Unterformen der Schizophrenie nach ICD 10 und deren Klinik

Tab. 2: $\quad$ Lokalisationskoordinaten der relevanten Hirnregionen ausgehend vom Bregma

Tab. 3: $\quad$ Koordinaten für die Lage und den Abstand der Zählkästchen

Tab. 4: $\quad$ Mittelwert und Standardabweichung aus der Anzahl der ausgewerteten Schnitte je Hirnregion PD 13 Kontrolle

Tab. 5: $\quad$ Mittelwert und Standardabweichung aus der Anzahl der ausgewerteten Schnitte je Hirnregion PD 13 Hypoxie

Tab. 6: $\quad$ Mittelwert und Standardabweichung aus der Anzahl der ausgewerteten Schnitte je Hirnregion PD 39 Kontrolle

Tab. 7: $\quad$ Mittelwert und Standardabweichung aus der Anzahl der ausgewerteten Schnitte je Hirnregion PD 39 Hypoxie

Tab. 8: $\quad$ Darstellung der Details zur stereologischen Zellbestimmung Hypoxie/Kontrolle PD 13

Tab. 9: $\quad$ Darstellung der Details zur stereologischen Zellbestimmung Hypoxie/Kontrolle PD 39

Tab. 10: $\quad$ Mittelwerte der gezählten Zellen für Hypoxie/Kontrolle PD 13 und PD 39 der vier Hirnregionen

Tab. 11: Gewicht und Gewichtszunahme der Hypoxie- und Kontrolltiere PD 13

Tab. 12: $\quad$ Gewicht und Gewichtszunahme der Hypoxie- und Kontrolltiere PD 39

Tab. 13: Gezählte Zellen Hypoxie- und Kontrolltiere PD 13

Tab. 14: Gezählte Zellen Hypoxie- und Kontrolltiere PD 39

Tab. 15: Deskriptive Statistiken, (M)ANOVA: Absolute Zellzahlen und Volumina Hypoxie- und Kontrolltiere PD 13

Tab. 16: Deskriptive Statistiken, (M)ANOVA: Absolute Zellzahlen und Volumina Hypoxie- und Kontrolltiere PD 39

Tab. 17: $\quad$ Korrelationen zwischen absoluter Zellzahl ACC PD 13 und Gewicht/Gewichtszunahme

Tab. 18: Korrelationen zwischen absolutem Volumen CPU PD 13 und Gewicht/Gewichtszunahme

Tab. 19: $\quad$ Anzahl ( $\mathrm{n}$ ) der ausgewerteten Schnitte je Hirnregion und Gehirn PD 13 Kontrolle

Tab. 20: $\quad$ Anzahl $(n)$ der ausgewerteten Schnitte je Hirnregion und Gehirn PD 13 Hypoxie 
Tab. 21: $\quad$ Anzahl (n) der ausgewerteten Schnitte je Hirnregion und Gehirn

PD 39 Kontrolle

Tab. 22: $\quad$ Anzahl (n) der ausgewerteten Schnitte je Hirnregion und Gehirn PD 39 Hypoxie

\section{Abbildungsverzeichnis}

Abb. 1: Versuchaufbau Normoxie versus Hypoxie $\quad 25$

Abb. 2: $\quad$ BrdU und Desoxythymidin 26

Abb. 3: $\quad$ Darstellung des knöchernen Rattenschädels 28

Abb. 4: $\quad$ Stereo Investigator System (Klinik für Psychiatrie und Psychotherapie der Universität Göttingen): Beispielhafte Darstellung der SVZ 30

Abb. 5: $\quad$ Umgrenzung ACC in 2-facher Vergrößerung 33

Abb. 6: Umgrenzung SVZ in 2-facher Vergrößerung 33

Abb. 7: Umgrenzung CPU in 2-facher Vergrößerung 34

Abb. 8: $\quad$ Umgrenzung DG in 2-facher Vergrößerung 34

Abb. 9: Zählkästchen mit drei markierten Zellen in 50-facher Vergrößerung 34

Abb. 10: $\quad$ Zellen ACC in 50-facher Vergrößerung PD 13 Hypoxie und Kontrolle $\quad 35$

Abb. 11: $\quad$ Zellen ACC in 50-facher Vergrößerung PD 39 Hypoxie und Kontrolle $\quad 35$

Abb. 12: $\quad$ Zellen SVZ in 50-facher Vergrößerung PD 13 Hypoxie und Kontrolle

Abb. 13: $\quad$ Zellen SVZ in 50-facher Vergrößerung PD 39 Hypoxie und Kontrolle

Abb. 14: $\quad$ Zellen CPU in 50-facher Vergrößerung PD 13 Hypoxie und Kontrolle

Abb. 15: $\quad$ Zellen CPU in 50-facher Vergrößerung PD 39 Hypoxie und Kontrolle

Abb. 16: $\quad$ Zellen DG in 50-facher Vergrößerung PD 13 Hypoxie und Kontrolle

Abb. 17: $\quad$ Zellen DG in 50-facher Vergrößerung PD 39 Hypoxie $\begin{array}{ll}\text { und Kontrolle } & 38\end{array}$

Abb. 18: $\quad$ Gewichtsverlauf PD 4 bis PD 13, Vergleich Hypoxie und Kontrolle 42

Abb. 19: $\quad$ Gewichtsverlauf PD 4 bis PD 39, Vergleich Hypoxie und Kontrolle 42

Abb. 20: $\quad$ Gezählte Zellen ACC PD 13 und PD 39, Vergleich Hypoxie und Kontrolle 44

Abb. 21: $\quad$ Gezählte Zellen CPU PD 13 und PD 39, Vergleich Hypoxie und Kontrolle 44 
Abb. 22: $\quad$ Gezählte Zellen DG PD 13 und PD 39, Vergleich Hypoxie und Kontrolle 45

Abb. 23: $\quad$ Gezählte Zellen SVZ PD 13 und PD 39, Vergleich Hypoxie und Kontrolle 45

Abb. 24: $\quad$ Absolute Zellzahl ACC PD 13 und PD 39, Vergleich Hypoxie und Kontrolle

Abb. 25: $\quad$ Absolute Zellzahl CPU PD 13 und PD 39, Vergleich Hypoxie und Kontrolle

Abb. 26: $\quad$ Absolute Zellzahl DG PD 13 und PD 39, Vergleich Hypoxie und Kontrolle

Abb. 27: $\quad$ Absolute Zellzahl SVZ PD 13 und PD 39, Vergleich Hypoxie und Kontrolle

Abb. 28: Volumen ACC PD 13 und PD 39, Vergleich Hypoxie und Kontrolle $\quad 50$

Abb. 29: Volumen CPU PD 13 und PD 39, Vergleich Hypoxie und Kontrolle 50

Abb. 30: Volumen DG PD 13 und PD 39, Vergleich Hypoxie und Kontrolle $\quad 51$

Abb. 31: Volumen SVZ PD 13 und PD 39, Vergleich Hypoxie und Kontrolle $\quad 51$

\section{Abkürzungsverzeichnis}

\begin{tabular}{|c|c|}
\hline ACC & Anterior ćingulate cortex (anteriorer Gyrus cinguli) \\
\hline ACCo & Arteria carotis communis \\
\hline ACM & Arteria cerebri media \\
\hline ANOVA & analysis of variance (Varianzanalyse) \\
\hline BrdU & Bromodeoxyuridin \\
\hline $\mathrm{CO}_{2}$ & Kohlenstoffdioxid \\
\hline CPU & caudate putamen (Striatum) \\
\hline DAB & 3,3'-Diauminobenzidine \\
\hline DG & dentate gyrus (Gyrus dentatus) \\
\hline DNA & Deoxyribonucleic a acid (Desoxyribonukleinsäure) \\
\hline DSM V & 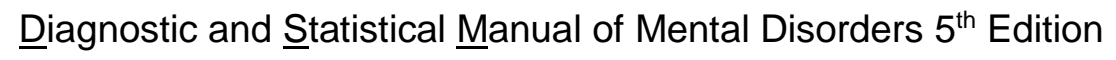 \\
\hline GABA & Gamma-ạminobutyric a acid (Gamma- Amino- Buttersäure) \\
\hline GWAS & Genomweite $\underline{\text { Assoziationsstudie }}$ \\
\hline $\mathrm{H}_{2} \mathrm{O}$ & Wasser \\
\hline $\mathrm{H}_{2} \mathrm{O}_{2}$ & Wasserstoffperoxid \\
\hline $\mathrm{HCl}$ & Salzsäure \\
\hline HIF $1 / 2$ & 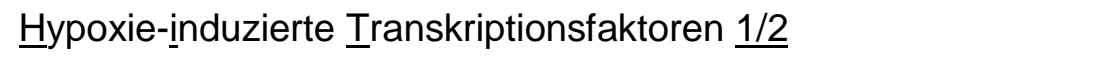 \\
\hline ICD 10 & 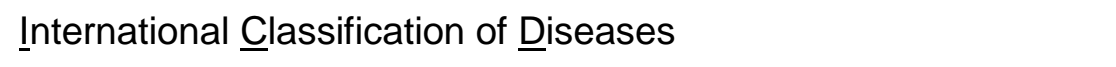 \\
\hline MANOVA & 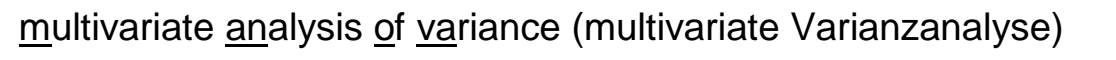 \\
\hline MR/MRT & Magnetresonanztomografie \\
\hline
\end{tabular}




\begin{tabular}{|c|c|}
\hline $\mathbf{N}_{2}$ & Stickstoff \\
\hline $\mathrm{NaCl}$ & $\underline{\text { Natriumchlorid }}$ \\
\hline NeuN & neuronal specific nuclear protein (Neuronen-spezifisches Protein) \\
\hline NGS & normal goat serum (normales Ziegenserum) \\
\hline \multicolumn{2}{|l|}{ NMDA- } \\
\hline Rezeptor & N-Methyl-D- - Aspartat-Rezeptor \\
\hline NRG 1 & Neuregulin 1 \\
\hline NSE & Neuronen-spezifische Enolase \\
\hline $\mathrm{O}_{2}$ & Sauerstoff \\
\hline PD & postnatal day (postnataler Tag) \\
\hline PPI & Präpulsinnhibition \\
\hline SVZ & subventricular żone (subventrikuläre Zone) \\
\hline TBS & tris-b buffered saline (Tris-gepufferte Salzlösung) \\
\hline ZNS & żentrales Nervensystem \\
\hline
\end{tabular}




\section{$1 \quad$ Einleitung}

Bei der Schizophrenie handelt es sich um ein komplexes Syndrom, das Störungen im seelischen Erleben, aber auch in anderen Bereichen wie Denken, Wahrnehmung, Ichfunktion, Affektivität, Antrieb und Psychomotorik beinhaltet. Bewusstseinslage und Orientierung hingegen sind in der Regel ungestört (Wobrock et al. 2004a).

Seit dem Beginn des letzten Jahrhunderts wird die Schizophrenie als eine Erkrankung des Gehirns angesehen. Obwohl es zahlreiche Hypothesen zur Entstehung der Schizophrenie gibt, handelt es sich dennoch um eine Erkrankung, deren Ursachen noch weitgehend unbekannt sind und bei der genetische und umweltbedingte Faktoren als multifaktorielles Geschehen zusammenwirken. Dazu zählen vor allem genetische Veränderungen, gestörte Hirnentwicklung, veränderte Neurotransmitter, gestörte neuronale Regelkreise, aber auch perinatale Umweltfaktoren wie Geburts- und Schwangerschaftskomplikationen (Kornhuber et al. 2004).

Emil Kraepelin war 1896 der erste Kliniker, der eine ausführliche Definition entwickelte, die weltweite Akzeptanz fand. Mit der Bezeichnung dementia praecox definierte er ein Syndrom, das sich relativ früh im Leben manifestiert (praecox) und eine durchdringende und persistierende Einschränkung in kognitiven Funktionen und Verhaltensfunktionen (dementia) herbeiführt (Kraepelin 1919, zit. nach Andreasen und Carpenter 1993). 1911 definierte Eugen Bleuler den Begriff „Schizophrenie“ (griechisch schizo=abspalten und phren=Seele), um die Spaltung der Seele als wichtigstes Merkmal zu betonen (Bleuler 1911, zit. nach Andreasen und Carpenter 1993). Kurt Schneider versuchte später wie Eugen Bleuler, Merkmale zu definieren, die eine hohe Spezifität für die Schizophrenie aufweisen und bei anderen Erkrankungen nicht auftreten (Schneider 1959, zit. nach Andreasen und Carpenter 1993). So entstanden die Symptome ersten und zweiten Ranges der Schizophrenie (siehe Kapitel 6.1 Systematik der Symptome ersten und zweiten Ranges nach Kurt Schneider 1938), die heute als Grundlage der gültigen Diagnosesysteme International Classification of Diseases (ICD) und Diagnostic and Statistical Manual of Mental Disorders (DSM V) gelten (Dilling et al. 2014, American Psychiatric Association 2013).

Im Alter von 15 bis 44 Jahren gehört die Schizophrenie zu den am häufigsten zu Behinderung führenden Erkrankungen. Die entstehenden Kosten sind mit denen somatischer Volkskrankheiten vergleichbar, somit ist sie die kostenintensivste psychiatrische Erkrankung (Wobrock et al. 2004a). Weltweit sind circa 21 Millionen Menschen betroffen (WHO 2014). 


\subsection{Symptome und klinische Aspekte}

Bei der Schizophrenie handelt es sich um ein sehr heterogenes Krankheitsbild. Die Diagnose erfolgt heutzutage nach den zwei international anerkannten Diagnosemanualen ICD 10 (Unterkapitel F20) und DSM V (Unterkapitel 295). Die krankheitskennzeichnenden Symptome werden nach ICD 10 in folgenden Gruppen aufgeführt (Dilling et al. 2014):

1. Gedankenlautwerden, -eingebung, -entzug, -ausbreitung

2. Kontroll- und Beeinflussungswahn, Gefühl des Gemachten (wie Gedanken, Empfindungen oder Tätigkeiten), Wahnwahrnehmungen

3. kommentierende oder dialogische Stimmen

4. anhaltender, kulturell unangemessener oder unrealistischer (bizarrer) Wahn

5. anhaltende Halluzinationen jeder Sinnesmodalität täglich über Wochen oder Monate auftretend (begleitet von Wahngedanken oder überwertigen Ideen)

6. Gedankenabreißen oder -einschiebungen in den Gedankenfluss

7. katatone Symptome wie Erregung, Haltungsstereotypien, wächserne Biegsamkeit, Negativismus, Mutismus, Stupor

8. Negativsymptome wie auffällige Apathie, Sprachverarmung, verflachter oder inadäquater Affekt

Für die Diagnose nach ICD 10 ist mindestens ein eindeutiges Symptom der Gruppen eins bis vier oder mindestens zwei Symptome der Gruppen fünf bis acht erforderlich (Dilling et al. 2014). Nach DSM V sind mindestens zwei der folgenden Symptome notwendig: Wahn, Halluzinationen, desorganisierte Sprechweise, unangemessenes oder katatones Verhalten und/oder Negativsymptome (American Psychiatric Association 2013), wobei die Symptome über mindestens einen Monat anhalten sollten (Dilling et al. 2014, American Psychiatric Association 2013). Es sollte keine Schizophrenie infolge einer Erkrankung des Gehirns, bei Vergiftung (Intoxikation) oder während eines Entzuges diagnostiziert werden, hier steht das Bild einer organischen Psychose im Vordergrund. Der Krankheitsverlauf ist entweder kontinuierlich oder episodisch mit Voll- oder Teilremissionen (Dilling et al. 2014). Sehr gebräuchlich ist heutzutage die zusätzliche Unterscheidung zwischen sogenannten Positiv- oder Plussymptomen und den Negativ- oder Minussymptomen. Positivsymptome sind hiernach Wahn, Halluzinationen, formale Denkstörungen und psychomotorische Symptome. Unter den Negativsymptomen werden Apathie (Mangel an Energie, Antriebsmangel bis zum Autismus), Aufmerksamkeitsstörung (Konzentrationsstörung, Verlangsamung des Denkens), Affektverflachung (Verarmung von Ausdruck und Reaktionsfähigkeit), Alogie (Sprachverarmung), Anhedonie (Unfähigkeit für Freude oder Vergnügen) und Asozialität (Mangel an Kontaktfähigkeit, sozialer Rückzug) zusammengefasst (Gleixner et al. 2007). In über $75 \%$ der Fälle ist 
die erste schizophrene Episode bereits fünf Jahre vor dem ersten klinischen Aufenthalt (Wobrock et al. 2004a). Der Beginn der Erkrankung kann akut durch schwer gestörtes Verhalten gekennzeichnet sein oder aber schleichend mit seltsamen Gedanken und/oder Verhaltensweisen einhergehen. Prodromalsymptome sind soziale Funktionseinbußen wie Interesseverlust an der Arbeit, sozialen Aktivitäten, Körperhygiene, persönlichem Erscheinungsbild, begleitet von Angst, Depression und Selbstversunkenheit (Dilling et al. 2014). Ein weiteres Problem schizophrener Patienten stellt das gewalttätige Verhalten dar, das vor allem mit positiven psychotischen Symptomen wie Verfolgungswahn assoziiert ist (Swanson et al. 2006). Suizid ist die Hauptursache für den frühzeitigen Tod schizophrener Patienten. Das Lebenszeitrisiko liegt bei 10 bis $13 \%$ gegenüber $1 \%$ bei der Normalbevölkerung (Caldwell und Gottesmann 1992). Risikofaktoren für Suizid sind Kinderlosigkeit, junges Alter bei Erkrankungsbeginn (Müller et al. 2005) sowie männliches Geschlecht, er ist aber auch gehäuft bei alleinstehenden, geschiedenen oder verwitweten Frauen (Besnier et al. 2009).

Die Schizophrenie gliedert sich nach ICD 10 in verschiedene Unterformen, die in Tabelle 1 zusammengefasst sind (Dilling et al. 2014): 


\begin{tabular}{|c|c|}
\hline Einteilung & Klinik / typische Merkmale \\
\hline $\begin{array}{l}\text { paranoide } \\
\text { Schizophrenie }\end{array}$ & $\begin{array}{l}\text { wahnhafte/halluzinatorische Symptome und Wahrnehmungsstö- } \\
\text { rungen, aber auch Störung der Stimmung, des Antriebs und der } \\
\text { Sprache }\end{array}$ \\
\hline $\begin{array}{l}\text { hebephrene } \\
\text { Schizophrenie }\end{array}$ & $\begin{array}{l}\text { Jugendalter und junge Erwachsene, vor allem affektive Verände- } \\
\text { rungen, „läppische“ Gestimmtheit und psychotisch- } \\
\text { unangemessenes Verhalten im Vordergrund, Faxen, Kichern, } \\
\text { Manierismen, schnelle Entwicklung einer Minussymptomatik, } \\
\text { Prognose eher ungünstig }\end{array}$ \\
\hline $\begin{array}{l}\text { katatone } \\
\text { Schizophrenie }\end{array}$ & $\begin{array}{l}\text { psychomotorische Störung (Erregung, Stupor, Negativismus und } \\
\text { Befehlsautomatismen), Zwangshaltungen und -stellungen }\end{array}$ \\
\hline $\begin{array}{l}\text { undifferenzierte } \\
\text { Schizophrenie }\end{array}$ & $\begin{array}{l}\text { erfüllt diagnostische Kriterien der Schizophrenie (F20), können } \\
\text { aber keiner Unterform zugeordnet werden }\end{array}$ \\
\hline $\begin{array}{l}\text { postschizophrene } \\
\text { Depression }\end{array}$ & $\begin{array}{l}\text { länger anhaltende depressive Episoden im Anschluss an eine } \\
\text { schizophrene Krankheit, erhöhtes Suizidrisiko }\end{array}$ \\
\hline $\begin{array}{l}\text { schizophrenes } \\
\text { Residuum }\end{array}$ & $\begin{array}{l}\text { chronisches Stadium mit Verschlechterung der Symptomatik und } \\
\text { lang andauernder Negativsymptomatik }\end{array}$ \\
\hline $\begin{array}{l}\text { Schizophrenia } \\
\text { Simplex }\end{array}$ & $\begin{array}{l}\text { schleichende Progredienz, merkwürdiges Verhalten, schlechtere } \\
\text { Leistungsfähigkeit, gesellschaftliche Anforderungen können nicht } \\
\text { erfüllt werden }\end{array}$ \\
\hline
\end{tabular}

Tab. 1: Unterformen der Schizophrenie nach ICD 10 und deren Klinik

\subsection{Therapie}

Schizophrene Störungen werden mehrdimensional durch die Kombination von Pharmakotherapie, Psychotherapie und Soziotherapie behandelt (Wobrock et al. 2004b).

1952 war Chlorpromazin das erste Medikament, das die Symptomatik der Schizophrenie lindern konnte und damit den Vorreiter einer neuen therapeutischen Option darstellte sowie zu einem Rückgang der Hospitalisierungsraten führte (Berger 2009). Der Begriff „Neuroleptikum“ weist auf einen Zusammenhang zwischen dem Auftreten von extrapyramidalmotorischen Nebenwirkungen und der antipsychotischen Wirksamkeit der Substanz hin und trifft vor allem auf die typischen bzw. konventionellen Antipsychotika zu (Antipsychotika der ersten Generation). Durch die Einführung einer neuen Medikamentengruppe, der sogenannten Atypika (Antipsychotika der zweiten Generation) wurde der Begriff „Neuroleptikum“ zunehmend nicht mehr benutzt und durch die Bezeichnung „Antipsychotikum“ ersetzt (Berger 2009). Auch heute noch gelten diese als Mittel der ersten Wahl in der Behandlung der Schizophrenie. Wichtig ist dabei ein frühzeitiger Therapiebeginn, da das Ansprechen umso höher 
ist, je kürzer die unbehandelte akute schizophrene Psychose besteht (Karow und Lang-Roth 2009). Aufgrund des geringeren Risikos extrapyramidal-motorischer Nebenwirkungen und der vergleichbaren Wirksamkeit sind Antipsychotika der zweiten Generation (z. B. Risperidon, Olanazapin) die bevorzugte Medikation in der Behandlung der ersten schizophrenen Episode gegenüber typischen Antipsychotika (z. B. Haloperidol). Jedoch sollte die Medikamentenwahl individuell erfolgen und an die geistigen und körperlichen Vorraussetzungen des Patienten angepasst sein, denn beide Medikamentengruppen sind effektiv in der Behandlung psychotischer Symptome. Auch bei primärer Negativsymptomatik scheint eine Therapie mit Atypika effektiver zu sein (Hasan et al. 2012). Die medikamentöse Therapie der ersten schizophrenen Episode sollte aufgrund der hohen Rezidivgefahr für ein bis zwei Jahre fortgeführt werden. Bei zahlreichen früheren Episoden oder mehr als zwei Episoden wird eine Therapie über zwei bis fünf Jahre oder auch dauerhaft (hohes Suizidrisiko, aggressives Verhalten, erhöhtes Rückfallrisiko) empfohlen (Hasan et al. 2013). Besonderes Augenmerk in der Therapie mit Antipsychotika gilt dem neurologischen (malignes neuroleptisches Syndrom, extrapyramidal-motorische Nebenwirkungen, Epilepsie), metabolischen (Hyperprolaktinämie, sexuelle Dysfunktion, Gewichtszunahme) und kardiovaskulären (erhöhte Herzfrequenz, niedriger Blutdruck, Long QT-Syndrom, Kammerflimmern) Nebenwirkungsspektrum (Hasan et al. 2012).

Ein wichtiges Problem in der medikamentösen Behandlung ist die Noncompliance der Patienten, die bis zu 70 \% beträgt. Patienten geben hierfür folgende Ursachen an: Unwissenheit über die Vorteile der Therapie, unbezahlbare Medikamente, Nebenwirkungen der medikamentösen Therapie, keine ausreichende Aufklärung durch den behandelnden Arzt, unfreundliche Haltung des Arztes, Stigmatisierung, fehlendes Krankheitsgefühl nach Symptombesserung (Taj und Khan 2005, Hasan et al. 2012).

Je nach der im Vordergrund stehenden Symptomatik sind psychotherapeutische Interventionen entsprechend der Krankheitsphase zu gestalten. In der Akutphase umfasst dies symptomreduzierende, vulnerabilitätsmindernde, stressreduzierende sowie bewältigungsfördernde therapeutische Interventionen. Nach dem Erreichen einer Stabilisierung können auch verhaltensmodifizierende Psychotherapieverfahren ergänzt werden (Wobrock et al. 2004b).

Die Langzeittherapie dient vor allem der Rückfallprophylaxe sowie Präventions- und Rehabilitationsmaßnahmen und sollte von psychiatrisch-psychotherapeutischen Interventionen begleitet sein. Die Pharmakotherapie dient der Optimierung des Krankheitsverlaufs durch Linderung und Kontrolle der Symptomatik und der Wiederherstellung der Lebensqualität (Hasan et al. 2013). Die Soziotherapie bildet den dritten Pfeiler in der Therapie der Schizophrenie und ist aufgrund von Hospitalisierungsschäden bei reizarmer Umgebung und der Gefahr der Ausbildung einer chronischen Negativsymptomatik besonders wichtig. Vorhandene soziale Fähigkeiten des Patienten sollen gefördert und die Entstehung bzw. Verstärkung sozialer 
Defizite verhindert werden. Die Soziotherapie umfasst die Arbeits- und Beschäftigungstherapie, Berufsrehabilitation, Strukturierung des Tagesablaufs und das Training sozialer Fertigkeiten (Möller et al. 2005).

\section{3 Ätiologie der Schizophrenie}

Die Lebenszeitprävalenz, eine Schizophrenie zu entwickeln, liegt bei circa $1 \%$ (Kornhuber et al. 2004). Jedes Jahr erkrankt eine von 10.000 Personen im Alter zwischen 12 und 60 Jahren, wobei die Inzidenzrate über die letzten 50 Jahre, selbst über Landesgrenzen hinaus und zwischen verschiedenen Kulturen, stabil erscheint. Das Haupterkrankungsalter liegt zwischen 20 und 35 Jahren. Daneben wird zwischen einem früheren Beginn, dem early onset (vor dem 20. Lebenjahr), und einem späteren Beginn, dem late onset (nach dem 35. Lebensjahr), unterschieden. Männer und Frauen sind von der Erkrankung gleich häufig betroffen. Frauen erkranken allerdings durchschnittlich drei bis vier Jahre später als Männer und weisen einen zweiten Erkrankungsgipfel um die Menopause (40 bis 45 Jahre) auf (Häfner und an der Heiden 1997). Diese Gegebenheit erklärt sich durch die Feststellung, dass Östrogene der Frau die Sensitivität von Dopamin $\left(D_{2}\right)$-Rezeptoren im zentralen Nervensystem (ZNS) erniedrigen und somit vor einem früheren Beginn der Erkrankung schützen. Mit der Abnahme des Östrogenspiegels in der Menopause und Postmenopause entsteht der zweite Erkrankungsgipfel (Häfner et al. 1998).

Die Äthiopathogenese ist vielschichtig und wird aktuell am besten durch das Diathese/Vulnerabilitäts-Stress-Modell erklärt (Nuechterlein et al. 1994). Dieses geht von einer andauernden Vulnerabilität im Sinne einer Disposition für die Manifestation einer Schizophrenie aus (siehe auch Kapitel 1.5.3 Einfluss von Stress auf die Neurogenese). Die Ursachen für diese Disposition werden in genetischen und nicht-genetischen Einflüssen gesehen, wobei die genetische Prädisposition einen Anteil von bis zu $80 \%$ ausmacht (Arnedo et al. 2015, Sullivan et al. 2003, Cannon TD et al. 1998). Endogene und exogene Stressfaktoren (z. B. belastende Lebensereignisse) führen dann bei nicht ausreichenden Verarbeitungsmöglichkeiten und Bewältigungsstrategien zum klinischen Bild einer akuten Psychose (Wobrock et al. 2004a).

\subsubsection{Gene und Umweltfaktoren}

Anhand von Familien-, Adoptions- und Zwillingsstudien konnte die bedeutende Rolle der genetischen Komponente der Schizophrenie belegt und verstanden werden. Verwandte von an Schizophrenie erkrankten Patienten teilen einen größeren Anteil ihrer Gene als NichtVerwandte und haben somit ein größeres Risiko, prädisponierende Gene vererbt zu bekommen als in der Normalbevölkerung. Dieses Risiko hängt natürlich auch mit dem Verwandtschaftsgrad und dem Anteil der vererbten Risikogene zusammen (Kessler 1980). 
Die folgende Übersicht nach Schmitt et al. (2014) stellt die prozentuale Wahrscheinlichkeit eine Schizophrenie zu entwickeln in Abhängigkeit vom Verwandtschaftsgrad dar:

Kinder

Geschwister

Eineiige Zwillinge

Zweieiige Zwillinge
$30 \%$

$20 \%$

$80 \%$

$40 \%$

Es konnte bisher noch nicht bewiesen werden, dass bei familiärer Häufung nur ein einziges Gen für die Entstehung der Schizophrenie verantwortlich ist. Vielmehr tragen interagierende Genkonstellationen (Polymorphismus) und der polygene Vererbungsmechanismus zum Erkrankungsrisiko bei (Schwab und Wildenauer 2013). Zahlreiche Chromosomen konnten bereits detektiert werden. Kandidatengenregionen sind unter anderem $8 p$ und 13q, aber auch Abschnitte der Chromosomen 5, 6, 8 und 22 (Wobrock et al. 2004a). So ist beispielsweise die Region 9q33.1 und 14q24.2 mit dem Krankheitsverlauf und die Region 6q23.1 mit dem Alter bei Erkrankungsbeginn assoziiert (Fanous et al. 2007). Zusätzlich konnten risikomodulierende Kandidatengene identifiziert werden. Beispiele wie Neuregulin 1 (NRG1), Disrupted in schizophrenia 1 (DISC1), dystrobrevin binding protein 1 (DTNBP1) und Catechol-OMethyltransferase (COMT) werden mit der Entstehung der Schizophrenie in Verbindung gebracht, da sie sowohl die neuronale Plastizität als auch die adulte Neurogenese beeinflussen (Allan et al. 2008, Le Strat et al. 2009).

Genomweite Assoziationsstudien (GWAS) offenbarten eine Vielzahl genetischer Varianten (single nucleotide polymorphisms) mit unterschiedlich starken Auswirkungen auf den Phänotyp der Schizophrenie (Schwab und Wildenauer 2013), wobei über 100 Genloci zum Erkrankungsrisiko beitragen (Ripke et al. 2014). In einer weiteren GWAS wurde angenommen, dass der Schizophrenie über 8.300 einzelne Neukleotidpolymorphismen zugrunde liegen, die zusammen ein Risiko von 32 \% ausmachen (Ripke et al. 2013). Ein höheres Erkrankungsrisiko ist assoziiert mit Polymorphismen in Genen, die für Zinkfingerprotein 804a (ZNF804a), Transkripitonsfaktor 4 (TCF4), Mikro-RNA 137 (Mir137), Untereinheiten spannungsabhängiger Kalziumkanäle (CACNA1C, CACNB2), Inter Alpha-Globulin Inhibitor H3/H4 (ITIH3/ITIH4) sowie Ankyrin 3 (Ank3) kodieren, wobei die neurobiologischen Auswirkungen meist unbekannt sind (Schwab und Wildenauer 2013).

Le Strat et al. (2009) definierten das Two-hit-Modell, welches die Gen-Umwelt-Interaktion beleuchtet. Eine Veränderung in einem Gen gilt hierbei als first hit und der Einfluss eines Umweltfaktors während der Hirnentwicklung als second hit. Diese Vulnerabilitäts- und Trig- 
gerfaktoren sind möglicherweise Vorraussetzung für Defizite in der Neurogenese und könnten auch zum Krankheitsbild der Schizophrenie führen.

Verschiedene Studien haben gezeigt, dass prä- und perinatale Komplikationen mit einem erhöhten Risiko für die Schizophrenie einhergehen (z. B. Haukvik und Agartz 2010) und zu einem früheren Erkrankungsbeginn führen (O'Callaghan et al. 1992).

Die Hypoxie als gemeinsamer Faktor von Geburts- und Schwangerschaftskomplikationen gilt deshalb als wichtiger Risikofaktor. Sie führt zu größeren strukturellen Hirnanomalien (siehe Kapitel 1.4.1 Auswirkungen von Hypoxie auf das Gehirn) und ist assoziiert mit Notkaiserschnitt, Rhesusinkompatibilität, Diabetes, Blutungen während der Schwangerschaft, Plazentainsuffizienz, Uterusatonie und Präeklampsie (Cannon M et al. 2002, McNeil et al. 2000, Dalman et al. 1999). Klinische Zeichen sind blaue Verfärbung der Haut (Zyanose), Atemstillstand (Apnoe) und Reanimation (Rosso et al. 2000). Insgesamt erleiden (je nach Definition) 25 bis $30 \%$ der Gesamtpopulation eine Schwangerschafts- und/oder Geburtskomplikation (Cannon M et al. 2002), aber nur ein geringer Prozentsatz aller Kinder mit Hypoxieassoziierten Geburtskomplikationen entwickelt später eine Schizophrenie (Mittal et al. 2008). Das Risiko mit einer positiven Anamnese zu erkranken, ist 2-fach erhöht (Geddes und Lawrie 1995). Des Weiteren erhöht sich das Risiko mit der Anzahl und Schwere der Hypoxieassoziierten Geburtskomplikationen (Cannon TD et al. 1999). Als weitere Faktoren gelten Multipara oder Geburt im späten Winter. Ein erhöhtes Risiko fand man außerdem bei Jungen, die bei Geburt zu klein oder mindestens das vierte Kind in der Geburtsfolge waren (Hultmann et al. 1999). Ein niedriger APGAR-Score (null bis drei) nach der Entbindung ist mit einer erhöhten Wahrscheinlichkeit, eine Schizophrenie zu entwickeln, die durch eine prominentere Negativsymptomatik und einen chronischen Verlauf gekennzeichnet ist, assoziiert (Kotlicka-Antczak et al. 2001). Auch erhöhte Werte der Aminosäure Homozystein können zu einer abnormalen Hirnentwicklung und einer Schädigung plazentaler Gefäße führen. Daraus kann eine Hypoxie resultieren, wodurch eine Sauerstoffunterversorgung des Fötus begünstigt wird (Brown et al. 2007).

Eine weitere Hypothese besagt, dass die Schizophrenie Resultat einer Infektion des zentralen Nervensystems (speziell einer Virusinfektion) oder einer Autoimmunreaktion gegen Gewebe des zentralen Nervensystems (die auf eine Infektion folgen kann) ist (Kirch 1993). Solch eine Infektion resultiert anschließend in einer Störung der frühen Hirnentwicklung bzw. in einer direkten Schädigung des Gehirns zwischen dem ersten und zweiten Trimenon der Schwangerschaft (Fruntes und Limosin 2008). Als Auslöser gelten Influenzaviren mit einem 3- bis 7-fach erhöhten Risiko, durch eine Infektion im ersten Trimester, Rötelviren mit einem 10 bis 20 \% erhöhten Risiko, aber auch Toxoplasmen mit einem 2,5-fach erhöhten Risiko, eine Schizophrenie zu entwickeln (Hagberg et al. 2012). 
In einer Kohortenstudie wurde ein erhöhtes Risiko für die Diagnose einer Schizophrenie festgestellt, wenn die Betroffenen während der Influenza-Epidemie im Jahre 1975 im Mutterleib infiziert wurden (Mednick et al. 1988). In tierexperimentellen Studien chronisch infizierter Toxoplasmose-Mäuse zeigten sich um $14 \%$ erhöhte Dopaminlevel, wie sie auch bei der Schizophrenie nachweisbar sind (Stibbs 1985). Es wurde geschlussfolgert, dass Toxoplasma gondii verschiedene Neurotransmitter in Hirnregionen, die in die Schizophrenie involviert sind, beeinflusst wie z. B. Gamma-Amino-Buttersäure (GABA), Glutamat oder Dopamin (Yolken et al. 2009).

Eine Studie in den USA konnte auch eine jahreszeitliche Assoziation der Schizophrenie feststellen. Demnach erkranken circa $10 \%$ mehr Menschen, die in den Monaten Dezember bis Mai geboren werden (Torrey et al. 1977). Ursachen hierfür sind saisonal bedingte Temperaturminderungen, Ernährungsdefizite und Infektionen während der Schwangerschaft (Berger 2009).

Bedenkt man auch den Einfluss gesellschaftlicher Faktoren, eignet sich die „Drift- Hypothese“. Nach dieser kommt es durch kognitive und interaktionelle Auffälligkeiten zu einem sozialen Abstieg und zu einer höheren Rate an Neuerkrankungen in sozial desintegrierten Zentren von Großstädten und bei sozial schlechter gestellten Personen (Wobrock et al. 2004a). Beispielsweise war die Inzidenz psychischer Störungen anhand von Untersuchungen in der deutschen Stadt Mannheim in sozial niedrig gestellten Gebieten des Stadtzentrums höher als im Bereich des Stadtrandes (Häfner et al. 1969). Ursachen hierfür sind Engstand und daraus resultierender Stress, aber auch Migration und Kultur (Freemann 1994). Weitere exogene Risikofaktoren sind Verlust der Eltern unter einem Alter von sieben Jahren sowie Cannabismissbrauch im Jugendalter (Schmitt et al. 2014).

\subsubsection{Neuronale Hypothesen}

Die weltweit valideste neurochemische Hypothese der Schizophrenie ist die Dopaminhypothese, welche zugrundelegt, dass Symptome aus einer exzessiv erhöhten DopaminNeurotransmission vor allem im Striatum sowie Dopamindefiziten in der Präfrontalregion resultieren (Javitt 2007). Die Aussage stützt sich auf die Beobachtung, dass alle antipsychotischen Medikamente eine Dopamin $\left(D_{2}\right)$-Rezeptorblockade hervorrufen und dass ihre Affinität zum Dopaminrezeptor mit der klinischen Potenz des Medikamentes korreliert (Seeman et al. 1975). Eine weitere Feststellung liegt in der Zunahme von Positivsymptomen nach Verabreichung von Amphetaminen an schizophrene Patienten. Diese führen über verschiedene Mechanismen zu einer Erhöhung der extrazellulären Dopaminkonzentration. Es konnte außerdem gezeigt werden, dass schizophrene Patienten nach Amphetamingabe mehr Dopamin ausschütten als gesunde Kontrollpersonen (Laruelle et al. 1996). Im Gegensatz zu dieser Überaktivität des dopaminergen Systems in der mesolimbischen Region wird die Hypoaktivi- 
tät im präfrontalen Kortex mit der Ausbildung von Negativsymptomen in Verbindung gebracht (Wobrock et al. 2004a).

Eine weitere potentielle Rolle spielt das Model der N-Methyl-D-Aspartat (NMDA)-Rezeptor Unterfunktion der Schizophrenie. Ausgang hierfür war das Anästhetikum Phencyclidin, das verstärkt in den 50er Jahren eingesetzt wurde (Olney und Farber 1995a). Der Wirkmechanismus liegt in einer nicht kompetitiven Blockade des lonenkanals eines NMDA-Subtyps des Glutamatrezeptors (Lodge und Anis 1982). Nach Verabreichung von Phencyclidin kam es bei Patienten zur Ausbildung von schizophrenietypischen Symptomen (Positiv- und Negativsymptome wie Halluzinationen, Affektinstabilität, Katatonie oder Apathie sowie Denkstörungen). Später wurden die gleichen Symptome auch durch den NMDA-Rezeptorblocker Ketamin hervorgerufen, konnten aber durch den Einsatz von Benzodiazepinen und Barbituraten verhindert werden (Olney und Farber 1995a). Eine typische Konsequenz der NMDARezeptorblockade ist eine exzessive Freisetzung von Glutamat (Moghaddam et al. 1997) und Acetylcholin im zerebralen Kortex (Giovannini et al. 1994). Es wird angenommen, dass sowohl genetische als auch nicht-genetische Faktoren zu einer NMDA-RezeptorUnterfunktion in den frühen Lebensabschnitten beitragen, aber erst im jungen Erwachsenenalter psychotische Manifestationen verursachen, wenn verschiedene Hirnreifungsprozesse stattgefunden haben. Die exzitatorischen Transmitter verursachen dabei eine konsequente Überstimulation postsynaptischer Neurone und könnten somit für die kognitiven und Verhaltensstörungen der Schizophrenie verantwortlich sein (Olney und Farber 1995b).

Synaptic pruning ist ein physiologisches Phänomen, bei dem während der Hirnentwicklung entstandene synaptische Verbindungen abgebaut werden und bei bestehender Disposition einen Auslöser für die Schizophrenie darstellen können. Durch diesen synaptischen Verlust kann es zu einer Beeinträchtigung der weiteren zerebralen Entwicklung in präfrontalen, temporalen und limbischen Regionen kommen (Granger 1996). Nach der Geburt steigt die synaptische Dichte mit einem Maximum im ersten bis zweiten Lebensjahr an. In der späten Kindheit und frühen Aldoleszenz kommt es dann zu einem steilen Abfall bis auf die Verknüpfungen, die bis in das hohe Alter erhalten bleiben (Huttenlocher 1979).

Ein vorbestehende Schädigung oder ein Defekt innerhalb dieser Elimination (z. B. hervorgerufen durch genetische Komponenten, perinatale Umwelteinflüsse oder Einwirkungen in der Aldoleszens wie Drogen oder Stress) kann Anlass für die Auslösung der Symptome der Schizophrenie sein. Folge eines Defektes kann die Elimination zu vieler, zu weniger oder der falschen Synapsen sein. Die Konsequenz in diesem eigentlich genetisch determinierten Programm ist dann die Auslösung der schizophrenen Symptomatologie (Feinberg 1983). 


\subsection{Hypoxie: Ein Umweltfaktor in der Ätiologie der Schizophrenie}

Von den bisher bekannten Geburtskomplikationen (siehe Kapitel 1.3.1 Gene und Umweltfaktoren) stellt die fetale Hypoxie den stärksten prädisponierenden Faktor in der Äthiopathogenese der Schizophrenie dar (Cannon TD 1997). Dass nicht alle Individuen, die einer Hypoxie ausgesetzt sind oder waren, eine Schizophrenie entwickeln (Buka et al. 1993), bestätigt das multifaktorielle Konzept mit der Annahme einer additiven hypoxischen Wirkung sowie einer Interaktion von Umwelteinflüssen mit genetischen Faktoren (Cannon TD 1997).

Hypoxie (englisch hypoxia) ist definiert als eine „Verminderung des Sauerstoffpartialdrucks im arteriellen Blut (unter $70 \mathrm{mmHg}$ ) bzw. verminderte Sauerstoffversorgung im Gesamtorganismus oder bestimmten Körperregionen“ (Pschyrembel 2002, S. 764).

\subsubsection{Auswirkungen von Hypoxie auf das Gehirn}

Hypoxie führt neben einer Schädigung des Gehirns auch zu einer Störung der Hirnentwicklung des menschlichen Fötus oder des Neugeborenen. Durch den Mangel an Sauerstoff kommt es zu Veränderungen im Zellmetabolismus und zur Exzitotoxizität, wodurch eine Zellschädigung verursacht wird, die anschließend in den Zelltod mündet (Björkman et al. 2010). Inwieweit das sich entwickelnde Gehirn für den Umweltfaktor Hypoxie anfällig ist, hängt von verschiedenen Faktoren ab. Hierzu zählen die Lipidzusammensetzung der Zellmembran im Gehirn, ihr Anteil an Antioxidantien und Lipidperoxidasen, die Entwicklung von NMDARezeptoren und ihre modulierende Wirkung sowie die Expression von Apoptose- und Antiapoptosegenen. Die Entwicklung dieser Regulationsmechanismen und ihre Wirkung auf hypoxische Einflüsse entscheiden über das Schicksal einer Zelle. Unter der Einwirkung von Hypoxie auf das Hirngewebe kann es zu einer Zerstörung der Zellmembran kommen: Einerseits durch eine verminderte Natrium-Kalium-ATPase-Aktivität, andererseits durch verstärkte Oxidation von Membranlipiden. Folge ist eine Ansammlung freier Radikale und ein intrazellulärer Anstieg von Calcium. Dieser führt wahrscheinlich auch zu einer intranukleären (innerhalb des Zellkerns) Erhöhung der Calciumkonzentration. Hierdurch werden spezifische Gene aktiviert, die für den programmierten Zelltod (Apoptose) verantwortlich sind und zum Untergang der Zelle führen (Mishra und Delivoria-Papadopoulos 1999). Des Weiteren führt im Tiermodell die Einwirkung postnataler Hypoxie auf das sich entwickelnde Gehirn zu einer vermehrten Glutamatausschüttung. Diese Aminosäure ist mit neuronalem Zelltod assoziiert und eine persistierende Aktivierung von Glutamatrezeptoren wird mit neurodegenerativen Veränderungen in Verbindung gebracht (Krajnc et al. 1996).

Relativ kurze Perioden fetaler Hypoxie führen insbesondere im Kleinhirn (Cerebellum), im Hippocampus und in der Großhirnrinde (zerebraler Kortex) zu einer neuronalen Schädigung, aber auch zu Störungen der weißen Substanz und vermindertem Wachstum neuronaler Prozesse wie Myelinisierung und Konnektivität (Rees und Inder 2005). 
Die Reduktion der grauen Substanz im Sinne einer Minderung der kortikalen Dicke ist ein pathoanatomisches Korrelat der perinatalen Hypoxie, wie sie auch bei an Schizophrenie erkrankten Patienten mit Hilfe der Magnetresonanztomografie (MRT) nachgewiesen werden konnte. Hierzu zählen auch vermehrtes Nervenwasser (Liquor) sowie die Erweiterung des Ventrikelsystems, vor allem der Seitenventrikel (Cannon TD et al. 2002). Andere MRT gestützte Studien ergaben zudem Volumenminderungen in den Basalganglien, im Thalamus und im Hippocampus ersterkrankter Patienten (z. B. Corson et al. 1999, Watson et al. 2012). Das geringere Volumen des Hippocampus korreliert positiv mit dem Erkrankungsalter (van Erp et al. 2002).

Einen wichtigen Einfluss übt die Hypoxie außerdem auf NMDA-Rezeptoren des Glutamatsystems aus. Diese spielen eine bedeutende Rolle in zahlreichen ontogenetischen Entwicklungsprozessen des Gehirns. Dazu zählen neuronale Zellproliferation, Migration, programmierter Zelltod und die Entwicklung der Konnektivität. Physiologisch kommt es in der Postnatalphase des Rattenhirns vor allem im präfrontalen Kortex zeitweise zu einer Überexpression von NMDA-Rezeptoren. Die Phase geht mit erhöhter Vulnerabilität dieser Rezeptoren einher (Kalus et al. 2008). Es konnte nachgewiesen werden, dass der Einfluss von perinataler Hypoxie während dieser Vulnerabilitätsperiode zu einer verstärkten Expression der obligatorischen Untereinheit NR1 des NMDA-Rezeptors in frontalen und temporalen Regionen, im Nucleus accumbens und im Hippocampus führt, also in Hirnregionen, die in die Pathophysiologie der Schizophrenie involviert sind. Diese verstärkte Genexpression wurde als Kompensationsmechanismus angesehen und könnte auf eine primäre NMDA-Rezeptor-Unterfunktion zurückgeführt werden. Außerdem zeigten NMDA-Rezeptoren, die aus vielen NR1 und NR2 Untereinheiten bestanden, eine verminderte Glutamat-Rezeptorbindung. Hierdurch entsteht ebenfalls eine NMDA-Rezeptor-Unterfunktion, was die neuronale Hypothese (siehe Kapitel 1.3.2 Neuronale Hypothesen) in der Pathogenese der Schizophrenie bestätigen würde (Schmitt et al. 2007).

1.4.2 Tiermodelle in der Schizophrenie: Untersuchungen des Verhaltens und Auswirkungen postnataler Hypoxie

Die Hypothese, dass eine frühe abnorme Hirnentwicklung zur Entstehung der Schizophrenie beiträgt, ist nur schwer am Modell des Menschen zu verdeutlichen, da es nicht möglich ist, vorherzusagen, welche Individuen tatsächlich einmal dieses Krankheitsbild entwickeln (Falkai et al. 2010). Tiermodelle sind daher ein nützliches Mittel, um offene Fragen in Bezug auf Geburtskomplikationen und ihre Auswirkungen auf die Hirnfunktion und das Verhalten zu beantworten (Boksa 2004). Ein häufig genutztes Labortier der experimentellen Neurobiologie ist die Ratte. Sie dient als Modell für Unterscheidungen zwischen normalen und pathologischen Prozessen, die im ZNS des Menschen auftreten. Besonders gern genutzt ist sie für 
die Beurteilung früher Einschnitte in die Hirnentwicklung, da diese in der Ratte größtenteils erst postnatal stattfindet und sich um die Geburt in einem noch sehr frühen Reifungsprozess befindet (Romijn et al. 1991). Die Hirnentwicklung in der frühen postnatalen Periode der Ratte ist daher vergleichbar mit der eines menschlichen Fötus im dritten Trimenon der Schwangerschaft (Dobbing und Sands 1979), wobei die größten Übereinstimmungen an ihrem 12. bis 13. postnatalen Lebenstag bestehen (Romijn et al. 1991). Die größte Vulnerabilität gegenüber Hypoxie besteht bei der Ratte um den sechsten postnatalen Lebenstag. Ursache hierfür ist die bereits genannte Überempfindlichkeit von NMDA-Rezeptoren gegenüber exzitotoxischen Einflüssen in der frühen postnatalen Phase, die zu einer Hypervulnerabilität von Neuronen führt, die entsprechende Rezeptoren besitzen (Ikonomidou et al. 1989). Dabei zeigt das männliche ZNS eine höhere Vulnerabilität gegenüber verschiedener Geburtskomplikationen als das weibliche (El-Khodor und Boksa 2003). Ursachen könnten in der unterschiedlichen Hirnentwicklung sowie in dem Zusammenspiel verschiedener Hormone z. B. der Sexualhormone liegen (Leung und Chue 2000).

An Schizophrenie Erkrankte zeigen Defizite in der Reizverarbeitung und in der Aufmerksamkeit. Die Präpulsinhibition (PPI) ist ein sehr eindrucksvolles Verhaltensmodell um Reizverarbeitungsdefizite in der Schizophrenie nachzuweisen. Physiologisch bezeichnet die PPI eine abgeschwächte (inhibierte) Schreckreaktion auf einen plötzlichen und intensiven Stimulus. 30 bis 500 ms vor diesem wird ein schwächerer Stimulus präsentiert, den man als Präpuls bezeichnet. Dieser ist so schwach, dass darauf keine Schreckreaktion folgt (Hamm et al. 2001). Übermäßige oder triviale Reize werden durch diesen Mechanismus aus dem Bewusstsein ausgeblendet, sodass ein Individuum seine Aufmerksamkeit nur auf die wichtigsten Aspekte der Umwelt fokussiert (Braff et al. 2001). Die zentrale Regulation der PPI erfolgt durch das limbische System, die Pons, die Basalganglien und den frontalen Kortex (Swerdlow et al. 2001). Typischerweise zeigen Defizite in der PPI bei schizophrenen Patienten eine hohe Assoziation mit formalen Denkstörungen sowie Positivsymptomen (Braff et al. 1999). Des Weiteren konnte nachgewiesen werden, dass die systemische Verabreichung von direkten und indirekten Dopaminagonisten (Amphetamine, Apomorphine), Serotoninantagonisten oder NMDA-Rezeptorantagonisten sowie spezifische Hirnläsionen (neonataler ventraler Hippocampus) auch in einem PPI-Defizit resultieren. Tierstudien wiesen nach, dass diese experimentell induzierten Defizite der PPI durch Antipsychotika behandelt werden konnten (Hamm et al. 2001). Auch die Hypoxie als gemeinsamer Faktor von Schwangerschafts- und Geburtskomplikationen führt zu Defiziten in der Reizverarbeitung. Auswirkungen postnataler Hypoxie auf das Verhalten wurde bereits im Tiermodell untersucht. Übereinstimmend mit dem Erkrankungsbeginn der Schizophrenie konnte ein PPI-Defizit ab dem frühen Erwachsenenalter nachgewiesen werden. Eine anschließende chronische Therapie mit Clozapin, ei- 
nem atypischen Antipsychotikum, führte zu einer Normalisierung der PPI-Defizite und konnte diese bei einer prophylaktischen Gabe sogar verhindern (Fendt et al. 2008).

Ein weiteres Verhaltensmodell der Schizophrenie ist die soziale Interaktion und das soziale Wiedererkennen. Es ist eng assoziiert mit der Negativsymptomatik sowie mit Gedächtnisstörungen (Porsolt et al. 2010). Soziale Interaktionen bemessen sich z. B. an Kampfspielen, gegenseitigem Beschnuppern bzw. Fellpflege. Soziales Wiedererkennen basiert auf der Grundlage, dass das Nagetier z. B. in der Lage ist, ein neues, unbekanntes Tier von einem Tier aus dem bekannten Umfeld zu unterscheiden (Thor und Holloway 1982).

Des Weiteren ist bekannt, dass neonatale Läsionen des ventralen Hippocampus in Verhaltensänderungen von Ratten im Erwachsenenalter resultieren. Diese Art der Schädigung führt zu einer Unterbrechung neuronaler Leitungsbahnen und abnormer Konnektivität im Gehirn (Falkai et al. 2010) und kann auch durch Hypoxie ausgelöst werden. Eine neonatale Verletzung des ventralen Hippocampus am postnatalen Tag (postnatal day=PD) 7 mit lbutensäure führte zu einer verminderten sozialen Interaktion (Negativsymptomatik) der Ratte, die auch durch anschließende Antipsychotikagabe (Clozapin) nicht reversibel war (Becker et al. 1999, Sams-Dodd et al. 1997). Des Weiteren führte diese Form der Schädigung zu einer Stress induzierten Hypermotorik (Lipska et al. 1993), welche die Positivsymptomatik der Schizophrenie darstellt. Dieses Phänomen zeigte sich auch nach experimentell induzierter globaler Hypoxie im Rahmen von Kaiserschnittgeburten im Tiermodell (El-Khodor und Boksa 2000). Hippocampale Läsionen spielen also sowohl eine Rolle in positiven wie auch in negativen Symptomen der Schizophrenie (Sams-Dodd et al. 1997).

\subsection{Neurogenese und Stammzellproliferation}

Während der neuronalen Entwicklung wird das Nervensystem vor allem durch Zellen geprägt, die das Potential besitzen, zu proliferieren, sich zu reproduzieren oder zu differenzieren (Kuhn et al. 2001). Die Rede ist von Stammzellen, die in den 1960er Jahren durch McCulloch und Till erstmals beschrieben wurden (Girlovanu et al. 2015). Eine Stammzelle ist unspezialisiert, aber charakterisiert zu Selbsterneuerung, d.h. der undifferenzierte Status wird auch nach einer Vielzahl von Zellteilungen (Proliferation) beibehalten, wodurch sie in der Lage sind extensiv zu proliferieren (Till et al. 1963). Um dies zu ermöglichen erfolgt eine sogenannte asymmetrische Zellteilung: eine entstandene Zelle ist der Mutterzelle identisch, die andere differenziert sich. Eine wichtige Rolle spielen hierbei Transkriptionfaktoren (Girlovanu et al. 2015). Die Weiterentwicklung in verschiedene Zelltypen (Pluripotenz) ist möglich (Pschyrembel 2002).

Die Stammzellproliferation umfasst das Wachstum und die Vermehrung von Zellen (Pschyrembel 2002). Die Entstehung von Nervenzellen (Neurone) aus diesen Stamm- und Vorläuferzellen wird als Neurogenese bezeichnet (Kempermann et al. 2003). 
Lange Zeit ging man davon aus, dass das Gehirn nicht in der Lage ist, neue Zellen zu generieren und Nervenzellen von Geburt an einem stetigen Untergang erliegen. Die Entdeckung, dass auch im erwachsenen Gehirn lebenslang neue Nervenzellen gebildet werden, bezeichnet man als adulte Neurogenese und wurde 1965 im Rattenhirn durch den amerikanischen Neuroanatomen Joseph Altman erstbeschrieben (Altman und Das 1965). Anhand von Untersuchungen des Maushippocampus handelt es sich dabei um einen Prozess mit dauerhafter Präsenz und stellt nicht nur eine flüchtige Erscheinung dar (Kempermann et al. 2003). Die adulte Neurogenese bleibt nur wenigen eng umschriebenen Hirnarealen vorbehalten. Dies ist zum einen die subventrikuläre Zone (SVZ), die die Grenze zwischen Striatum (caudate putamen=CPU) und Seitenventrikel bildet. Von hier aus migrieren neu entstandene Zellen zum Riechkolben (Bulbus olfactorius), um dort zu Interneuronen zu differenzieren (GarciaVerdugo et al. 1998). Sie enthält neben Stammzellen auch reife Vorläuferzellen von Neuronen, Astrozyten und Oligodendrozyten (Goldman 1995). Die andere Nische der adulten Neurogenese befindet sich in der subgranulären Zone des Gyrus dentatus (DG) im Hippocampus. Die ersten embryonalen Vorläuferzellen wurden 1993 durch Ray et al. (1993) isoliert. Die Mehrheit der in hoher Anzahl lokal produzierten oder aus dem Hilus migrierten Zellen differenzieren allerdings zu Neuronen und weniger zu Gliazellen, wie im adulten Rattenhirn nachgewiesen werden konnte (Cameron et al. 1993). Gerade in der frühen postnatalen Hirnentwicklung unterliegt die Mehrheit dieser Zellen der Apoptose (Kuhn et al. 1996), wobei über $50 \%$ der täglich entstehenden Zellen innerhalb weniger Wochen zugrunde gehen (Dayer et al. 2003). Die Aktivierung von NMDA-Rezeptoren spielt eine wichtige Rolle bei dieser Regulation (Tashiro et al. 2006). Nur ein kleiner Teil überlebt dauerhaft (Kempermann et al. 2003), wahrscheinlich erreichen nur $10 \%$ das Stadium der terminalen Differenzierung zum funktionierenden Neuron (Reif et al. 2007). Auch andere Orte adulter Neurogenese (allerdings in viel geringerer Ausprägung) sind bereits diskutiert worden. Hierzu zählen Cortex, Amygdala, Hypothalamus und die Substantia nigra (Gould 2007). In einer aktuellen Studie konnte adulte Neurogenese auch erstmals im humanen CPU nachgewiesen werden (Ernst et al. 2014). Die Entdeckung von Stammzellen im erwachsenen Gehirn stellt eine neue Form der neuronalen Plastizität dar. Diese bezeichnet die Adaptation an dynamische Prozesse, die die Anzahl von Neuronen, Gliazellen, Synapsen und Rezeptoren als Antwort auf Veränderungen der internen und externen Umwelt beeinflussen. Beispiele hierfür sind Lernen, Wachstumsfaktoren, Glukokortikoide und Sexualhormone, Stress, Alter, Neurotransmitter (Glutamat, Serotonin) oder Psychostimulanzien (Fuchs 2007).

\subsubsection{Neurogenese und Schizophrenie}

Neurogenese, vor allem im adulten Hippocampus, ist vorrangig involviert in Lernprozesse sowie Gedächtnis- und Erinnerungsfunktionen. In dieser Verbindung entstanden neue Theo- 
rien mit der Annahme, dass Ausfälle oder Fehler in der Neurogenese mit neuropsychiatrischen Erkrankungen wie der Schizophrenie assoziiert seien (Heckers und Konradi 2002). Dass die Stammzellproliferation im Hippocampus als erste Ebene der Neurogenese bei Patienten mit schizophrenen Erkrankungen (im Gegensatz zu gesunden Kontrollen und affektiven psychiatrischen Erkrankungen wie Depression und bipolaren Störungen) signifikant vermindert ist, konnte anhand humaner Post-mortem-Hirnschnitte bereits nachgewiesen werden. Es wurde geschlussfolgert, dass die reduzierte neuronale Stammzellproliferation möglicherweise eine Rolle in der Pathophysiologie der Erkrankung spielt (Reif et al. 2006). Diese Feststellung passt zu den vorhandenen kognitiven Defiziten bei schizophrenen Patienten, da Veränderungen der Neurogenese mit falschen Kodierungen neuer Gedächtnisinhalte assoziiert sein könnten (Reif et al. 2007). Es wurde angenommen, dass die verminderte Anzahl neu gebildeter Neurone in einem verminderten Volumen des Hippocampus und anderer Gehirnregionen resultiert, wie es auch in der Pathogenese der Schizophrenie beschrieben wird (Schmitt et al. 2009a). Auch Veränderungen somatodendritischer, axonaler und synaptischer Komponenten könnten ursächlich sein und zu Konnektivitätsstörungen im neuronalen Netzwerk führen (Czéh und Lucassen 2007). Allerdings ist unklar, welche Rolle zu Lebzeiten eingenommene Antipsychotika in den Ergebnissen der Post-mortem-Studien spielen (Schmitt et al. 2009a).

\subsubsection{Einfluss von Clozapin und Haloperidol auf die Neurogenese}

Typische (z. B. Haloperidol) und atypische (z. B. Clozapin) Antipsychotika können die Zellproliferation im Tiermodell beeinflussen, wobei sich die Ergebnisse widersprüchlich zeigen. Eine Akuttherapie in Form einer Einzeldosis Clozapin $(30 \mathrm{mg} / \mathrm{kg}$ intraperitoneal bzw. $45 \mathrm{mg} / \mathrm{kg}$ oral) oder Haloperidol ( $1 \mathrm{mg} / \mathrm{kg}$ intraperitoneal bzw. $1,5 \mathrm{mg} / \mathrm{kg}$ oral) zeigte keinen Effekt auf die Zellproliferation im DG. Hingegen erbrachte die chronische Behandlung mit Haloperidol über 28 Tage im Vergleich zu Clozapin eine Erhöhung des totalen Hippocampusvolumens. Dieses Ergebnis legt nahe, dass Haloperidol eher die Neuroplastizität bzw. die Morphologie von Synapsen beeinflusst als die Zellproliferation (Schmitt et al. 2004). Eine akute Therapie mit hohen Dosen ( $5 \mathrm{mg} / \mathrm{kg}$ intraperitoneal) des typischen Antipsychotikums Haloperidol zeigte wiederrum eine um $75 \%$ erhöhte Zellproliferation im Hippocampus. Hier sollte allerdings entgegengesetzt werden, dass die Dosierung des Medikaments an die klinische Dosierung des Menschen angepasst sein sollte, um ein repräsentatives Ergebnis zu erhalten (Dawirs et al.1998). Eine andere Studie ergab eine 2-fach erhöhte Zellzahl im DG nach geringen Dosen Clozapin (0,5 mg/kg intraperitoneal) im Vergleich zu einer Hochdosistherapie (20 mg/kg intraperitoneal) über 28 Tage, aber die neu generierten Zellen überlebten nicht dauerhaft. Diese Untersuchungen beweisen, dass es trotz einer anfänglichen Beeinflussung der Zellproliferation nicht zu einer Integration in den hippocampalen Kreislauf 
kommt. Wahrscheinlich fehlt es an trophischen Faktoren oder Signalen, um zu überleben (Halim et al. 2004).

Des Weiteren konnte mit Hilfe von MRT-Studien schizophrener Patienten eine Volumenzunahme des Nucleus caudatus (Teil des CPU) nach chronischer Therapie mit typischen Antipsychotika festgestellt werden. Diese war nach Therapieumstellung auf Clozapin wieder regredient. Als Ursache wurde der Antagonismus von typischen Antipsychotika zu Dopamin $\left(D_{2}\right)$-Rezeptoren diskutiert, der zu anhaltenden trophischen, funktionellen und ultrastrukturellen Veränderungen im CPU führen könnte. Clozapin zeigt aber nur eine sehr geringe Affinität zu diesem Rezeptor (Chakos et al.1995). Anatomische und biochemische Effekte auf das CPU nach chronischer Haloperidoltherapie wurden beschrieben. Dazu zählen z. B. die Vergrößerung von Zellen, Dendriten und Axonendigungen (Benes et al. 1985) sowie eine Vermehrung glutamaterger Synapsen und Glutamat in präsynaptischen Nervenendigungen (Meshul et al. 1996).

\subsubsection{Einfluss von Stress auf die Neurogenese}

Schon lange besteht die Ansicht, dass psychosozialer Stress eine Rolle in der Entstehung schizophrener Symptome spielt (Stress-Vulnerabilitäts-Hypothese, siehe Kapitel 1.3 Ätiologie der Schizophrenie). Stress interagiert mit der neuronalen Vulnerabilität, die wiederum durch genetische und frühe Umwelteinflüsse bedingt ist (Corcoran et al. 2002). Die biologische Grundlage bildet die Hypothalamus-Hypophysen-Nebennieren-Achse, welche die Cortisolfreisetzung regelt (Corcoran et al. 2003). Die Proliferation neuer Zellen wird im neonatalen Tiermodell von zirkulierenden Steroiden beeinflusst (Sapolsky und Meaney 1986). Diese inhibieren die Zellproliferation im DG in der frühen postnatalen Periode und im Erwachsenenalter. Der Einfluss von Stress erhöht die Konzentration zirkulierender Glukokortikoide, die auch als Stresshormone bekannt sind und stimuliert die hippocampale Glutamatfreisetzung, welche wiederum die Proliferation von Vorläuferzellen hemmt. Chronischer Stress führt demnach zu einer persistierenden Inhibition der Zellproliferation und strukturellen Veränderungen im DG (Gould und Tanapat 1999). Es wird angenommen, dass die vermehrte Aktivierung der Hypothalamus-Hypophysen-Nebennieren-Achse durch Stress auch zu einem verstärkten Effekt auf die Dopaminsynthese und seiner Rezeptoren führt. Diese Feststellung wird durch die neuronale Hypothese der abnormalen Dopaminaktivität in der Ätiologie der Schizophrenie unterstützt (siehe Kapitel 1.3.2 Neuronale Hypothesen). Schädigungen des Hippocampus und Störungen der Dopaminrezeptoraktivität zur gleichen Zeit führen demnach zu einer Hypersensitivität gegenüber Stress und werden als Diathese/Vulnerabilitäts-StressModell beschrieben. Pränatale Risikofaktoren und abnormale Hirnentwicklung, wie sie als Auslöser der Schizophrenie angenommen werden, sind auf diese Annahme übertragbar (Walker und Diforio 1997). Ältere Individuen zeigen dabei eine höhere Anfälligkeit gegenüber 
stressinduzierten negativen Effekten auf die Zellproliferation im DG als jüngere (Simon et al. 2005). Psychosozialer Stress sowie Negativsymptome schizophrener Patienten können möglicherweise durch eine chronische Therapie mit Antidepressiva (z. B. Fluoxetin) vermindert werden. Darunter zeigte sich auch wieder eine vermehrte Neurogenese in tierexperimentellen Studien im Hippocampus (z. B. Malberg et al. 2000, Encinas et al. 2006). Die Hemmung der Neurogenese im Hippocampus ist demnach ein reversibler Prozess, der auch durch eine auf das Individuum bereichernd wirkende Umgebung verbessert werden kann. Im Tiermodell ist die Untersuchung z. B. durch Laufräder, Rohre, Leitern und Nistmaterial in einem erweiterten Lebensbereich möglich (Schloesser et al. 2010).

\subsubsection{Einfluss von Glutamat auf die Neurogenese}

Glutamat und seine Rezeptoren, vor allem der NMDA-Rezeptor, nehmen eine bedeutende Rolle im neuronalen Netzwerk ein. Sie sind bekannt für entscheidende Einschnitte in die frühen und späten Stadien der Neurogenese und sind Elemente der neuronalen Plastizität (Vicini 2008). Glutamat ist der dominierende exzitatorische Neurotransmitter im Gehirn und beeinflusst die Proliferation unreifer neuronaler Zellen und deren Differenzierung. Die zugrunde liegenden Mechanismen mit der Glutamat in die Neurogenese im neonatalen und adulten Gehirn eingreift, zeigen deutliche Unterschiede und sind nur unzureichend bekannt (Schlett 2006). Sowohl Glutamat als auch seine Rezeptoren werden schon in der frühen Entwicklung exprimiert. Dabei können die Aktivität sowie die Transmitterkonzentration durch exogene Faktoren beeinflusst werden, die dadurch in Entwicklungsstörungen resultieren (Ghiani et al. 2007). NMDA-Rezeptoren gelten als wichtiger Regulationsmechanismus in der Homöostase zwischen Zellaufbau und -abbau. Cameron et al. (1995) untersuchten die Auswirkungen der NMDA-Rezeptoraktivierung auf die Neurogenese im DG der adulten Ratte. Es zeigte sich bei Aktivierung des NMDA-Rezeptors eine starke Abnahme der Zellzahl, wohingegen eine NMDA-Rezeptorblockade die Zellteilung beschleunigte und die Zellzahl erhöhte. Zusätzlich erhöhte auch eine akute Medikation mit NMDA-Rezeptorantagonisten die Neurogenese und die Gesamtdichte der Neurone im DG. Selbige Ergebnisse konnten auch durch den Einsatz des NMDA-Rezeptorantagonisten MK-801 nachgewiesen werden (Gould et al. 1997). Der NMDA-Rezeptorsubtyp des Glutamatrezeptors ist essentiell für die neuronale Differenzierung und Etablierung sowie Eliminierung von Synapsen in der Hirnentwicklung (Komuro und Rakic 1993). Die Aktivierung dieses Rezeptors spielt außerdem eine wichtige Rolle im Bereich des räumlichen Lernens. Nach Verabreichung des Rezeptorantagonisten MK-801 konnte eine dosisabhängige Beeinträchtigung des Arbeitsgedächtnisses und des räumlichen Lernens der Ratte nachgewiesen werden (Butelmann 1989). Die Regulation der Neurogenese durch den NMDA-Rezeptor kann als Mechanismus zur Stabilisierung der neuronalen Populationen während Phasen aktiven Lernens angesehen werden. Durch die Entstehung neu- 
er Nervenzellen kommt es außerdem zu einer Erhöhung der Speicherkapazität während Inaktivierungsphasen (Cameron et al. 1995).

\subsubsection{Einfluss von Hypoxie-Ischämie auf die Neurogenese}

Ischämie ist definiert als „Verminderung oder Unterbrechung der Durchblutung eines Organs, Organteils oder Gewebes infolge mangelnder arterieller Blutzufuhr (z. B. durch Thrombose oder Embolie). Die Folge ist eine Hypoxie und bei längerem Bestehen eine Nekrose“ (Pschyrembel 2002, S. 814-815). Viele Forscher haben in der Vergangenheit eine starke Erhöhung adulter Neurogenese durch ischämische Einflüsse festgestellt. So konnte beispielsweise nach Induktion lakunärer Infarkte im adulten Rattenhirn eine hohe Anzahl von neu generierten Zellen als Antwort auf die Ischämie festgestellt werden (Janowski et al. 2008). Im adulten Primaten zeigte sich infolge fokaler Ischämie eine Zellzahlerhöhung sowohl im Hippocampus als auch im Bulbus olfactorius (Koketsu et al. 2006). Dieses Ergebnis konnte auch für die SVZ neonataler Ratten belegt werden (Ong et al. 2005). Es wurde berichtet, dass Neurone des Hippocampus während einer Ischämie des Vorderhirns verschiedene Wachstums- und Transkriptionsfaktoren exprimieren, die in die Apoptose und Regeneration von Neuronen involviert sind, was einen wichtigen Regulationsmechanismus darstellen könnte (Kiessling et al. 1993). Oxidativer Stress ist ein frühes Merkmal zerebraler Ischämie (Blomgren und Hagberg 2006). Der Hippocampus gilt als besonders anfällig gegenüber hypoxischen, ischämischen und asphyktischen Schäden. Diese Tatsache ist wahrscheinlich auf die hohe Anzahl glutamaterger Neurone zurückzuführen, die eine größere Anfälligkeit gegenüber exzitatorisch induziertem Zelltod aufweisen (Scheepens et al. 2003). Das sich entwickelnde Gehirn besitzt jedoch ein beträchtliches Potential in Bezug auf Proliferation und Migration im Bereich der Schädigung. Das unreife Gehirn hat erwartungsgemäß eine höhere Kapazität für die Neurogenese und die neuronale Plastizität als das adulte (Ikeda 2008). Für diese Form der Selbsthilfe ist neben der erhöhten Zellproliferation und Neurogenese wahrscheinlich auch eine Migration von Zellen zum Ort der Schädigung notwendig, was bereits nachgewiesen werden konnte (z. B. Felling et al. 2006, Yang und Levison 2007). Die physiologische Migrationsrate ist dabei im neonatalen Gehirn größer als im adulten, was das hohe regenerative Potential des neonatalen Gehirns widerspiegelt (Plane et al. 2004). Insgesamt ist jedoch die Wirkung von perinataler Hypoxie auf die Proliferation von Zellen unklar. 


\subsection{Zielsetzung und Fragestellung}

In der vorliegenden Arbeit soll anhand der immunhistochemischen BrdU-Peroxidasefärbung die Zellproliferation im Rattenhirn unter dem Einfluss postnataler Hypoxie beurteilt werden. Die Untersuchungen erfolgen an Tieren unterschiedlichen Alters: Postnataler Tag (PD) 13 und postnataler Tag (PD) 39 verglichen mit unbehandelten Kontrollen, um Veränderungen über die Zeit zu erfassen. Untersucht werden folgende hypoxieanfällige Hirnregionen: Gyrus cinguli (anterior cingulate cortex=ACC), Striatum (caudate putamen=CPU), subventrikuläre Zone (SVZ) und der Gyrus dentatus (DG) des Hippocampus. Es ergeben sich folgende Fragestellungen:

1. Zeigen sich Unterschiede bezüglich der Zellproliferation nach Hypoxie in den zu untersuchenden Gebieten ACC, CPU, SVZ und DG?

2. Wie verhält sich die Zellproliferation nach perinataler Hypoxie im untersuchten Zeitraum zwischen PD 13 und PD 39?

3. Wie sind die Ergebnisse der vorliegenden Arbeit in Bezug auf die Äthiopathogenese der Schizophrenie zu werten? 


\section{Material und Methoden}

\subsection{Material}

\subsubsection{Versuchstiere}

40 männliche Wistar-Ratten

Charles River Laboratories, Sulzfeld

2.1.2 Medikamente und Perfusionslösungen

Ketamin

Xylazin

5-Brom-2-desoxyuridin (BrdU) $97 \%$

deionisiertes Wasser

Natriumchlorid $(\mathrm{NaCl})$

Kaliumchlorid (KCl)

Magnesiumchloridhexahydrat $\left(\mathrm{MgCl}_{2} 6 \mathrm{H} 2 \mathrm{O}\right)$

Natriumhydrogencarbonat $\left(\mathrm{NaHCO}_{3}\right)$

Natriumdihydrogenphosphat $\left(\mathrm{NaH}_{2} \mathrm{PO}_{4} \mathrm{H}_{2} \mathrm{O}\right)$

Glucose $\mathrm{H}_{2} \mathrm{O}$

Glutaraldehyd (25\%)

Dinatriumhydrogenphosphatdihydrat

$\left(\mathrm{Na}_{2} \mathrm{HPO}_{4} \cdot 2 \mathrm{H}_{2} \mathrm{O}\right)$

Paraformaldehyd

Natriumhydroxid $(\mathrm{NaOH})$

Pikrinsäure

Sucroselösung, $15 \%$

\subsubsection{Chemikalien und Enzyme}

Kryoprotektanslösung:

- Ethylenglykol

- Glycerin, $87 \%$

- Phosphat-gepufferte Salzlösung (PBS)

Immunhistochemie:

destilliertes Wasser

2-fach destilliertes Wasser
Krankenhausapotheke,

Universitätsmedizin Göttingen

Krankenhausapotheke,

Universitätsmedizin Göttingen

Sigma-Aldrich, Steinheim

Neurobiologisches Labor, Göttingen

Merck, Darmstadt

Merck, Darmstadt

Roth, Karlsruhe

Roth, Karlsruhe

Roth, Karlsruhe

Sigma-Aldrich, Steinheim

Sigma-Aldrich, Steinheim

Sigma-Aldrich, Steinheim

Sigma-Aldrich, Steinheim

AppliChem, Darmstadt

Sigma-Aldrich, Steinheim

Sigma-Aldrich, Steinheim

AppliChem, Darmstadt

AppliChem, Darmstadt

BioChem AG, Berlin Dulbecco

Neurobiologisches Labor, Göttingen

Neurobiologisches Labor, Göttingen 
Tris-gepufferte Salzlösung (TBS):

- Natriumchlorid ( $\mathrm{NaCl})$

Merck, Darmstadt

- Tris-HCl

Merck, Darmstadt

Wasserstoffperoxid $\left(\mathrm{H}_{2} \mathrm{O}_{2}\right)$

Merck, Darmstadt

Formamid

AppliChem, Darmstadt

SSC-Puffer (20x)

AppliChem, Darmstadt

Salzsäure $(\mathrm{HCl})$

Merck, Darmstadt

Borsäure

Sigma-Aldrich, Steinheim

normales Ziegenserum (NGS)

Biozol, Eching

Triton-X-100

Sigma-Aldrich, Steinheim

Rinderserumalbumin (BSA)

Sigma-Aldrich, Steinheim

3,3'-Diaminobenzidine (DAB)

Roche, Mannheim

Vectastatin AB-Komplex

Biozol, Eching

(Avidin-Biotin-Komplex)

Vitro-Clud®-Einbettmedium

Langenbrinck, Emmendingen

Immersionsöl für die Mikroskopie

Roth, Karlsruhe

\subsubsection{Antikörper}

anti-BrdU-Mausantikörper

Roche, Mannheim

biotinylierter Anti-Mausantikörper

Biozol, Eching

\subsubsection{Geräte und Materialien}

zwei Hypoxie-Kammern

Eigenbau Universität Göttingen

Schlauch Tygon® MEK Gr. 17

Novadirect, Kehl

Schlauch Tygon® MEK Gr. 14

Novadirect, Kehl

Verbinder Messing LUER M 6,4 mm

Novadirect, Kehl

$\mathrm{N}_{2}$-Gasflasche

Luftsauerstoff-Messgerät GOX 100

Messer Griesheim, Magdeburg

Luftsauerstoff-Messgerät GMH 3691

Greisinger Electronic $\mathrm{GmbH}$, Regentauf

Brain infusion Kit 2 mit Alzet®-Pumpe 100 3D

Greisinger Electronic $\mathrm{GmbH}$, Regentauf

Perfusionspumpe Masterflex® L/S mit

Charles River Laboratories, Sulzfeld

Easy load 3 Pumpenkopf PP/Edelstahl

Tiefkühlschrank $-80^{\circ} \mathrm{C}$

Heto-Holten, Allerod (Dänemark)

Tiefkühlschrank $-20^{\circ} \mathrm{C}$

Liebherr Deutschland

Kühlschrank

Liebherr Deutschland 
Operationstisch für Ratten

Butterfly-Kanülen

Mehrzweckgefäße mit Schnappdeckel

Schüttler VXR basic Vibrax®

Omnilab Laborwaage OL-310-P

Magnetrührer-RET

Vortexmischer

Zentrifuge

Microm Hm 550 (Cryostat)

Wasserbad Typ 1002

Well cell culture Platten 3524 Corning $\AA$ Costar ${ }^{\circledR}$

(Mikrotiterplatten)

5 I behroplast@ Kanister

Petrischalen-Falcon®1058/Becton

Messbecher

Glasflaschen

Cellstar® PP-Test Röhrchen, 50 ml

Digitalstoppuhr

Eppendorf® Pipetten

Pipettenspitzen, $1000 \mu \mathrm{l}$

Pipettenspitze, $200 \mu \mathrm{l}$

Eppendorf $\circledast$-cups $0,5 \mathrm{ml}$

Einmal-Pasteurpipetten mit Saugball

Labortücher Kimtech Science 200

Verschlussfolie Parafilm $\AA$

Peha-soft@-Handschuhe

Objektträger Superfrost®

Deckgläser 24 x 60 mm

Lichtmikroskop

Komplettes Stereo Investigator System:

Stereo Investigator Software zentrale tierexperimentelle Einrichtung der Georg-August-Universität Göttingen

Becton, Dickinson and Company, Franklin

Lakes (New Jersey)

Greiner Bio-One, Frickenhausen

Roth, Karlsruhe

Nordlab, Bremen

Janke\&Kunkel, Staufen

Janke\&Kunkel, Staufen

National Labnet Co., Woodbridge

(New Jersey)

Microm GmbH, Walldorf

GFL, Burgwedel

Sigma-Aldrich, Steinheim

Behr-Labortechnik, Düsseldorf

Dickinson Labware, Lincoln Park

(New Jersey)

Schott AG, Mainz

Schott AG, Mainz

Greiner Bio-One, Frickenhausen

Hanhart, Hamburg

Eppendorf AG, Hamburg

Sarstedt, Nümbrecht

Sarstedt, Nümbrecht

Eppendorf AG, Hamburg

Sarstedt, Nümbrecht

Kimberly-Clark, Surrey (England)

Bemis, Oshkosh (Wisconsin)

Hartmann, Heidenheim

Menzel GmbH, Braunschweig

Menzel $\mathrm{GmbH}$, Braunschweig

Leica Deutschland

MicroBrightField Europe e.K. Bioscience, Magdeburg 
PC Intel Pentium 4

Olympus BX-51 Mikroskop

digitale Farbkamera

3-Achsen-Computer gesteuertes Schrittmotorsystem

\subsection{Methoden}

\subsubsection{Einteilung der Versuchstiere}

Für das Experiment wurden nach der Versuchsgenehmigung gemäß $\S 8$ des Tierschutzgesetzes (Zeichen 33.42502-005/07) durch das Niedersächsische Landesamt für Verbraucherschutz und Lebensmittelsicherheit in Braunschweig 40 männliche Wistar-Ratten der Charles River Laboratories (Sulzfeld) verwendet. Es erfolgte die Bestellung von fünf trächtigen Weibchen über die Zentrale Tierexperimentelle Einrichtung der Georg-August-Universität Göttingen. Die Muttertiere warfen jeweils ein Mal. Aus dem ersten und zweiten Wurf entstammten 12, aus dem dritten Wurf neun, aus dem vierten Wurf 16 und aus dem fünften Wurf 21 männliche Jungtiere. Die Tiere wurden mit den Müttern in Einzelkäfigen und nach der Entwöhnung jeweils zu dritt oder viert in Makrolonkäfigen Typ IV $\left(1800 \mathrm{~cm}^{2}\right)$ gehalten. Die Ratten unterlagen einem zwölfstündigen Hell-Dunkel-Rhythmus mit Zugang zu Futter und Wasser ad libidum.

Um die neuronale Zellproliferation über einen definierten Zeitraum beurteilen zu können, wurden zwei Gruppen unterschiedlichen Alters gebildet:

Gruppe eins: 20 Wistar-Ratten, Sakrifizierung PD 13

Gruppe zwei: 20 Wistar-Ratten, Sakrifizierung PD 39

Von den jeweils 20 Versuchstieren gehörten immer 10 der Hypoxiegruppe und 10 der Kontrollgruppe an, um einen Vergleich und letztendlich auch eine Beurteilung der Zellproliferation im Altersverlauf zwischen behandelten und unbehandelten Tieren zu ermöglichen.

\subsubsection{Chronische Hypoxie}

In den Hypoxie-Versuchsgruppen wurden die Ratten von PD 4 bis PD 8 täglich in eine luftdichte, durchsichtige und isolierte Box (BTH: $42 \mathrm{~cm} \times 37 \mathrm{~cm} \times 26 \mathrm{~cm})$ gesetzt. Dies erfolgte zusammen mit dem Muttertier, um soziale Isolation mit Auswirkungen auf den Gehirnmetabolismus zu vermeiden. Wasser und Futter standen ad libidum zur Verfügung.

Die Box besaß zwei Gaseinleitungsstutzen, durch die täglich zum gleichen Zeitpunkt ein hypoxisches Gasgemisch von $11 \%$ Sauerstoff $\left(\mathrm{O}_{2}\right)$ und $89 \%$ Stickstoff $\left(\mathrm{N}_{2}\right)$ für jeweils sechs Stunden eingeleitet wurde sowie einen Gasausleitungsstutzen. Dieses Gasgemisch wurde durch ein Luftsauerstoffmessgerät kontinuierlich kontrolliert. Es bestand ein Gasflow von $3 \mathrm{l} / \mathrm{min}$, sodass überschüssiges Gas und abgeatmetes Kohlenstoffdioxid $\left(\mathrm{CO}_{2}\right)$ kontinuierlich abgeführt werden konnten. Parallel dazu wurden die Kontrolltiere in einer zweiten Box, aber 
ausschließlich mit Raumluft (Normoxie) behandelt, um gleichartige Bedingungen und Belastungssituationen zu schaffen (Abb. 1).

Normoxie-Box

$\mathrm{O}_{2}$-Gehalt $21 \%$

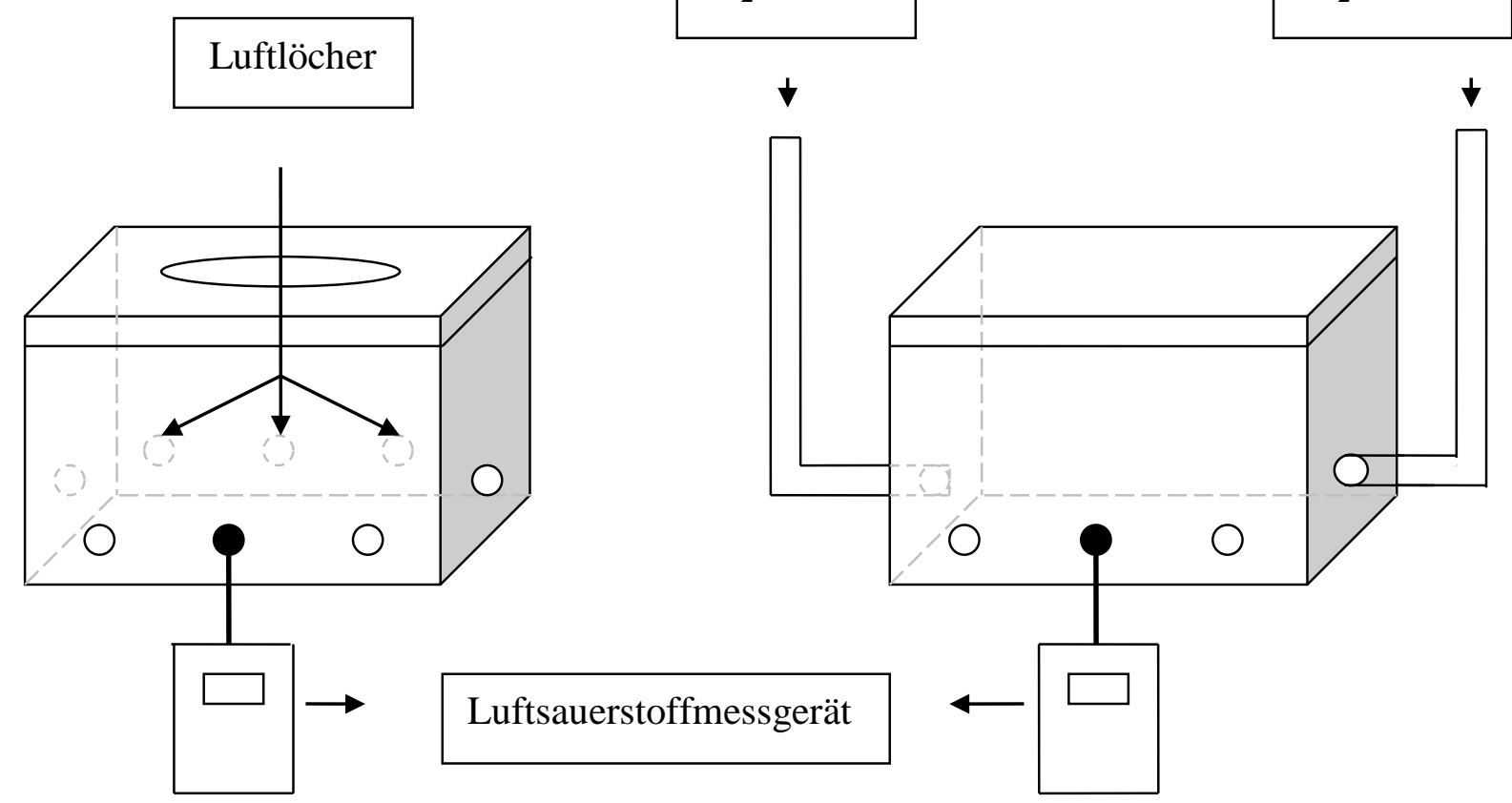

Hypoxie-Box

$\mathrm{O}_{2}$-Gehalt $11 \%$

Abb. 1: Versuchaufbau Normoxie versus Hypoxie

\subsubsection{BrdU-Injektionen und Perfusion}

Alle Versuchstiere erhielten an PD 11 eine viermalige intraperitoneale Injektion von jeweils

$75 \mathrm{mg} / \mathrm{kg}$ Bromdesoxyuridin (BrdU), gelöst in $1 \mathrm{ml} \mathrm{0,9 \% iger} \mathrm{NaCl-Lösung.} \mathrm{Die} \mathrm{Injektionen}$ erfolgten alternierend alle zwei Stunden in den linken oder rechten Peritonealraum.

BrdU ist ein chemisches Analogon des Nucleosids Thymidin (Abb. 2), welches während der DNA-Synthesephase in den Doppelstrang eingebaut wird (DNA=Desoxyribonukleinsäure). Die proliferierenden Zellen können anschließend über die immunhistochemische BrdUPeroxidasefärbung mit Hilfe monoklonaler Antikörper dargestellt werden. Da BrdU im Körper nur kurz verfügbar ist, markiert man mit dieser Methode nur Zellen, die sich zum Zeitpunkt der Injektion in der Zellteilung befinden (Takahashi et al. 1992). 
<smiles></smiles>

$\mathrm{C}_{9} \mathrm{H}_{11} \mathrm{BrN}_{2} \mathrm{O}_{5}$

\section{5-Brom-2-desoxyuridin}

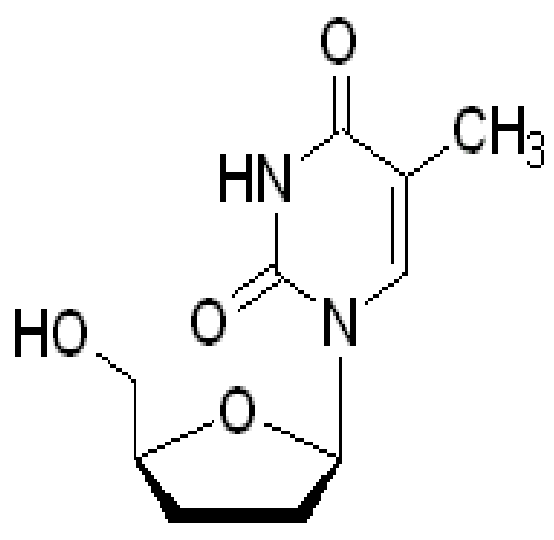

$\mathrm{C}_{10} \mathrm{H}_{14} \mathrm{~N}_{2} \mathrm{O}_{5}$

Desoxythymidin

Abb. 2: BrdU und Desoxythymidin (Sigma-Aldrich 2009, S. 497 und S. 2493)

Der Abdruck erfolgt mit freundlicher Genehmigung der Sigma-Aldrich Corporation (USA).

Für die Untersuchung der neuronalen Zellproliferation wurden alle männlichen Jungtiere der ersten Gruppe 48 Stunden (PD 13) und alle Jungtiere der zweiten Gruppe 28 Tage (PD 39) nach der BrdU-Injektion mittels Perfusionsfixierung sakrifiziert. Hierfür erhielten die Ratten eine tiefe intraperitoneale Narkose bestehend aus Ketamin $(100 \mathrm{mg} / \mathrm{kg})$ und Xylazin $(15 \mathrm{mg} / \mathrm{kg})$. Nach einer durchschnittlichen Wartezeit von fünf bis 10 Minuten waren Schmerzreize und Reflexe ausgeschaltet. Die Tiere wurden an allen vier Extremitäten auf einem Operationstisch fixiert. Nach Inzision des Fells im thorakalen Bereich konnte von abdominalwärts mit Hilfe einer Schere der Thorax eröffnet werden. Dazu wurden die Rippen durchtrennt. Anschließend wurde eine Kanüle in die linke Herzkammer (Ventrikel) eingeführt und die In-SituHirnfixierung mittels intrakardialer Perfusion eingeleitet. Die Sakrifizierung erfolgte durch Ausbluten aus dem während der Perfusion eröffneten rechten Vorhof (Atrium). Die Dauer der Perfusion lag im Schnitt bei 20 Minuten, der Perfusionsdruck lag bei $3 \mathrm{ml} / \mathrm{min}$. Das individuelle Perfusionsvolumen richtete sich nach dem Gewicht der Ratten, welches sowohl am Tag der Sakrifizierung (PD 13 bzw. PD 39) als auch an PD 4 (erster Hypoxie-Tag), PD 8 (fünfter Hypoxie-Tag) und PD 11 (BrdU-Injektionen) protokolliert wurde. Die Perfusionslösung setzte sich wie folgt zusammen:

1. Perfusionslösung (Tyrode-Lösung, $37^{\circ} \mathrm{C}$ ):

- $1000 \mathrm{ml}$ deionisiertes Wasser

- $\quad 8 \mathrm{~g}$ Natriumchlorid ( $\mathrm{NaCl})$

- $0.2 \mathrm{~g}$ Kaliumchlorid (KCl)

- $0.05 \mathrm{~g}$ Magnesiumchloridhexahydrat $\left(\mathrm{MgCl}_{2} 6 \mathrm{H}_{2} \mathrm{O}\right)$

- $1 \mathrm{~g}$ Natriumhydrogencarbonat $\left(\mathrm{NaHCO}_{3}\right)$ 
- $0.04 \mathrm{~g}$ Natriumdihydrogenphosphat $\left(\mathrm{NaH}_{2} \mathrm{PO}_{4} \cdot \mathrm{H}_{2} \mathrm{O}\right)$

- $1 \mathrm{~g}$ Glucose $\mathrm{H}_{2} \mathrm{O}$

Die Lösung muss 30 Minuten vor Gebrauch mit $\mathrm{CO}_{2}$ begast werden.

2. Perfusionslösung (Fixativ $1 ; 4^{\circ} \mathrm{C}$ ):

- $500 \mathrm{ml}$ Phosphatpuffer (siehe unten)

- $200 \mathrm{ml}$ Paraformaldehyd $20 \%$ (siehe unten)

- $150 \mathrm{ml}$ gesättigte Pikrinsäure (siehe unten)

- $2 \mathrm{ml}$ Glutaraldehyd (25\%)

- $148 \mathrm{ml}$ deionisiertes Wasser

Postfixation (Fixativ 2, Raumtemperatur):

- $500 \mathrm{ml}$ Phosphatpuffer (siehe unten)

- $200 \mathrm{ml}$ Paraformaldehyd $20 \%$ (siehe unten)

- $150 \mathrm{ml}$ gesättigte Pikrinsäure (siehe unten)

- $150 \mathrm{ml}$ deionisiertes Wasser

Phosphatpuffer (0.2 M; $\mathrm{pH}=7.6)$

- $1000 \mathrm{ml}$ deionisiertes Wasser

- $30.6 \mathrm{~g}$ Dinatriumhydrogenphosphatdihydrat $\left(\mathrm{Na}_{2} \mathrm{HPO}_{4} 2 \mathrm{H}_{2} \mathrm{O}\right)$

- $\quad 3.9 \mathrm{~g}$ Natriumdihydrogenphsphat $\left(\mathrm{NaH}_{2} \mathrm{PO}_{4} \mathrm{H}_{2} \mathrm{O}\right)$

Paraformaldehyd $20 \%$ (maximale Temperatur $=60^{\circ} \mathrm{C}$ )

- $20 \mathrm{~g}$ Paraformaldehyd

- 10 Gtt Natriumhydroxid $(\mathrm{NaOH}) 1 \mathrm{~N}$

- $100 \mathrm{ml}$ deionisiertes Wasser

Gesättigte Pikrinsäure (rühren über Nacht, danach Filtration)

- $15 \mathrm{~g}$ Pikrinsäure

- $1000 \mathrm{ml}$ deionisiertes Wasser

Nach der Paraformaldehyd-Perfusion (Fixativ 1) wurden die Tiere umgehend dekapitiert und die Gehirne entnommen. Es folgte eine Postfixation für zwei Stunden mit Fixativ 2 bei Raumtemperatur und anschließende Kryoprotektion in Sucrose-Lösung (15\%) bei $4^{\circ} \mathrm{C}$ über Nacht. Am Folgetag wurden die einzelnen Gehirne in Aluminiumfolie verpackt und mit Parafilm® umschlossen, entsprechend ihrer Zugehörigkeit gekennzeichnet und auf Trockeneis tiefgefroren. Die dauerhafte Lagerung erfolgte im Tiefkühlschrank bei $-80^{\circ} \mathrm{C}$. 


\subsubsection{Anfertigung von Dünnschnitten am Gefriermikrotom}

Für die Durchführung der immunhistochemischen Peroxidasefärbung wurden Hirnschnitte aller perfundierten Gehirne hergestellt. Die bei $-80^{\circ} \mathrm{C}$ gelagerten Gehirne wurden einen Tag vor der Verarbeitung in einen $-20^{\circ} \mathrm{C}$ Tiefkühlschrank umgebettet, um sie schnittfähig zu machen. Die Gehirnschnitte für die Zellproliferation wurden mit Hilfe eines Gefriermikrotoms in $60 \mu \mathrm{m}$ dicke Schnitte geschnitten. Jeder 10. Schnitt wurde für die Immunhistochemie verwendet, sodass alle zu untersuchenden Hirnregionen (ACC, SVZ, CPU, DG des Hippocampus) erfasst wurden. Um die Lage der vier relevanten Hirnregionen ausfindig zu machen, wurde ein spezieller Atlas genutzt, der die notwendigen Lokalisationskoordinaten im Rattenhirn lieferte (Paxinos und Watson 1998). Die Lokalisationskoordinaten (Tab. 2) wurden ausgehend vom Bregma (Abb. 3), dem Punkt des Schädels, an welchem Kranznaht (trennt Stirn- von Scheitelbein) und Pfeilnaht (trennt Scheitelbeine voneinander) zusammenfließen, aufgesucht. Bregma selbst liegt dabei definitionsgemäß $9 \mathrm{~mm}$ vor der interauralen (zwischen den Ohren) Linie.

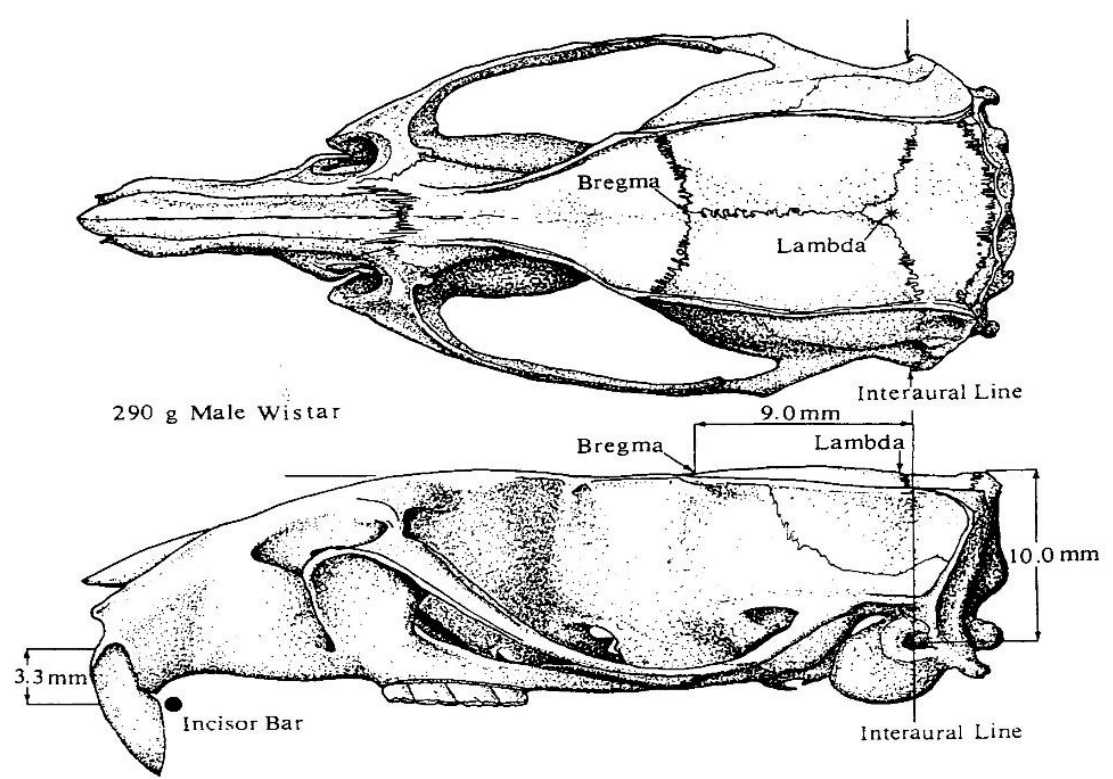

Abb. 3: Darstellung des knöchernen Rattenschädels (Paxinos und Watson 1998, S.xi) Der Abdruck erfolgt mit freundlicher Genehmigung von Elsevier

\begin{tabular}{|l|c|c|}
\hline Region & Anfang (mm) & Ende (mm) \\
\hline ACC & 3,70 & $-1,40$ \\
\hline SVZ & 1,60 & $-1,60$ \\
\hline CPU & 2,20 & $-1,60$ \\
\hline DG & $-1,80$ & $-6,30$ \\
\hline
\end{tabular}

Tab. 2: Lokalisationskoordinaten der relevanten Hirnregionen ausgehend vom Bregma 
Die Lagerung der Hirnschnitte erfolgte in Plastikgefäßen mit Schnappdeckel frei flottierend in $5 \mathrm{ml}$ Kryoprotektanslösung bei $-20^{\circ} \mathrm{C}$.

\subsubsection{Immunhistochemische BrdU-Peroxidasefärbung}

Die Durchführung der immunhistochemischen BrdU-Peroxidasefärbung erfolgte nach einem Protokoll der Universität Würzburg, modifiziert nach Angelika Schmitt. Verwendet wurden immer ein Hypoxiegehirn und ein Kontrollgehirn gleichen Alters. Die Hirnschnitte befanden sich dabei zu gleichen Anteilen in einer Mikrotiterplatte, welche zuvor in zwei Abschnitte geteilt und entsprechend beschriftet wurde. Das hatte den Effekt, dass identische Bedingungen zwischen den Gruppen gewährleistet wurden, sowohl in Bezug auf Inkubationszeiten als auch gleichwertig ausgesetzten Lösungskonzentrationen.

Zunächst erfolgte die Umbettung der Hirnschnitte aus der Kryoprotektanslösung in TBS und einen 2 x 10-minütigen Waschvorgang. Zur Optimierung des immunhistochemischen Nachweises von $\mathrm{BrdU}$ wurden die Schnitte 30 Minuten in $0,6 \% \mathrm{H}_{2} \mathrm{O}_{2}$ (in TBS) inkubiert. Dieser Schritt war wesentlich zur Blockierung endogener Peroxidasen, welche sonst später auch mit dem Chromogen DAB reagieren würden und zu falsch positiven Ergebnissen geführt hätten. Nach erneutem Waschen in TBS über 3 × 5 Minuten kam es zur Inkubation der Schnitte in $50 \%$ Formamid $/ 2 \times \mathrm{SSC}$ bei $65^{\circ} \mathrm{C}$ im Wasserbad für zwei Stunden. Danach erfolgte wieder ein 2 x 5-minütiger Waschvorgang in TBS und anschließend die Inkubation der Schnitte in $\mathrm{HCl}$ bei $37^{\circ} \mathrm{C}$ im Wasserbad für 30 Minuten. Die letzten beiden Schritte dienten der DNADenaturierung. Eine Freilegung der DNA-Doppelhelix und die Bindung entsprechender Antikörper an das während der Proliferationsphase integrierte BrdU-Antigen wurde somit möglich und erleichtert. Um den $\mathrm{pH}-$ Wert durch die stark saure $\mathrm{HCl}$ wieder anzuheben, erfolgte eine 10-minütige Inkubation in 0,1 molarer Borsäure $(\mathrm{pH} 8,5)$ und ein nochmaliger Waschvorgang in TBS über 3 x 10 Minuten. Die Schnitte wurden nun eine Stunde in Blocklösung inkubiert, um unspezifische Antikörperbindungsstellen zu blockieren. Über Nacht erfolgte die Inkubation der Schnitte in der 1. Antikörper-Lösung bei $4^{\circ} \mathrm{C}$. Der hierbei verwendete monoklonale anti-BrdU-Antikörper aus der Maus wurde dazu in der gleichermaßen angefertigten Blocklösung verdünnt (1:500). Der zweite Tag begann mit einem erneuten Waschvorgang über $3 \times 10$ Minuten in TBS, um nicht gebundene Antikörper zu entfernen. Hieran schloss sich nun die zweite Antikörperinkubation mit dem biotinylierten anti-Mausantikörper verdünnt in Blocklösung (1:400) für zwei Stunden bei Raumtemperatur. Die Zubereitung der Blocklösung war dabei die gleiche wie am Vortag, unterschied sich aber im Gehalt an NGS (2\% anstatt $5 \%$ ). Anschließend erfolgte $3 \times 10$ Minuten ein erneutes Waschen in TBS und eine darauf folgende Inkubation der Schnitte in Avidin-Biotin-Komplex (Avidin-Biotin-PeroxidaseKomplex) für eine Stunde. Avidin besitzt eine sehr hohe Affinität für das Vitamin Biotin und kann somit den biotinylierten Zweitantikörper binden. Da Avidin insgesamt vier Bindestellen 
für Biotin besitzt, wird eine zusätzliche Bindung biotinylierter Peroxidase ermöglicht. Nach diesem Schritt erfolgte ein erneutes Waschen $3 \times 10$ Minuten in TBS. Durch die Inkubation der Schnitte in DAB (fünf Minuten, Raumtemperatur, Abzug) überträgt die Peroxidase dann Wasserstoffionen vom zugefügten Wasserstoffperoxid auf das DAB. Es entsteht Wasser $\left(\mathrm{H}_{2} \mathrm{O}\right)$ und ein braunes Phenazinpolymer, wodurch sich die Schnitte anfärbten. Um überschüssiges Reagenz zu entfernen, erfolgte ein letzter Waschvorgang über $3 \times 5$ Minuten in TBS. Die fertigen Schnitte wurden auf Objektträger aufgezogen, über Nacht getrocknet und schließlich mit Vitro Clud® eingedeckt.

\subsubsection{Bestimmung der Zellzahl mit dem Stereologiemikroskop}

Die Anzahl der BrdU-markierten Zellen im ACC, der SVZ, des CPU und des DG wurden mit Hilfe des Stereologiemikroskops (Abb. 4) ermittelt, die Auswertung erfolgte verblindet.

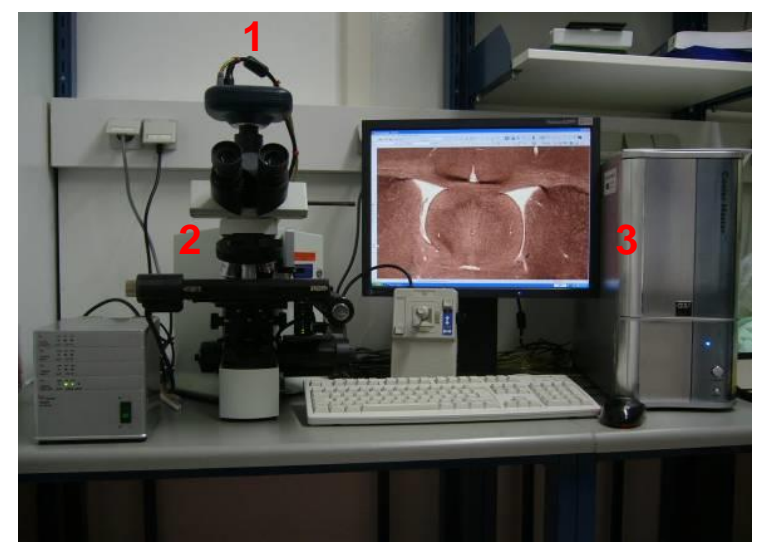

$1 \quad$ Digitalkamera

2 Olympus BX-51 Mikroskop mit Schrittmotorsystem

3 PC

Abb.4: Stereo Investigator System (Klinik für Psychiatrie und Psychotherapie der Universität Göttingen): Beispielhafte Darstellung der SVZ

Die dreidimensionale Zellzahlbestimmung sowie die Berechnung der Gesamtzellzahl erfolgte mit einer modifizierten Version des Optical Fractionator und der Stereo Investigator Software. Zunächst wurde das zu untersuchende Areal in 2-facher Vergrößerung mit Hilfe einer Konturlinie abgegrenzt. Aufgrund der hohen Zellzahlen, vor allem in den PD 13 sakrifizierten Tieren, war es unmöglich, alle Stammzellen des gewünschten Gebietes einzeln zu zählen, sodass Zählkammern im abgegrenzten Areal platziert wurden. Die enthaltenen Stammzellen wurden mit einem Zellmarker gekennzeichnet. Die Anzahl der Zählkammern ergab sich einerseits aus der Größe des abgegrenzten Gebietes und andererseits aus einem festgelegten X- und Y-Wert (Tab. 3), durch den die Zählkammern in einem definierten Abstand zueinander platziert wurden. Die Größe der Kästchen (counting frame size) betrug $30 \mu \mathrm{m}$ für PD 13 und $100 \mu \mathrm{m}$ für PD 39. 


\begin{tabular}{|l|c|c|c|}
\hline Region & Sakrifizierung & \multicolumn{2}{|c|}{$\begin{array}{c}\text { Abstand der Zählkästchen } \\
\text { X-Achse }\end{array}$} \\
\hline ACC & PD 13 & 173,74 & 256,52 \\
\hline SVZ & PD 13 & 78,20 & 100,96 \\
\hline CPU & PD 13 & 329,21 & 425,98 \\
\hline DG & PD 13 & 56,35 & 67,49 \\
\hline ACC & PD 39 & 100 & 100 \\
\hline SVZ & PD 39 & 100 & 100 \\
\hline CPU & PD 39 & 480 & 480 \\
\hline DG & PD 39 & 100 & 100 \\
\hline
\end{tabular}

Tab. 3: Koordinaten für die Lage und den Abstand der Zählkästchen

Bei anschließend 50-facher Vergrößerung wurden die innerhalb dieser Kästchen befindlichen Zellen gezählt und nach Fertigstellung automatisch über die Optical FractionatorMethode auf die totale Stammzellzahl für die gewünschte Hirnregion hochgerechnet.

Die Schnittdicke (mounted section thickness) betrug bei allen Gehirnen $30 \mu \mathrm{m}$. Diese Größe entstand durch Schrumpfung des Gewebes während der gesamten Prozedur (Fixation, Lagerung, Schneiden, Färbung). Festgelegt wurde sie durch Messen der Schnittdicke an drei unterschiedlichen Stellen eines Gehirns an insgesamt drei Gehirnen. Dabei suchte man einen Referenzpunkt im gewünschten Gebiet bei 2-facher Vergrößerung. Durch Fokussieren auf die obere Schnittebene sowie die untere Schnittebene in 50-facher Vergrößerung durch Verlagerung des Fokuspunktes bis zum jeweils eben noch scharf wahrgenommenen Bild erhielt man zwei Werte, die voneinander subtrahiert wurden. Nach Durchführung aller Messungen wurde aus allen Werten der Mittelwert gebildet und dieser für alle Schnitte genutzt.

Die BrdU-Peroxidasegefärbten Zellen waren braun bis dunkelbraun gefärbt, oval bis rundlich geformt und gut gegenüber dem umliegenden Gewebe abgrenzbar. Ihre Größe betrug circa 5 bis $10 \mu \mathrm{m}$. Es wurden alle BrdU-markierten Zellen gezählt, unabhängig von ihrer Form oder Größe solange Zellgrenzen erkennbar waren. Des Weiteren zeigten sich stärker und schwächer angefärbte Zellen, insbsondere bei den PD 39 Gehirnen. Ursache hierfür waren die inzwischen erfolgten Zellteilungen. Da es multifaktorielle und auch in der Natur der Zelle liegende Ursachen (Stoffwechselaktivität, DNA-Gehalt usw.) für das unterschiedliche Aussehen der Zellen gab, wurde dieses unspezifische Vorgehen gewählt, um ein möglichst repräsentatives Ergebnis zu erhalten. 
Die Auswertung des Volumens der gemessenen Regionen erfolgte nach dem Prinzip von Cavalieri (Schmitz und Hof 2005) nach der Formel:

$\mathrm{V}($ Volumen $)=\mathrm{a}($ Flächeninhalt) $\mathrm{x}$ h (Höhe). Die Höhe/Dicke (h) der Hirnschnitte von $60 \mu \mathrm{m}$ wurde mit 10 multipliziert, da nur jeder 10. Hirnschnitt verwendet wurde. Das Ergebnis $(\mathrm{h}=600 \mu \mathrm{m})$ multipliziert mit der Summe der Flächen (a) in diesem Gebiet ergab einen Wert, welcher mit den darauffolgenden Werten der entsprechenden Hirnregion addiert wurde.

Es ergaben sich in den Gruppen PD 13 Kontrolle/Hypoxie bzw. PD 39 Kontrolle/Hypoxie folgende Mittelwerte und Standardabweichungen aus der Anzahl (n) der ausgewerteten Schnitte, die die jeweiligen Hirnregionen enthielten (Tab. 4 bis 7, siehe Kapitel 6.2 Anzahl [n] der ausgewerteten Schnitte je Hirnregion und Gehirn):

\begin{tabular}{|l|c|c|}
\hline Hirnregion & Mittelwert (n) & Standardabweichung \\
\hline ACC & 6,7 & 0,48 \\
\hline CPU & 5,5 & 0,53 \\
\hline SVZ & 4,4 & 0,52 \\
\hline DG & 5,8 & 0,79 \\
\hline
\end{tabular}

Tab. 4: Mittelwert und Standardabweichung aus der Anzahl der ausgewerteten Schnitte je Hirnregion PD 13 Kontrolle

\begin{tabular}{|l|c|c|}
\hline Hirnregion & Mittelwert (n) & Standardabweichung \\
\hline ACC & 7 & 0,94 \\
\hline CPU & 5,8 & 0,63 \\
\hline SVZ & 4,7 & 0,67 \\
\hline DG & 5,5 & 0,53 \\
\hline
\end{tabular}

Tab. 5: Mittelwert und Standardabweichung aus der Anzahl der ausgewerteten Schnitte je Hirnregion PD 13 Hypoxie

\begin{tabular}{|l|c|c|}
\hline Hirnregion & Mittelwert (n) & Standardabweichung \\
\hline ACC & 7,8 & 0,79 \\
\hline CPU & 6 & 0,67 \\
\hline SVZ & 5,6 & 0,70 \\
\hline DG & 7 & 0,94 \\
\hline
\end{tabular}

Tab. 6: Mittelwert und Standardabweichung aus der Anzahl der ausgewerteten Schnitte je Hirnregion PD 39 Kontrolle 


\begin{tabular}{|l|c|c|}
\hline Hirnregion & Mittelwert (n) & Standardabweichung \\
\hline ACC & 7,8 & 0,42 \\
\hline CPU & 6,4 & 0,70 \\
\hline SVZ & 5,4 & 0,52 \\
\hline DG & 6,7 & 0,67 \\
\hline
\end{tabular}

Tab. 7: Mittelwert und Standardabweichung aus der Anzahl der ausgewerteten Schnitte je Hirnregion PD 39 Hypoxie

Durch die folgenden Abbildungen (5 bis 17 ) soll ein Eindruck über die Bestimmung der Zellzahl mit dem Stereologiemikroskop vermittelt werden.

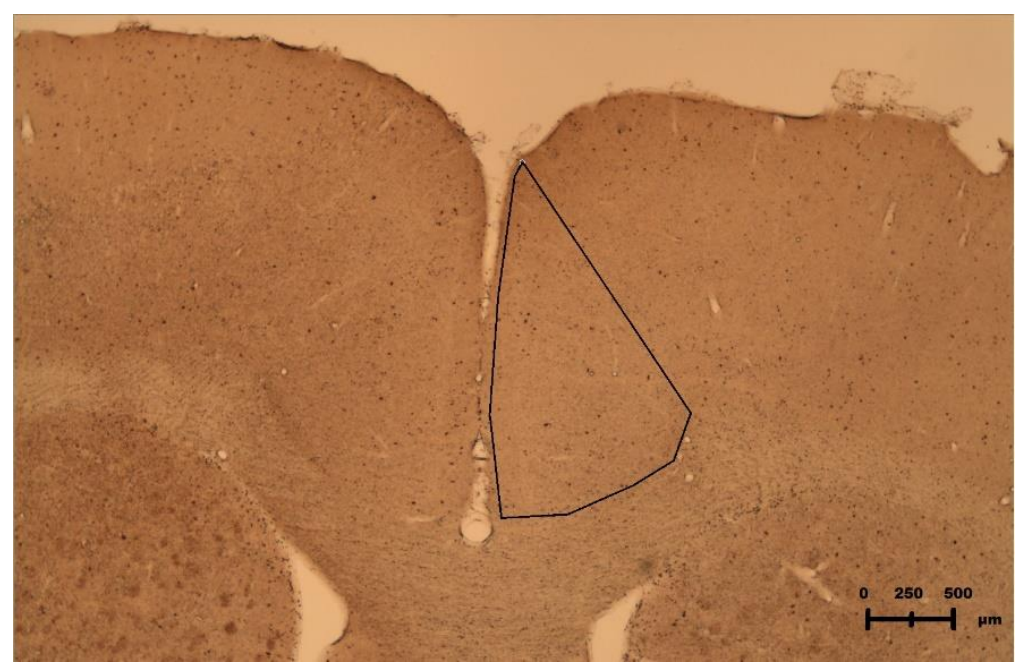

Abb. 5: Umgrenzung ACC in 2-facher Vergrößerung

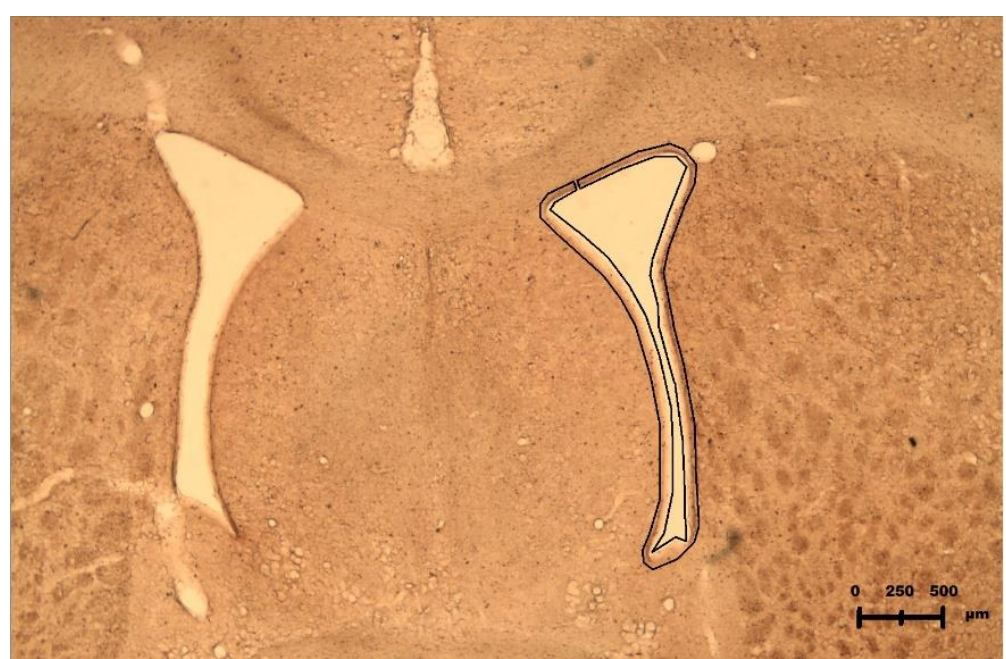

Abb. 6: Umgrenzung SVZ in 2-facher Vergrößerung 


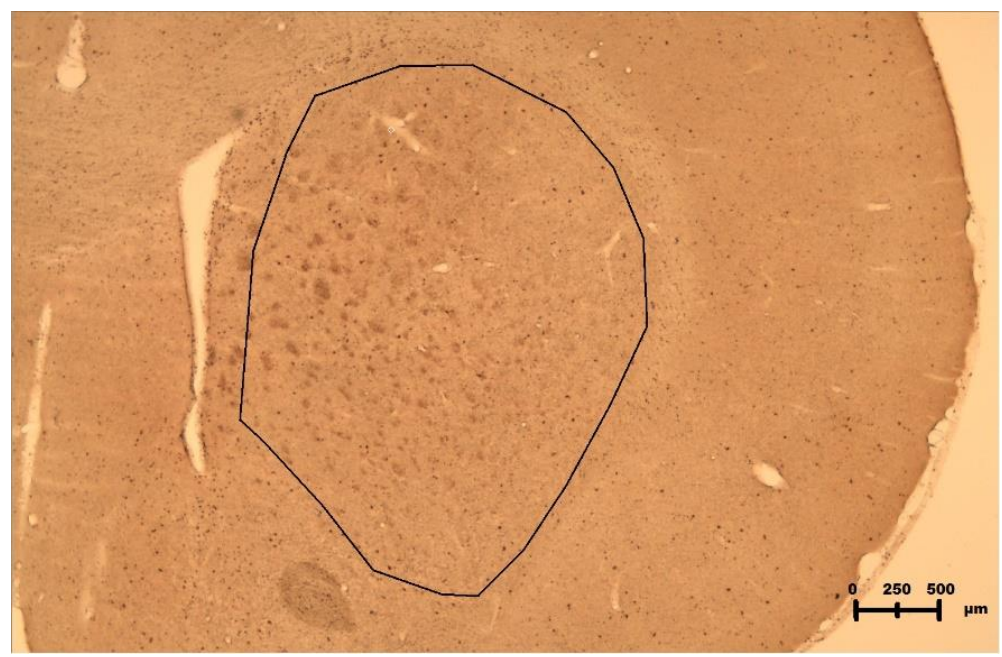

Abb. 7: Umgrenzung CPU in 2-facher Vergrößerung

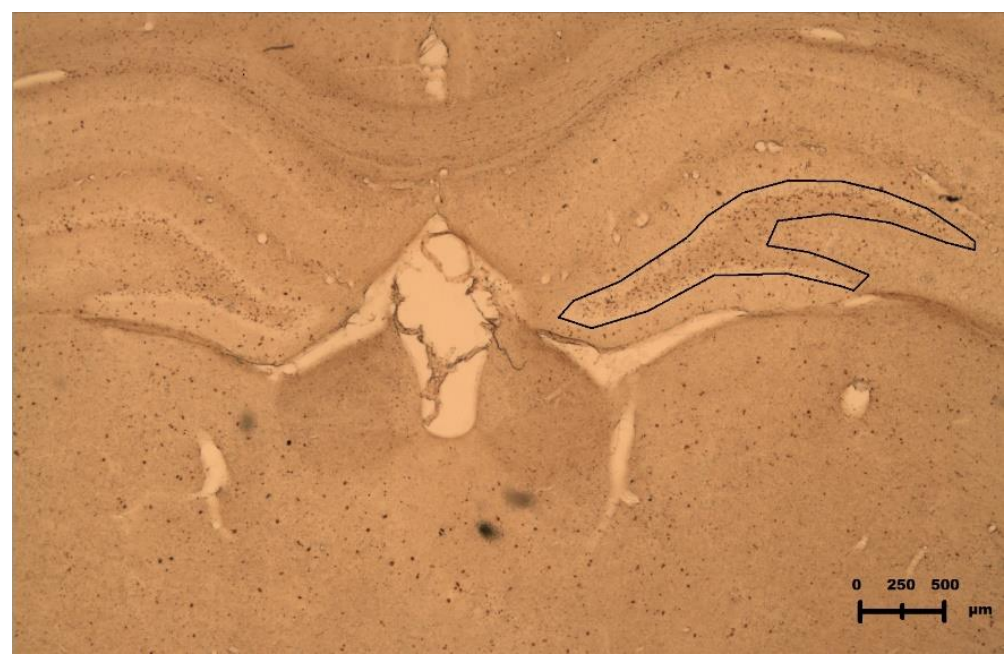

Abb. 8: Umgrenzung DG in 2-facher Vergrößerung

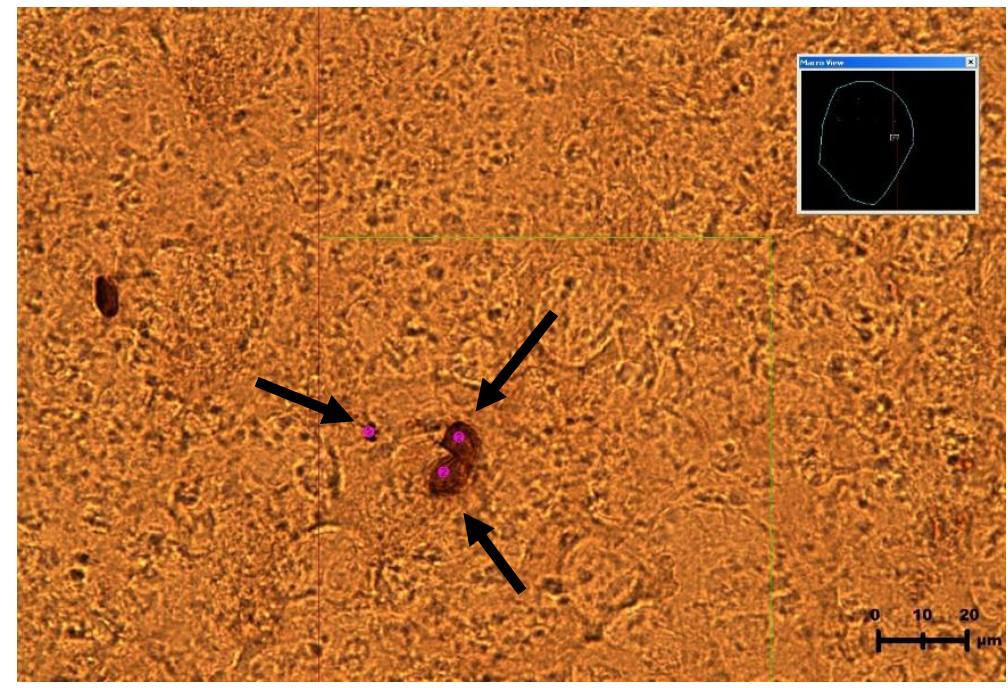

Abb. 9: Zählkästchen mit drei markierten Zellen in 50-facher Vergrößerung 


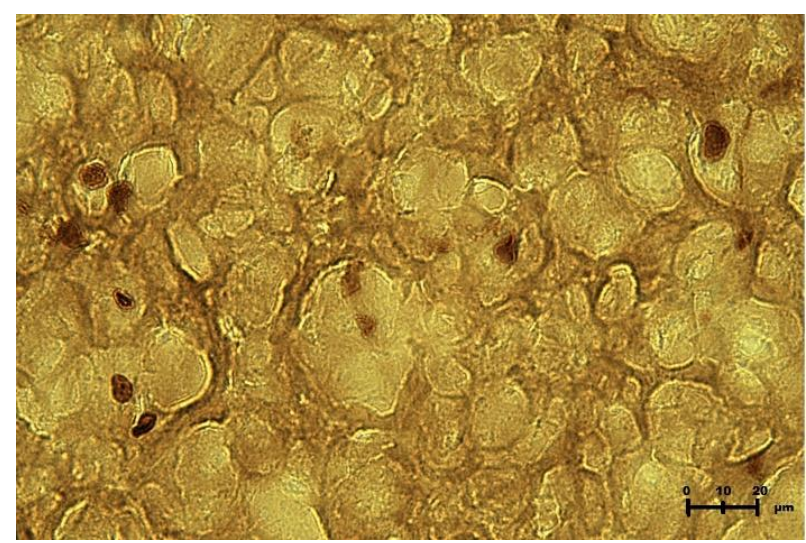

a

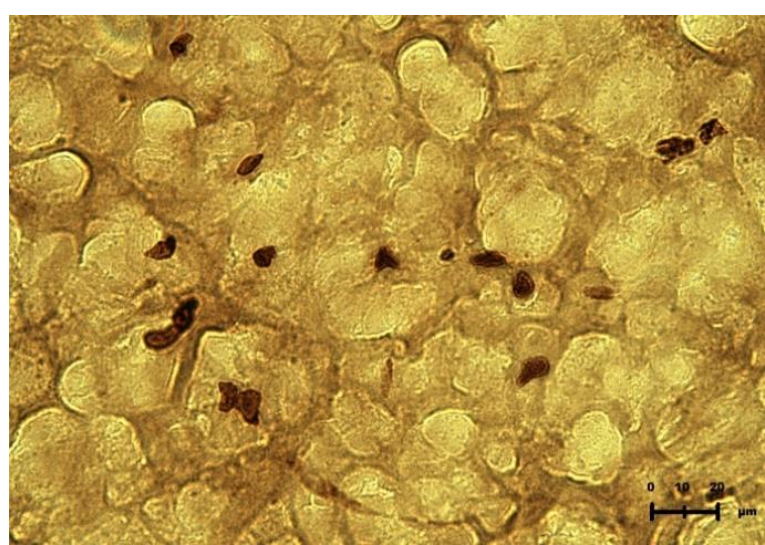

b

Abb. 10: Zellen ACC in 50-facher Vergrößerung PD 13 Hypoxie (a) und Kontrolle (b)

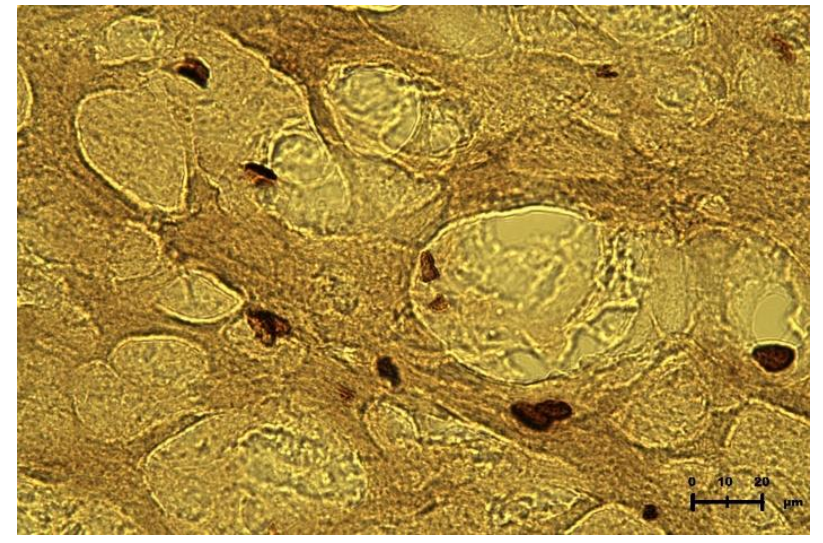

a

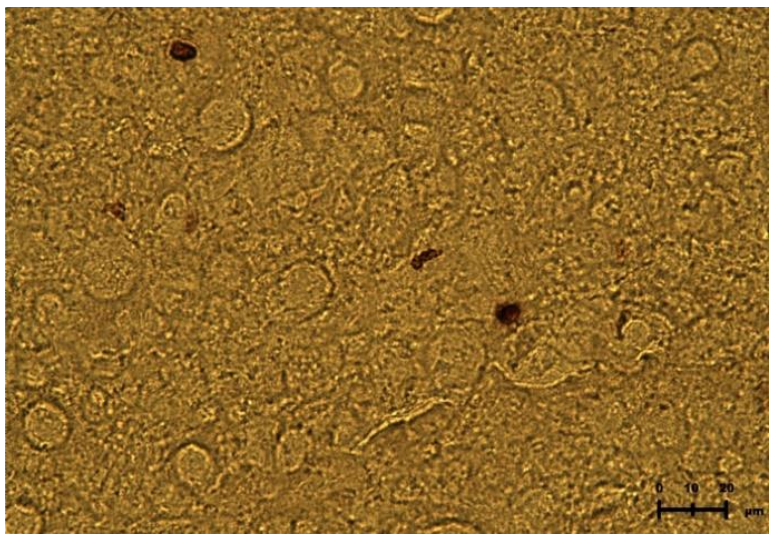

b

Abb. 11: Zellen ACC in 50-facher Vergrößerung PD 39 Hypoxie (a) und Kontrolle (b) 


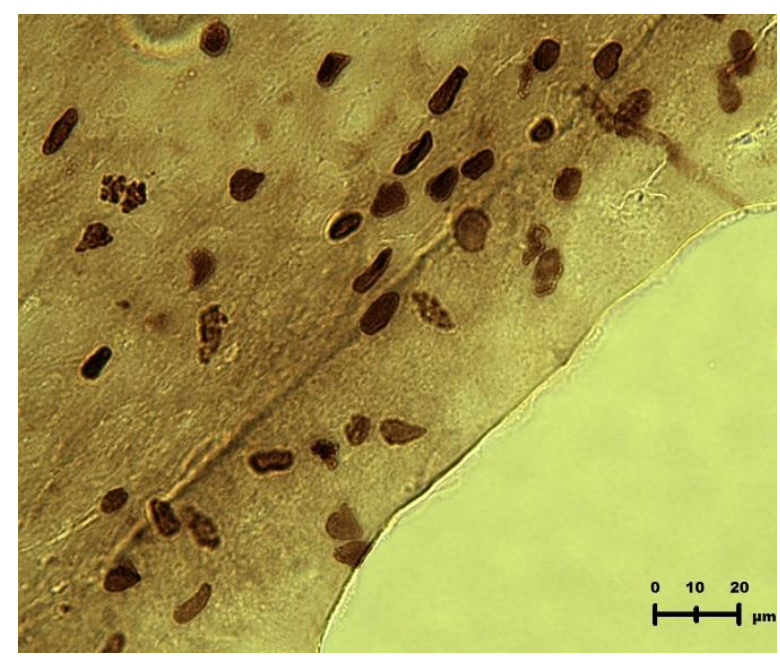

a

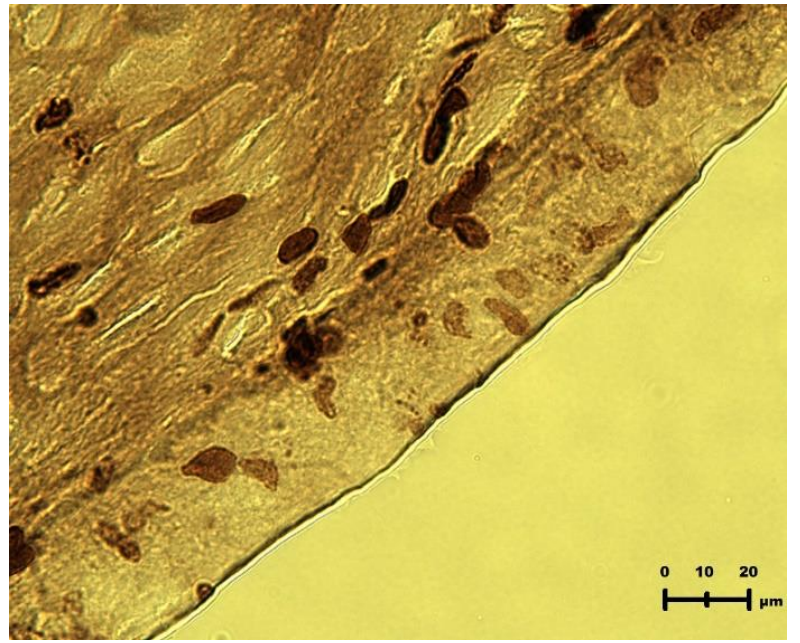

b

Abb. 12: Zellen SVZ in 50-facher Vergrößerung PD 13 Hypoxie (a) und Kontrolle (b)

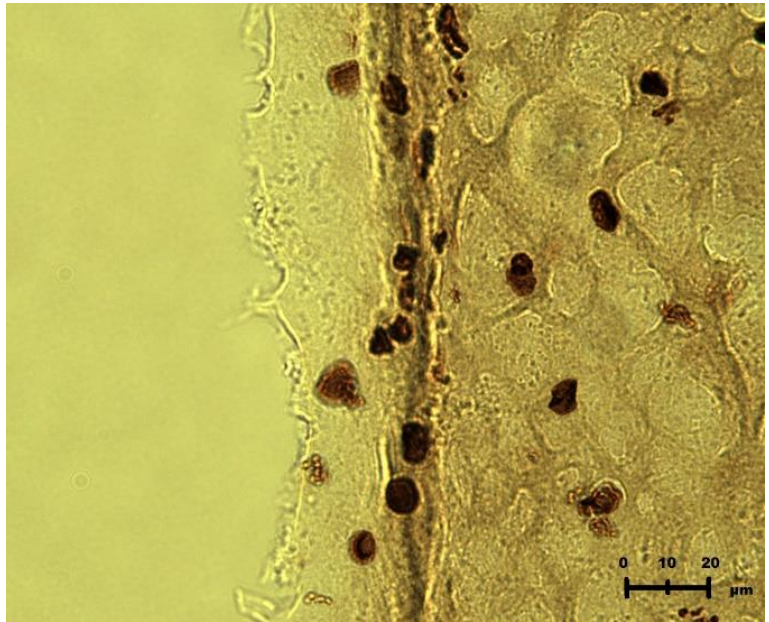

a

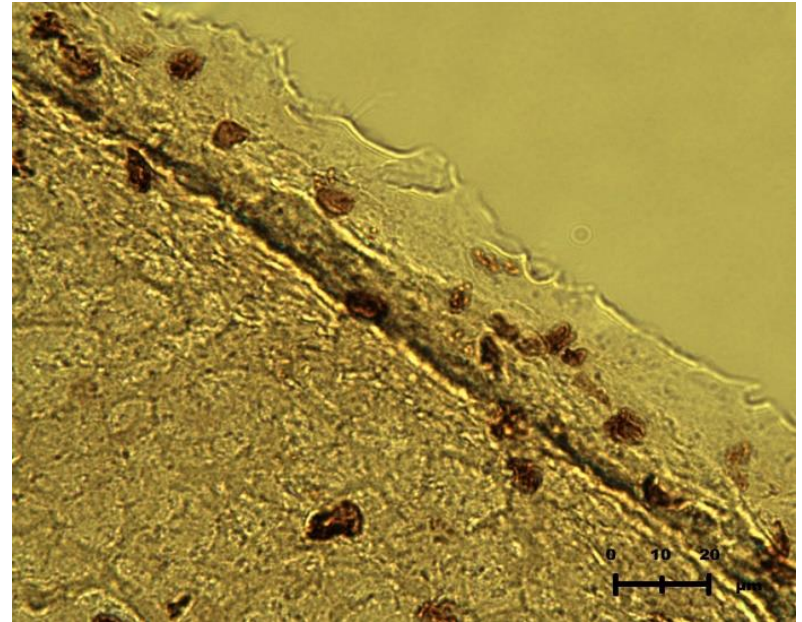

b

Abb. 13: Zellen SVZ in 50-facher Vergrößerung PD 39 Hypoxie (a) und Kontrolle (b) 


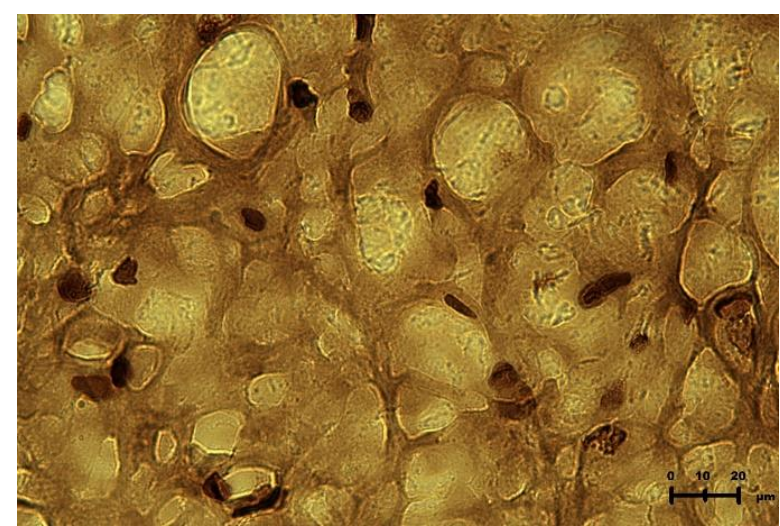

a

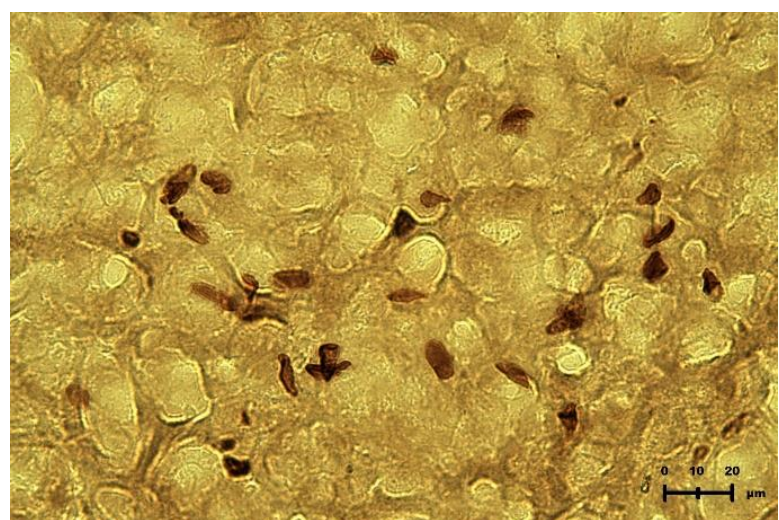

b

Abb. 14: Zellen CPU in 50-facher Vergrößerung PD 13 Hypoxie (a) und Kontrolle (b)

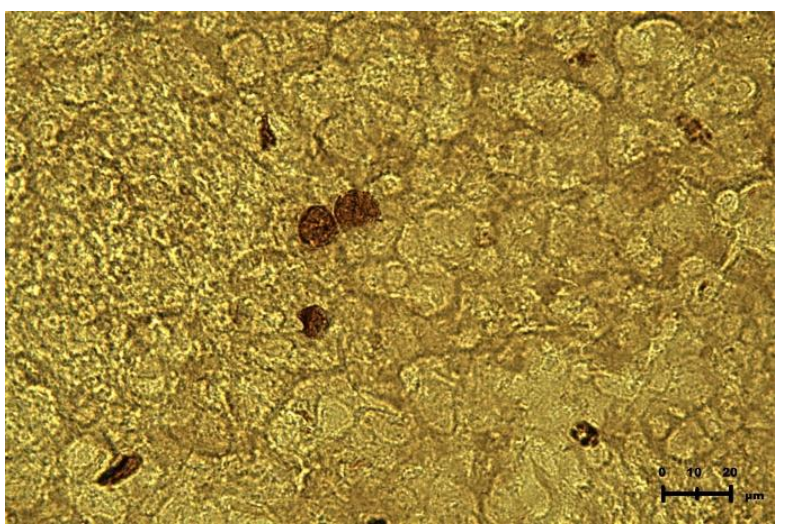

a

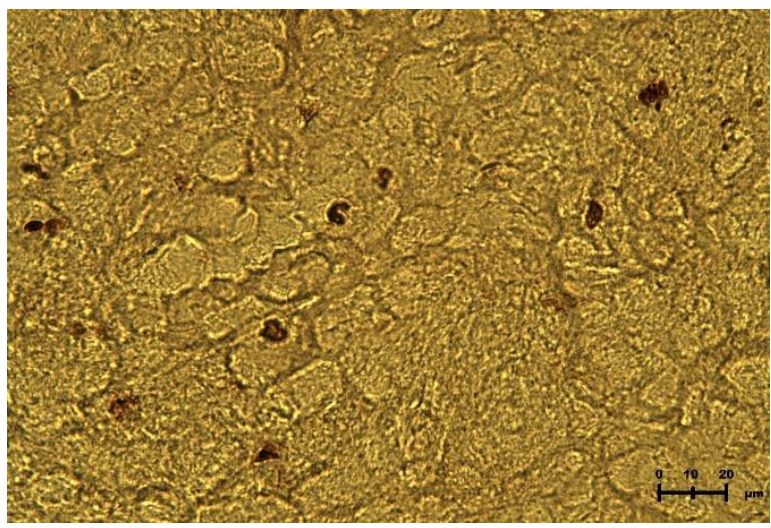

b

Abb. 15: Zellen CPU in 50-facher Vergrößerung PD 39 Hypoxie (a) und Kontrolle (b) 


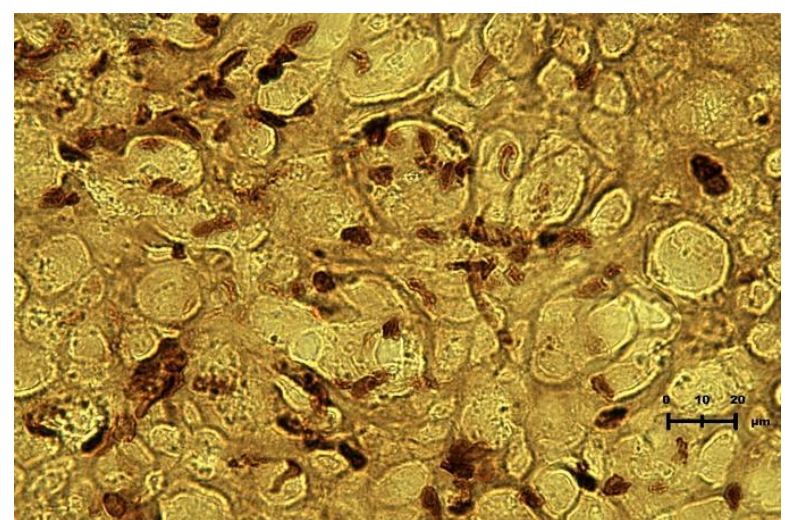

a

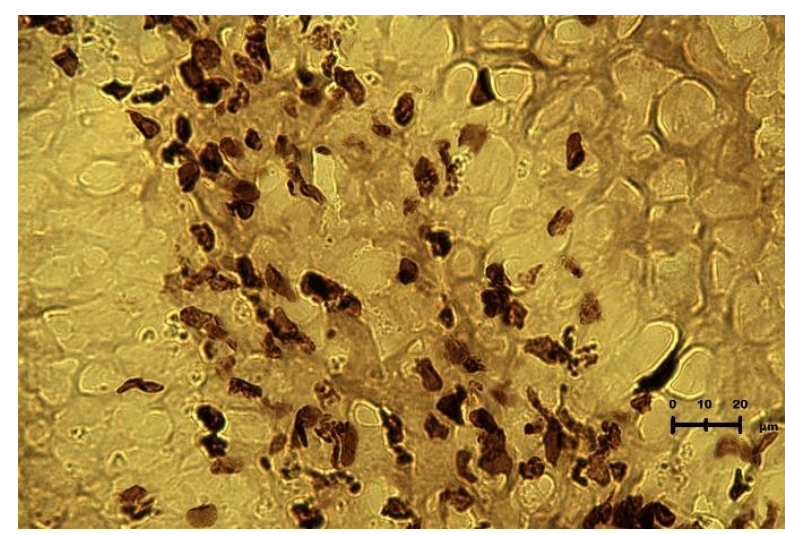

b

Abb. 16: Zellen DG in 50-facher Vergrößerung PD 13 Hypoxie (a) und Kontrolle (b)

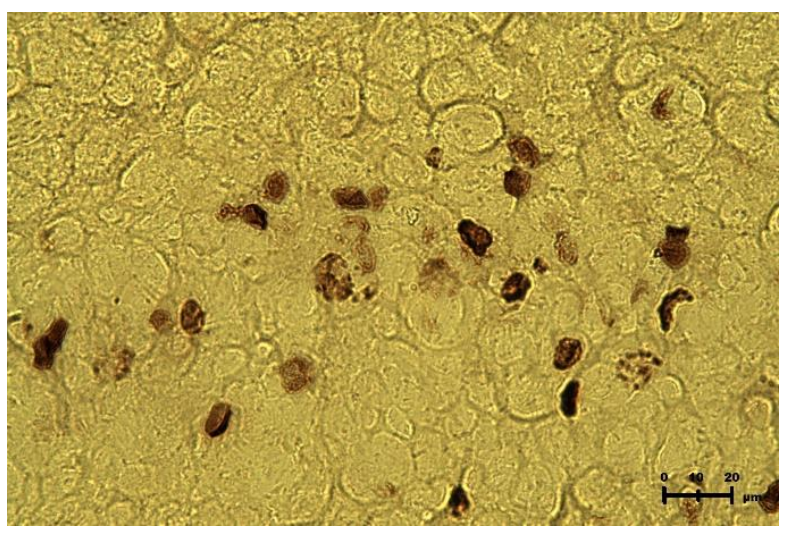

a

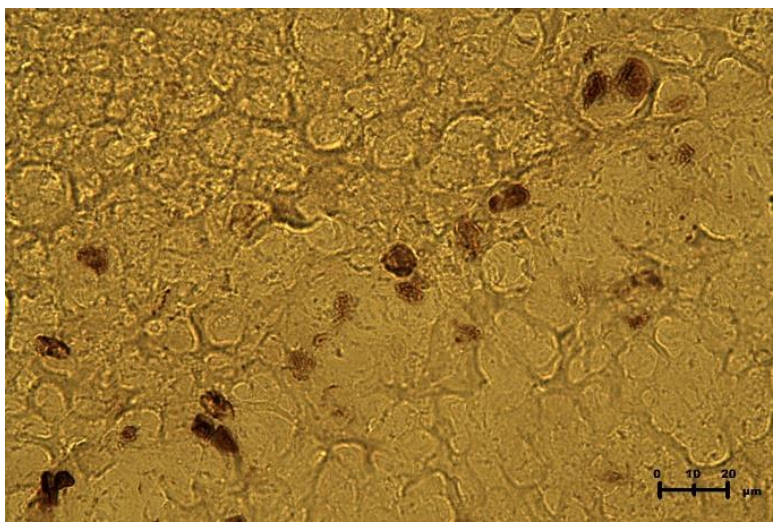

b

Abb. 17: Zellen DG in 50-facher Vergrößerung PD 39 Hypoxie (a) und Kontrolle (b) 
2.2.7 Tabellarische Zusammenfassung zur Zellzahlbestimmung mit der Optical Fractionator-Methode

\begin{tabular}{|l|c|c|c|c|}
\hline & ACC & CPU & SVZ & DG \\
\hline Obj & 50 & 50 & 50 & 50 \\
\hline $\mathbf{B}(\boldsymbol{\mu m})$ & 30 & 30 & 30 & 30 \\
\hline $\mathbf{H}(\boldsymbol{\mu m})$ & 30 & 30 & 30 & 30 \\
\hline $\mathbf{A}(\boldsymbol{\mu m})$ & $173,74 \times 256,52$ & $329,21 \times 425,98$ & $78,2 \times 100,96$ & $56,35 \times 67,49$ \\
\hline $\boldsymbol{\Sigma Z K}$ & 32 & 31 & 51 & 105 \\
\hline $\boldsymbol{\Sigma} \mathbf{S C}$ & 137,1 & 130,9 & 540,295 & 1309 \\
\hline SD & 12,5 & 1 & 7,895 & 44,3 \\
\hline
\end{tabular}

Tab. 8: Darstellung der Details zur stereologischen Zellbestimmung Hypoxie/Kontrolle PD 13

Obj=genutztes Objektiv, B und $\mathrm{H}=$ Breite und Höhe der Zählkästchen, A=Abstand zwischen den Zählkästchen in den zueinander senkrechten Richtungen $X$ und $Y, \Sigma Z K=$ Mittelwert aller Zählkästchen einer Hemisphäre, $\Sigma S C=$ Mittelwert aller gezählten Zellen aus Hypoxie und Kontrolle PD 13 einer Hemisphäre,

$\mathrm{SD}=$ Standardabweichung der Mittelwerte aller gezählten Zellen aus Hypoxie und Kontrolle ( $\Sigma S C)$

\begin{tabular}{|l|c|c|c|c|}
\hline & ACC & CPU & SVZ & DG \\
\hline Obj & 50 & 50 & 50 & 50 \\
\hline $\mathbf{B}(\boldsymbol{\mu m})$ & 100 & 100 & 100 & 100 \\
\hline $\mathbf{H}(\boldsymbol{\mu m})$ & 100 & 100 & 100 & 100 \\
\hline $\mathbf{A}(\boldsymbol{\mu m})$ & $100 \times 100$ & $480 \times 480$ & $100 \times 100$ & $100 \times 100$ \\
\hline $\boldsymbol{\Sigma Z K}$ & 185 & 34 & 97 & 88 \\
\hline $\boldsymbol{\Sigma S C}$ & 3052,815 & 484,65 & 1079,705 & 2777,4 \\
\hline SD & 110,315 & 35,55 & 27,845 & 33 \\
\hline
\end{tabular}

Tab. 9: Darstellung der Details zur stereologischen Zellbestimmung Hypoxie/Kontrolle PD 39 $\mathrm{Obj}=$ genutztes Objektiv, $\mathrm{B}$ und $\mathrm{H}=$ Breite und Höhe der Zählkästchen, $\mathrm{A}=$ Abstand zwischen den Zählkästchen in den zueinander senkrechten Richtungen $X$ und $Y, \Sigma Z K=$ Mittelwert aller Zählkästchen einer Hemisphäre, $\Sigma S C=$ Mittelwert aller gezählten Zellen aus Hypoxie und Kontrolle PD 39 einer Hemisphäre,

$\mathrm{SD}=$ Standardabweichung der Mittelwerte aller gezählten Zellen aus Hypoxie und Kontrolle ( $\Sigma S C)$

\begin{tabular}{|l|c|c|c|c|}
\hline \multirow{2}{*}{ Gezählte Zellen } & \multicolumn{2}{|c|}{ PD 13 } & \multicolumn{2}{c|}{ PD 39 } \\
& Kontrolle & Hypoxie & Kontrolle & Hypoxie \\
\hline ACC & 124,60 & 149,60 & 2942,50 & 3163,13 \\
\hline CPU & 131,90 & 129,90 & 449,10 & 520,20 \\
\hline DG & 1353,30 & 1264,70 & 2744,40 & 2810,40 \\
\hline SVZ & 532,40 & 548,19 & 1051,86 & 1107,55 \\
\hline
\end{tabular}

Tab. 10: Mittelwerte der gezählten Zellen für Hypoxie/Kontrolle PD 13 und PD 39 der vier Hirnregionen Im ACC war die Anzahl der gezählten Zellen an PD 13 bei den Hypoxietieren gegenüber den zugehörigen Kontrollen signifikant erhöht. In den Regionen CPU, DG und SVZ zeigten sich keine signifikanten Unterschiede, hier sind die gezählten Zellen ein Maß für die Güte der Messung. 


\subsubsection{Statistik}

Die statistische Auswertung erfolgte mit der Software SPSS, Version 17. Als Signifikanzniveau wurde $\alpha=0.05$ festgelegt. Es wurden zweiseitige Hypothesentests durchgeführt. Die Stichprobe setzte sich wie folgt zusammen ( $n=$ Fallzahl):

Hypoxie (PD 13, 2 Tage nach BrdU-Injektion sakrifiziert: $n=10$ )

Kontrolle (PD 13, 2 Tage nach BrdU-Injektion sakrifiziert: $n=10$ )

Hypoxie (PD 39, 28 Tage nach BrdU-Injektion sakrifiziert: $n=10$ )

Kontrolle (PD 39, 28 Tage nach BrdU-Injektion sakrifiziert: $n=10$ )

Als abhängige Variablen der ausgewerteten Regionen ACC, CPU, DG und SVZ wurden die absoluten Zellzahlen und das absolute Volumen (in $\mu \mathrm{m}^{3}$ ) definiert. Als intervenierende Variablen galten das Gewicht und die Gewichtszunahme in den entsprechenden Gruppen Hypoxie/Kontrolle PD 13 und Hypoxie/Kontrolle PD 39.

Für die Analyse wurden unterschiedliche Testverfahren angewandt.

In den Kolmogorov-Smirnov-Tests ergaben sich keine signifikanten Abweichungen von der Gaußschen Normalverteilung, so dass im Folgenden die Auswertung mittels parametrischer Verfahren (ANOVA, MANOVA) erfolgen konnte.

Aus den Mittelwerten der Gewichtsdaten und der gezählten Zellen erfolgte der Vergleich auf Gruppenunterschiede mittels einfaktorieller Varianzanalyse (ANOVA).

Für die abhängigen Variablen (ACC, CPU, DG, SVZ: absolute Zellzahlen, absolute Volumina) sind hier deskriptive Statistiken (Fallzahlen, Standardabweichung, Mittelwert) angegeben. Die Auswertung erfolgte mittels multivariater Varianzanalyse (MANOVA getrennt für ACC, CPU, DG, SV), gefolgt von einfaktorieller ANOVA jeweils für absolute Zellzahlen und absoluten Volumina mit Vergleich auf Gruppenunterschiede.

Die Korrelation zwischen Gewicht/Gewichtszunahme und den abhängigen Variablen (absolute Zellzahl, absolute Volumina) erfolgte gepoolt und separat für Kontrolle/Hypoxie PD 13 und Kontrolle/Hypoxie PD 39 mit Hilfe der bivariaten Produkt-Moment-Korrelation nach Pearson. 


\section{Ergebnisse}

\subsection{Gewicht der Ratten}

In den Tabellen 11 und 12 sind Mittelwerte und Standardabweichungen in den entsprechenden Tiergruppen aufgelistet. Diese beziehen sich auf das Gewicht und die Gewichtszunahme mit Vergleich auf Gruppenunterschiede mittels einfaktorieller ANOVA.

\begin{tabular}{|l|c|c|c|c|c|c|c|c|c|}
\hline & \multicolumn{3}{|c|}{ Kontrolle PD 13 } & \multicolumn{3}{c|}{ Hypoxie PD 13 } & \multicolumn{3}{c|}{ Einfaktorielle ANOVA } \\
\cline { 2 - 10 } & $\mathbf{M}$ & $\mathbf{N}$ & $\mathbf{S D}$ & $\mathbf{M}$ & $\mathbf{N}$ & $\mathbf{S D}$ & $\mathbf{d f}$ & $\mathbf{F}$ & $\mathbf{P}$ \\
\hline PD 4 (g) & 11,80 & 10 & 0,70 & 9,56 & 10 & 0,34 & 1,18 & 83.6 & $<\mathbf{0 . 0 0 0 5}$ \\
\hline PD 8 (g) & 19,17 & 10 & 1,42 & 14,30 & 10 & 1,49 & 1,18 & 55.7 & $<\mathbf{0 . 0 0 0 5}$ \\
\hline PD 11 (g) & 25,27 & 10 & 1,42 & 20,74 & 10 & 1,54 & 1,18 & 49.9 & $<\mathbf{0 . 0 0 0 5}$ \\
\hline PD 13 (g) & 29,01 & 10 & 1,83 & 25,26 & 10 & 2,07 & 1,18 & 18.5 & $<\mathbf{0 . 0 0 0 5}$ \\
\hline Zunahme(g) & 17,21 & 10 & 2,04 & 15,70 & 10 & 2,03 & 1,18 & 2.7 & 0.12 \\
\hline
\end{tabular}

Tab. 11: Gewicht und Gewichtszunahme der Hypoxie- und Kontrolltiere PD 13 $\mathrm{M}=$ Mittelwert, $\mathrm{N}=$ Fallzahl, $\mathrm{SD}=$ Standardabweichung, $\mathrm{df}=$ Freiheitsgrade, $\mathrm{F}=\mathrm{F}-\mathrm{Statistik}$, $\mathrm{p}=$ Fehlerwahrscheinlichkeit 1 . Art

In der Gruppe der Hypoxie- und Kontrolltiere PD 13 war das Gewicht der Hypoxietiere zu allen Zeitpunkten signifikant kleiner als das Gewicht der zugehörigen Kontrollen. Die Gewichtszunahme war bei den Hypoxietieren geringer als bei den zugehörigen Kontrollen, aber nicht signifikant.

\begin{tabular}{|l|c|c|c|c|c|c|c|c|c|}
\hline & \multicolumn{3}{|c|}{ Kontrolle PD 39 } & \multicolumn{3}{c|}{ Hypoxie PD 39 } & \multicolumn{3}{c|}{ Einfaktorielle ANOVA } \\
\cline { 2 - 10 } & $\mathbf{M}$ & $\mathbf{N}$ & $\mathbf{S D}$ & $\mathbf{M}$ & $\mathbf{N}$ & $\mathbf{S D}$ & $\mathbf{D f}$ & $\mathbf{F}$ & $\mathbf{P}$ \\
\hline PD 4 (g) & 9,59 & 10 & 1,58 & 9,75 & 10 & 1,57 & 1,18 & 0.1 & 0.82 \\
\hline PD 8 (g) & 17,01 & 10 & 3,19 & 14,88 & 10 & 2,30 & 1,18 & 2.9 & 0.10 \\
\hline PD 11 (g) & 25,73 & 10 & 4,34 & 21,43 & 10 & 1,41 & 1,18 & 8.9 & $\mathbf{0 . 0 0 8}$ \\
\hline PD 39 (g) & 197,50 & 10 & 20,17 & 179,00 & 10 & 16,63 & 1,18 & 5.0 & $\mathbf{0 . 0 3 8}$ \\
\hline Zunahme(g) & 187,91 & 10 & 20,29 & 168,55 & 10 & 15,52 & 1,18 & 5.7 & $\mathbf{0 . 0 2 8}$ \\
\hline
\end{tabular}

Tab. 12: Gewicht und Gewichtszunahme der Hypoxie- und Kontrolltiere PD 39 $\mathrm{M}=$ Mittelwert, $\mathrm{N}=$ Fallzahl, $\mathrm{SD}=\mathrm{Standardabweichung,} \mathrm{df}=$ Freiheitsgrade, $\mathrm{F}=\mathrm{F}-$ Statistik, $\mathrm{p}=$ Fehlerwahrscheinlichkeit 1. Art

In der Gruppe der Hypoxie- und Kontrolltiere PD 39 war das Gewicht der Hypoxietiere ab PD 11 signifikant geringer als bei den Kontrollen. Die Gewichtszunahme war bei den Hypoxietieren signifikant geringer als bei den Kontrollen. 
Die Gewichtsentwicklung in Abhängigkeit vom Alter und im Vergleich zwischen Hypoxie- und Kontrolltieren ist im Folgenden (Abb. 18 und 19) grafisch dargestellt. Die Fehlerbalken entsprechen der Standardabweichung.

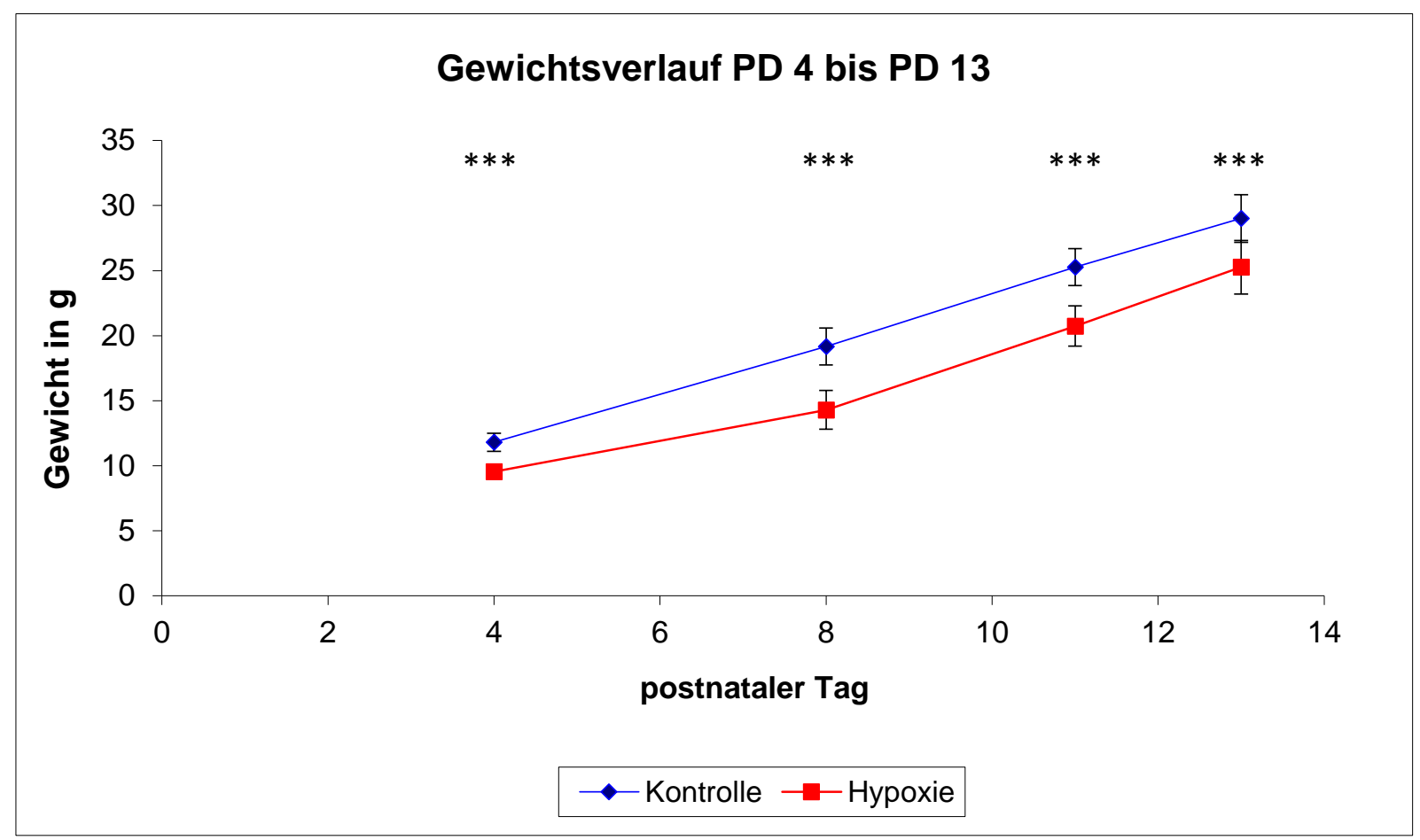

Abb. 18: Gewichtsverlauf PD 4 bis PD 13, Vergleich Hypoxie und Kontrolle ${ }^{* * *}(p<0.001)$

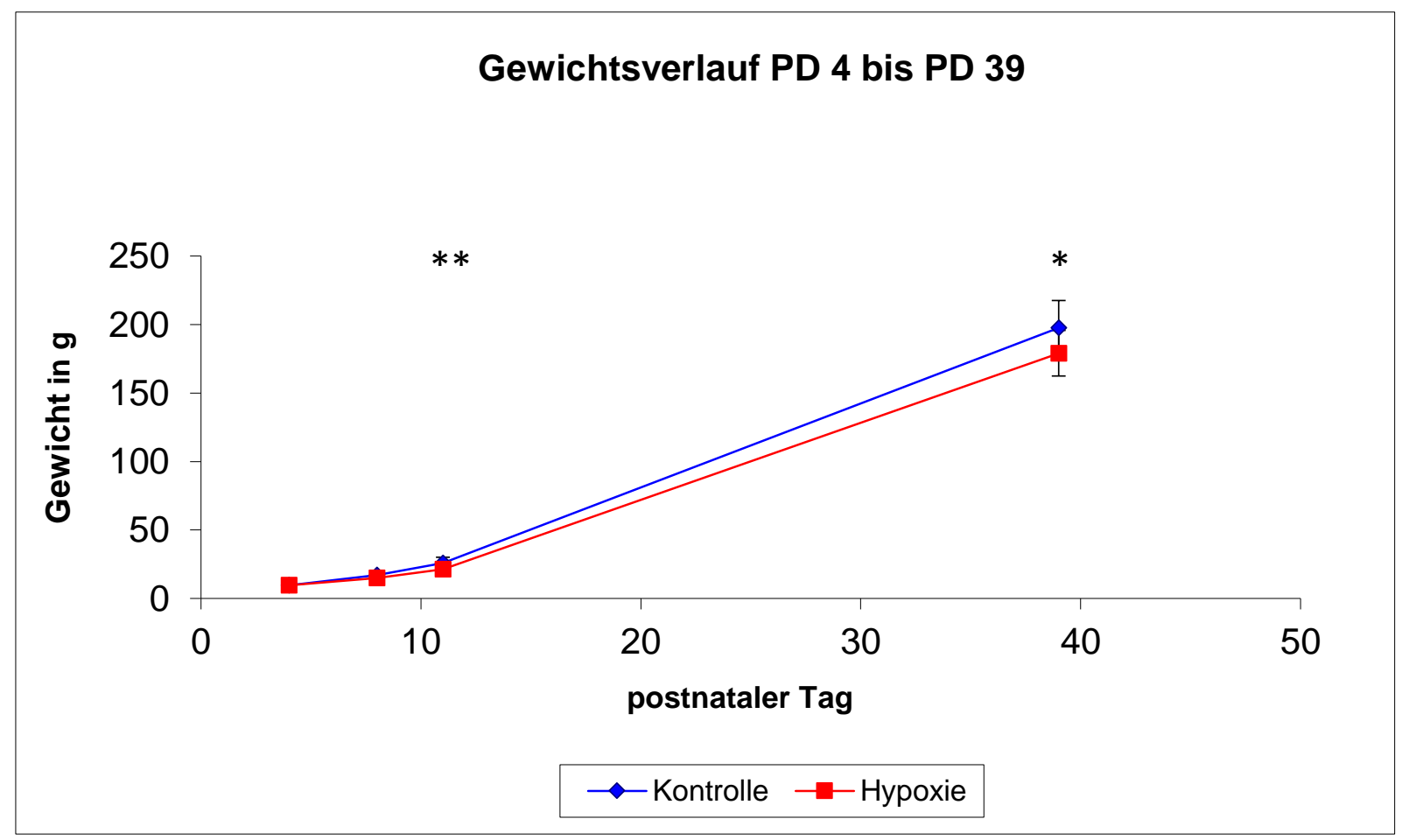

Abb. 19: Gewichtsverlauf PD 4 bis PD 39, Vergleich Hypoxie und Kontrolle ${ }^{*}(p<0.05),{ }^{* *}(p<0.01)$ 


\subsection{Zellen und Volumina}

\subsubsection{Gezählte Zellen}

In den Tabellen 13 und 14 sind Mittelwerte und Standardabweichungen in den entsprechenden Tiergruppen aufgelistet. Diese beziehen sich auf die gezählten Zellen mit Vergleich auf Gruppenunterschiede mittels einfaktorieller ANOVA.

\begin{tabular}{|l|c|c|c|c|c|c|c|c|c|}
\hline \multirow{2}{*}{ Region } & \multicolumn{4}{|c|}{ Kontrolle PD 13 } & \multicolumn{4}{c|}{ Hypoxie PD 13 } & \multicolumn{3}{c|}{ Einfaktorielle ANOVA } \\
\cline { 2 - 10 } & $\mathbf{M}$ & $\mathbf{N}$ & SD & $\mathbf{M}$ & $\mathbf{N}$ & SD & Df & F & P \\
\hline ACC & 124,60 & 10 & 18,03 & 149,60 & 10 & 26,79 & 1,18 & 6.0 & $\mathbf{0 . 0 2 5}$ \\
\hline CPU & 131,90 & 10 & 25,99 & 129,90 & 10 & 181,36 & 1,18 & 0.0 & 0.46 \\
\hline DG & 1353,30 & 10 & 323,47 & 1264,70 & 10 & 170,08 & 1,18 & 0.6 & 0.83 \\
\hline SVZ & 532,40 & 10 & 142,72 & 548,19 & 10 & 20,45 & 1,18 & 0.0 & 0.85 \\
\hline
\end{tabular}

Tab. 13: Gezählte Zellen Hypoxie- und Kontrolltiere PD 13

$\mathrm{M}=$ Mittelwert, $\mathrm{N}=$ Fallzahl, $\mathrm{SD}=$ Standardabweichung, $\mathrm{df}=$ Freiheitsgrade, F=F-Statistik, $\mathrm{p}=$ Fehlerwahrscheinlichkeit 1. Art

In der Gruppe der Hypoxie- und Kontrolltiere PD 13 war die Anzahl der gezählten Zellen im ACC bei den Hypoxietieren gegenüber den zugehörigen Kontrollen signifikant erhöht.

\begin{tabular}{|l|c|c|c|c|c|c|c|c|c|}
\hline \multirow{2}{*}{ Region } & \multicolumn{3}{|c|}{ Kontrolle PD 39 } & \multicolumn{3}{c|}{ Hypoxie PD 39 } & \multicolumn{3}{c|}{ Einfaktorielle ANOVA } \\
\cline { 2 - 10 } & $\mathbf{M}$ & $\mathbf{N}$ & SD & $\mathbf{M}$ & $\mathbf{N}$ & SD & Df & F & P \\
\hline ACC & 2942,50 & 10 & 600,62 & 3163,13 & 10 & 653,88 & 1,18 & 0.6 & 0.44 \\
\hline CPU & 449,10 & 10 & 127,26 & 520,20 & 10 & 93,04 & 1,18 & 2.0 & 0.17 \\
\hline DG & 2744,40 & 10 & 839,02 & 2810,40 & 10 & 753,04 & 1,18 & 0.0 & 0.86 \\
\hline SVZ & 1051,86 & 10 & 253,76 & 1107,55 & 10 & 261,10 & 1,18 & 0.2 & 0.63 \\
\hline
\end{tabular}

Tab. 14: Gezählte Zellen Hypoxie- und Kontrolltiere PD 39

$\mathrm{M}=$ Mittelwert, $\mathrm{N}=$ Fallzahl, $\mathrm{SD}=$ Standardabweichung, $\mathrm{df}=$ Freiheitsgrade, $\mathrm{F}=\mathrm{F}-$ Statistik,

$\mathrm{p}=$ Fehlerwahrscheinlichkeit 1 . Art

In der Gruppe der Hypoxie- und Kontrolltiere PD 39 ergaben sich keine signifikanten Unterschiede. 
Die Mittelwerte der gezählten Zellen in den Hirnregionen ACC, CPU, SVZ und DG sind im Folgenden (Abb. 20 bis 23) grafisch dargestellt. Die Fehlerbalken entsprechen der Standardabweichung.

\section{Zellen ACC PD 13 und PD 39}

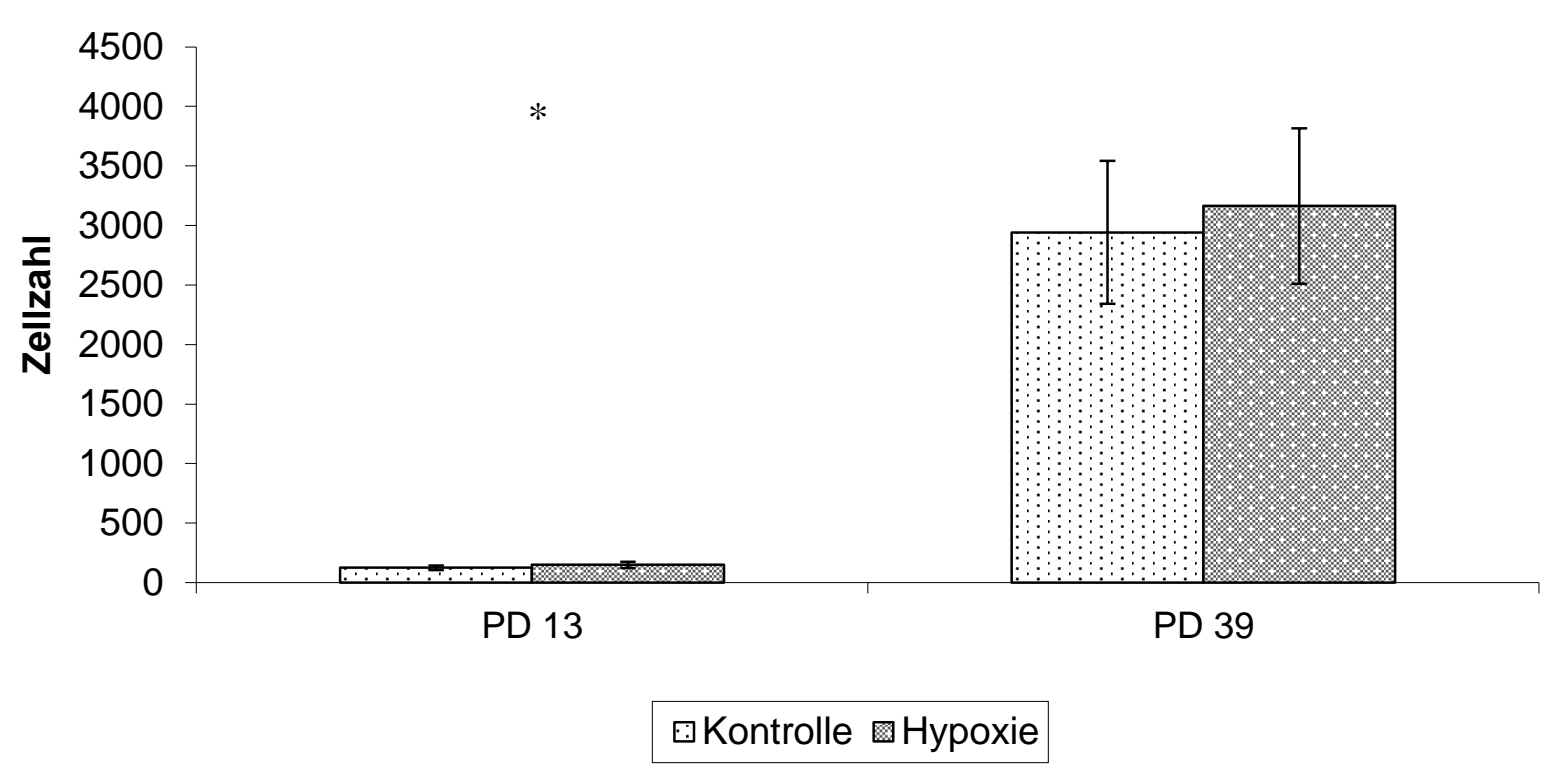

Abb. 20: Gezählte Zellen ACC PD 13 und PD 39, Vergleich Hypoxie und Kontrolle ${ }^{*}(p<0.05)$

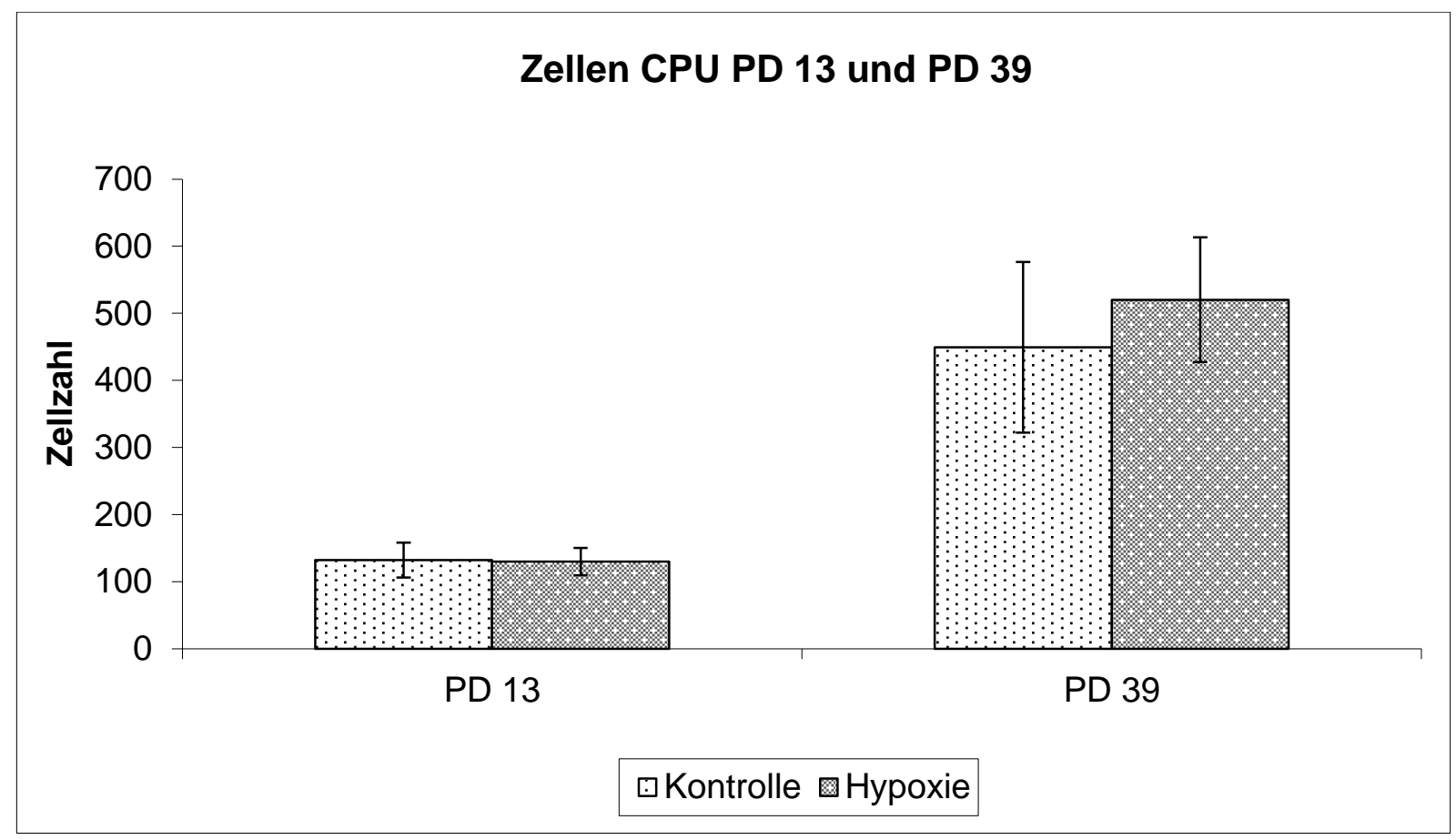

Abb. 21: Gezählte Zellen CPU PD 13 und PD 39, Vergleich Hypoxie und Kontrolle Es finden sich keine signifikanten Mittelwertdifferenzen 


\section{Zellen DG PD 13 und PD 39}

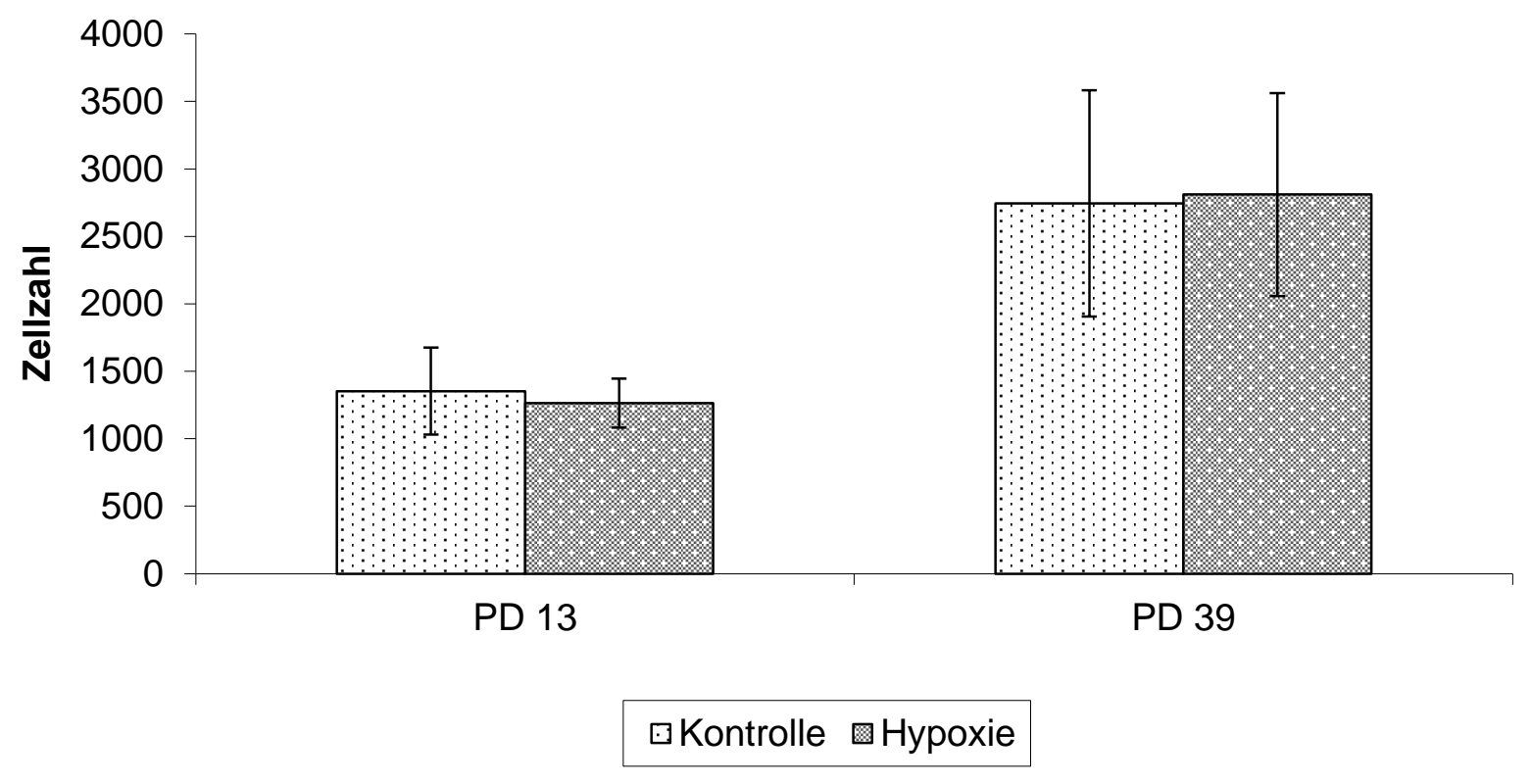

Abb. 22: Gezählte Zellen DG PD 13 und PD 39, Vergleich Hypoxie und Kontrolle Es finden sich keine signifikanten Mittelwertdifferenzen

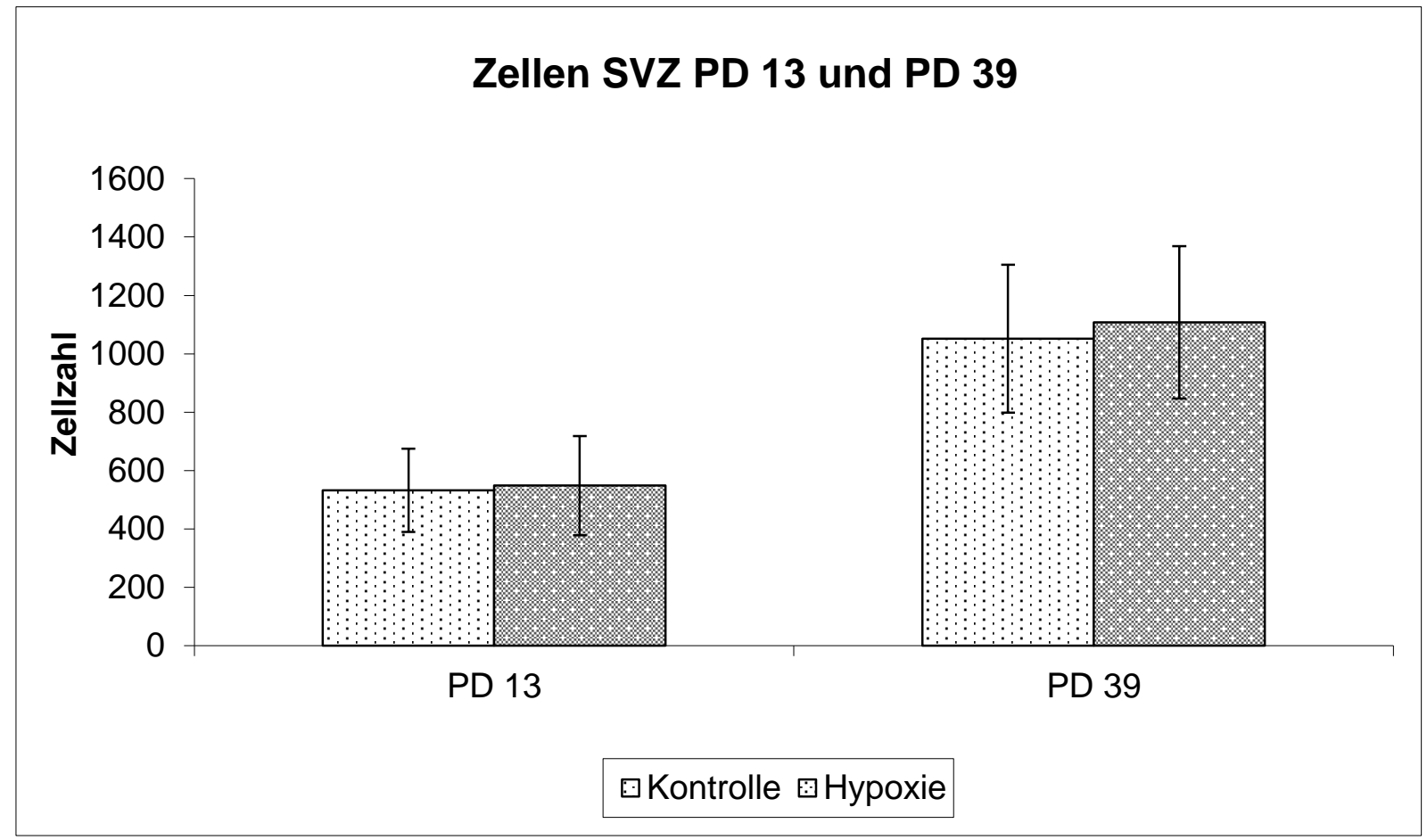

Abb. 23: Gezählte Zellen SVZ PD 13 und PD 39, Vergleich Hypoxie und Kontrolle Es finden sich keine signifikanten Mittelwertdifferenzen 


\subsubsection{Absolute Zellzahlen und Volumina}

In den Tabellen 15 und 16 sind Mittelwerte und Standardabweichungen in den entsprechenden Tiergruppen aufgelistet. Diese beziehen sich auf die mittels Optical Fractionator ermittelten absoluten Zellzahlen und Volumina mit Vergleich auf Gruppenunterschiede mittels (M)ANOVA.

\begin{tabular}{|c|c|c|c|c|c|c|c|c|c|}
\hline & \multicolumn{3}{|c|}{ Kontrolle PD 13} & \multicolumn{3}{|c|}{ Hypoxie PD 13} & \multicolumn{3}{|c|}{ ANOVA/MANOVA } \\
\hline & $\mathbf{m}$ & $\mathbf{N}$ & Sd & $\mathbf{M}$ & $\mathbf{N}$ & Sd & Df & $\mathbf{F}$ & $\mathbf{P}$ \\
\hline $\begin{array}{l}\text { Multivariat } \\
\text { (abs. Zellzahl, Vol. ACC) }\end{array}$ & & & & & & & 2,17 & 3.9 & 0.038 \\
\hline abs. Zellzahl ACC & 84139 & 10 & 12176 & 101010 & 10 & 18066 & 1,18 & 6.0 & 0.025 \\
\hline Volumen ACC $\left(\mu \mathrm{m}^{3}\right)$ & 5,51 & 10 & 1,02 & 5,52 & 10 & 0,64 & 1,18 & 0.0 & 0.99 \\
\hline $\begin{array}{l}\text { Multivariat } \\
\text { (abs. Zellzahl, Vol. CPU) }\end{array}$ & & & & & & & 2,17 & 5.9 & 0.012 \\
\hline abs. Zellzahl CPU & 274262 & 10 & 54093 & 276197 & 10 & 43564 & 1,18 & 0.0 & 0.93 \\
\hline Volumen CPU $\left(\mu \mathrm{m}^{3}\right)$ & 15,31 & 10 & 1,59 & 12,89 & 10 & 1,47 & 1,18 & 12.4 & 0.002 \\
\hline $\begin{array}{l}\text { Multivariat } \\
\text { (abs. Zellzahl, Vol. DG) }\end{array}$ & & & & & & & 2,17 & 0.4 & 0.68 \\
\hline abs. Zellzahl DG & 77980 & 10 & 18639 & 72875 & 10 & 10451 & 1,18 & 0.6 & 0.46 \\
\hline Volumen DG $\left(\mu m^{3}\right)$ & 1,01 & 10 & 0,25 & 0,99 & 10 & 0,14 & 1,18 & 0.1 & 0.81 \\
\hline $\begin{array}{l}\text { Multivariat } \\
\text { (abs. Zellzahl, Vol. SVZ) }\end{array}$ & & & & & & & 2,17 & 0.2 & 0.85 \\
\hline abs. Zellzahl SVZ & 63686 & 10 & 17071 & 65445 & 10 & 20154 & 1,18 & 0.0 & 0.84 \\
\hline Volumen SVZ $\left(\mu \mathrm{m}^{3}\right)$ & 0,71 & 10 & 0,14 & 0,68 & 10 & 0,10 & 1,18 & 0.2 & 0.62 \\
\hline
\end{tabular}

Tab. 15: Deskriptive Statistiken, (M)ANOVA: Absolute Zellzahlen und Volumina Hypoxie- und Kontrolltiere PD 13

$\mathrm{M}=$ Mittelwert, $\mathrm{N}=$ Fallzahl, $\mathrm{SD}=$ Standardabweichung, $\mathrm{df}=$ Freiheitsgrade, $F=F-S t a t i s t i k$,

$\mathrm{p}=$ Fehlerwahrscheinlichkeit 1 . Art

Aus der MANOVA der Hypoxie- und Kontrolltiere PD 13 ergaben sich signifikante Gruppeneffekte im $A C C$ ( $F=3.9 ; d f=2,17 ; p=0.038)$. In den nachfolgenden univariaten Analysen zeigte sich eine signifikante Erhöhung bei den absoluten Zellzahlen im ACC

$(F=6.0 ; d f=1,18 ; p=0.025)$ bei einer prozentualen Mittelwertdifferenz Kontrolle versus Hypoxie von $20 \%$.

Des Weiteren ergaben sich signifikante Gruppeneffekte im CPU ( $F=5.9 ; d f=2,17 ; p=0.012)$. In den nachfolgenden univariaten Tests zeigte sich eine signifikante Reduktion bei den absoluten Volumina $(F=12.4 ; d f=1,18 ; p=0.002)$ bei einer prozentualen Mittelwertdifferenz Kontrolle versus Hypoxie von $-16 \%$.

Aus den MANOVAs für die Regionen SVZ und DG ergaben sich keine signifikanten Gruppeneffekte. 


\begin{tabular}{|c|c|c|c|c|c|c|c|c|c|}
\hline & \multicolumn{3}{|c|}{ Kontrollen PD 39} & \multicolumn{3}{|c|}{ Hypoxie PD 39} & \multicolumn{3}{|c|}{ ANOVA/MANOVA } \\
\hline & $\mathbf{M}$ & $\mathbf{N}$ & Sd & $\mathbf{M}$ & $\mathbf{N}$ & Sd & df & $\mathbf{F}$ & $\mathbf{P}$ \\
\hline $\begin{array}{l}\text { Multivariat } \\
\text { (abs. Zellzahl, Vol. ACC) }\end{array}$ & & & & & & & 2,17 & 2.9 & 0.081 \\
\hline abs. Zellzahl ACC & 40130 & 10 & 8193 & 43133 & 10 & 8916 & 1,18 & 0.6 & 0.44 \\
\hline Volumen ACC $\left(\mu \mathrm{m}^{3}\right)$ & 7,30 & 10 & 0,99 & 6,53 & 10 & 0,55 & 1,18 & 5.0 & 0.044 \\
\hline $\begin{array}{l}\text { Multivariat } \\
\text { (abs. Zellzahl, Vol. CPU) }\end{array}$ & & & & & & & 2,17 & 1.1 & 0.35 \\
\hline abs. Zellzahl CPU & 141099 & 10 & 39982 & 163314 & 10 & 29339 & 1,18 & 2.0 & 0.17 \\
\hline Volumen CPU $\left(\mu \mathrm{m}^{3}\right)$ & 27,18 & 10 & 3,61 & 26,80 & 10 & 3,54 & 1,18 & 0.1 & 0.82 \\
\hline $\begin{array}{l}\text { Multivariat } \\
\text { (abs. Zellzahl, Vol. DG) }\end{array}$ & & & & & & & 2,17 & 1.9 & 0.18 \\
\hline abs. Zellzahl DG & 37422 & 10 & 11441 & 38332 & 10 & 10267 & 1,18 & 0.0 & 0.85 \\
\hline Volumen DG $\left(\mu \mathrm{m}^{3}\right)$ & 2,30 & 10 & 0,62 & 1,94 & 10 & 0,44 & 1,18 & 2.3 & 0.15 \\
\hline $\begin{array}{l}\text { Multivariat } \\
\text { (abs. Zellzahl, Vol. SVZ) }\end{array}$ & & & & & & & 2,17 & 1.7 & 0.22 \\
\hline abs. Zellzahl SVZ & 14461 & 10 & 3393 & 15103 & 10 & 3560 & 1,18 & 0.2 & 0.69 \\
\hline Volumen SVZ $\left(\mu \mathrm{m}^{3}\right)$ & 1,39 & 10 & 0,45 & 1,19 & 10 & 0,25 & 1,18 & 1.5 & 0.24 \\
\hline
\end{tabular}

Tab. 16: Deskriptive Statistiken, (M)ANOVA: Absolute Zellzahlen und Volumina Hypoxie- und Kontrolltiere PD 39

$\mathrm{M}=$ Mittelwert, $\mathrm{N}=$ Fallzahl, $\mathrm{SD}=$ Standardabweichung, $\mathrm{df}=$ Freiheitsgrade, $\mathrm{F}=\mathrm{F}-$ Statistik,

$\mathrm{p}=$ Fehlerwahrscheinlichkeit 1. Art

Aus der MANOVA der Hypoxie- und Kontrolltiere PD 39 ergab sich ein nicht signifikanter Trend zu Gruppeneffekten im ACC ( $F=2.9 ; \mathrm{df}=2,17 ; \mathrm{p}=0.081)$. In den nachfolgenden univariaten Tests zeigte sich eine signifikante Mittelwertreduktion Kontrolle versus Hypoxie für das Volumen im ACC ( $F=5.0 ; d f=1,18 ; p=0.044)$ von $-11 \%$ (Fehlerquelle, siehe Kapitel 4.7.2 Grenzen der Methodik).

Aus den MANOVAs für die Regionen CPU, SVZ und DG ergaben sich keine signifikanten Gruppeneffekte. 
Die Mittelwerte der absoluten Zellzahlen und der Volumina in den Hirnregionen ACC, CPU, DG und SVZ sind im Folgenden grafisch dargestellt (Abb. 24 bis 31). Die Fehlerbalken entsprechen der Standardabweichung.

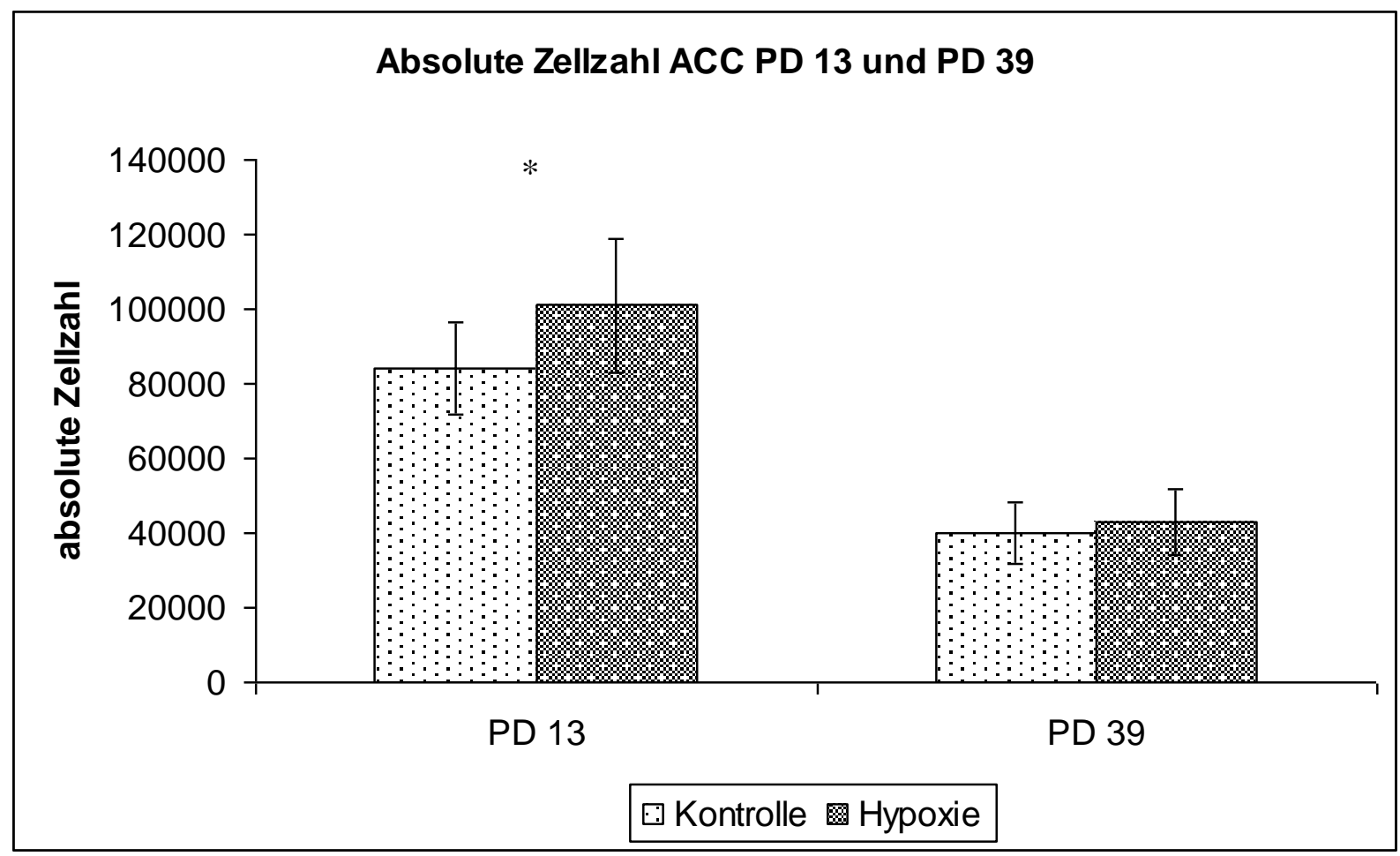

Abb. 24: Absolute Zellzahl ACC PD 13 und PD 39, Vergleich Hypoxie und Kontrolle ${ }^{*}(p<0,05)$

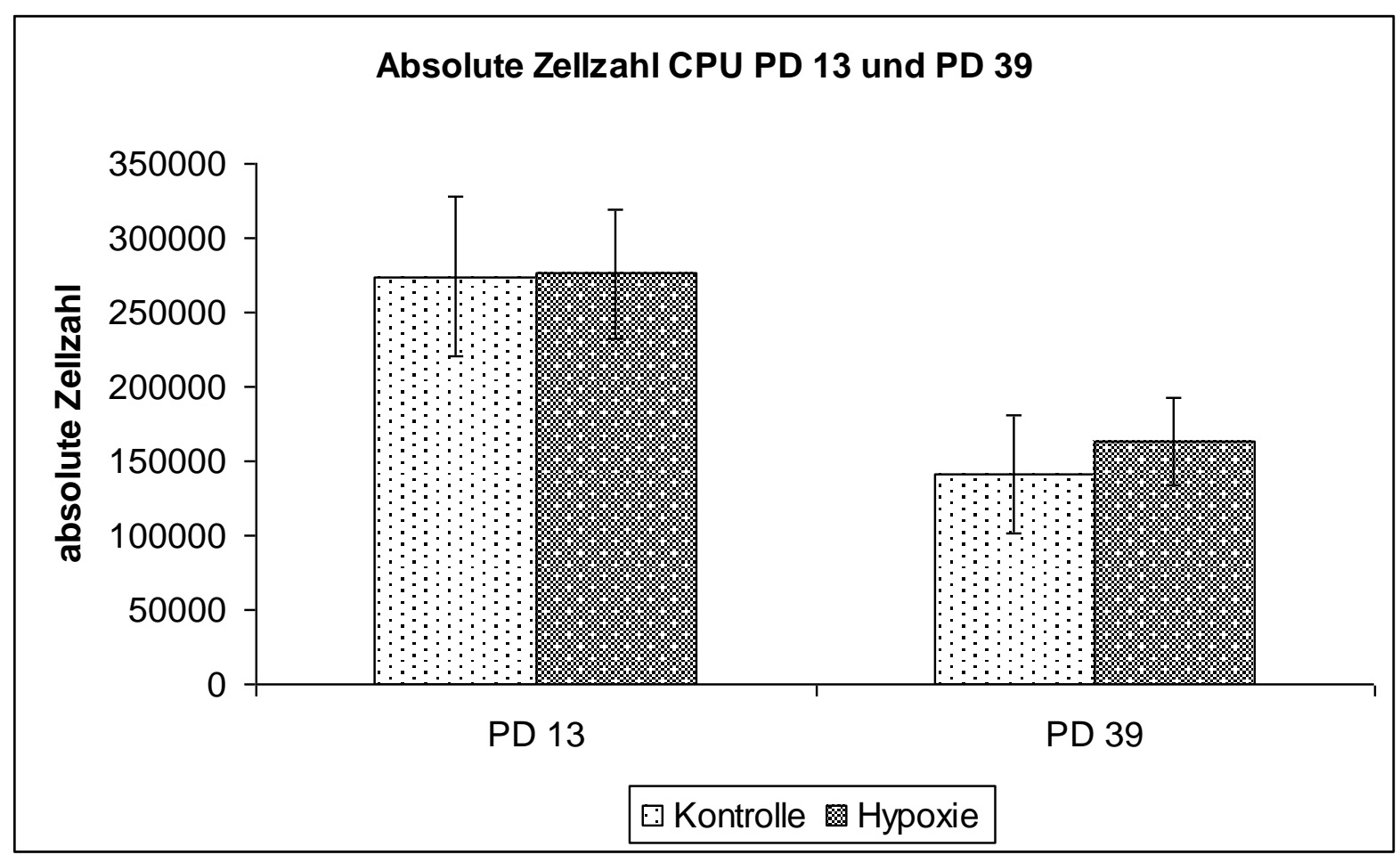

Abb. 25: Absolute Zellzahl CPU PD 13 und PD 39, Vergleich Hypoxie und Kontrolle Es finden sich keine signifikanten Mittelwertdifferenzen 


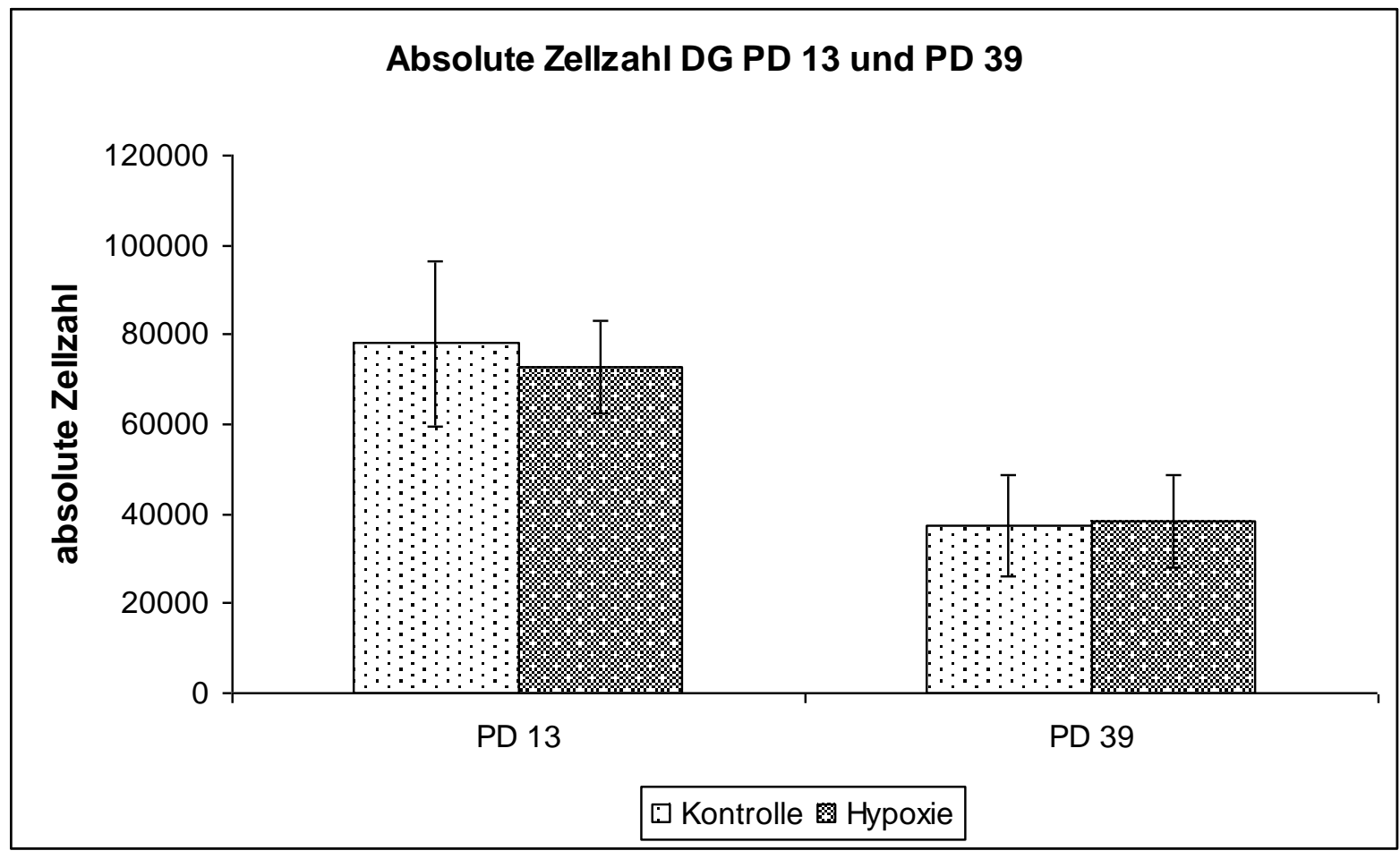

Abb. 26: Absolute Zellzahl DG PD 13 und PD 39, Vergleich Hypoxie und Kontrolle Es finden sich keine signifikanten Mittelwertdifferenzen

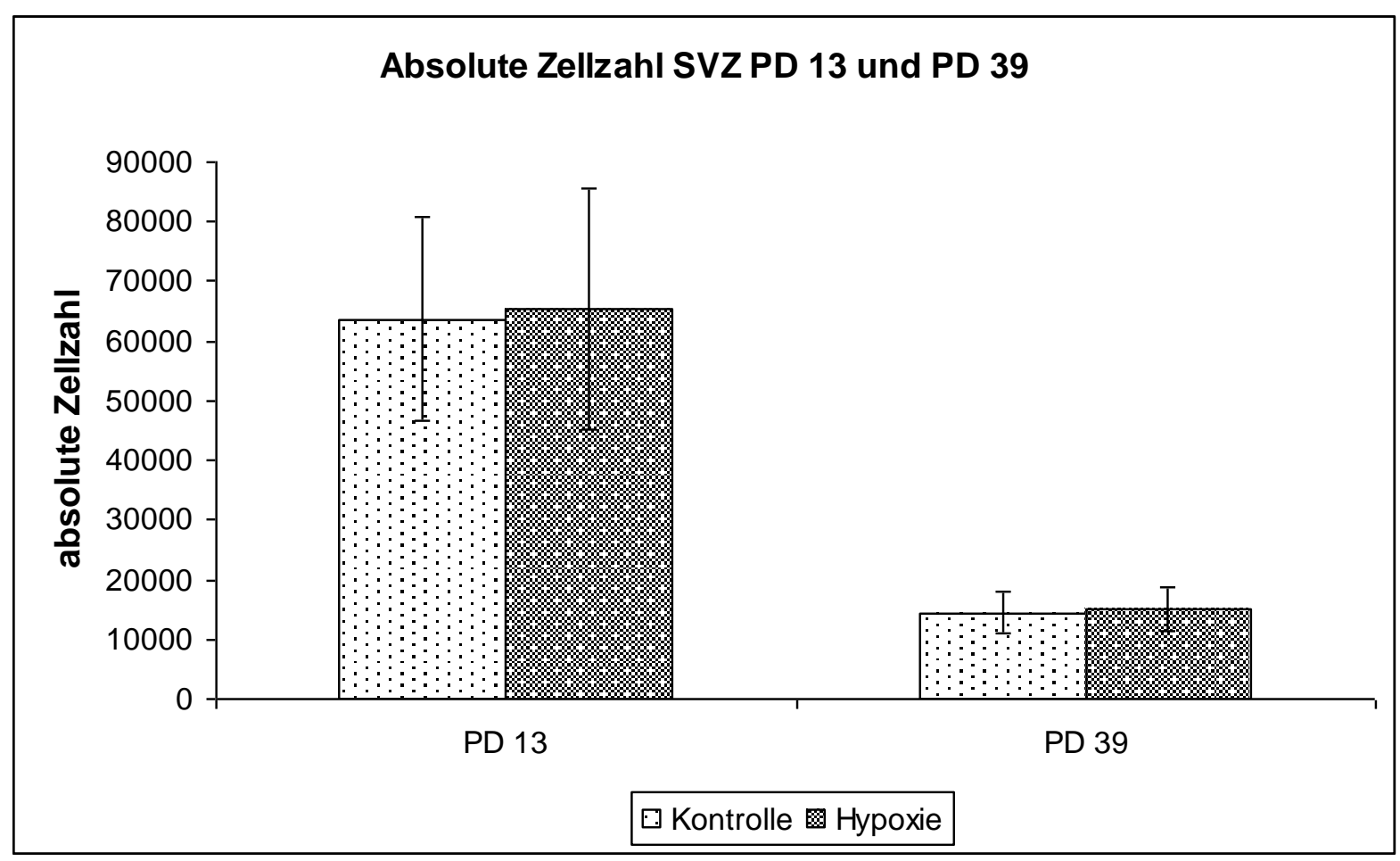

Abb. 27: Absolute Zellzahl SVZ PD 13 und PD 39, Vergleich Hypoxie und Kontrolle Es finden sich keine signifikanten Mittelwertdifferenzen 


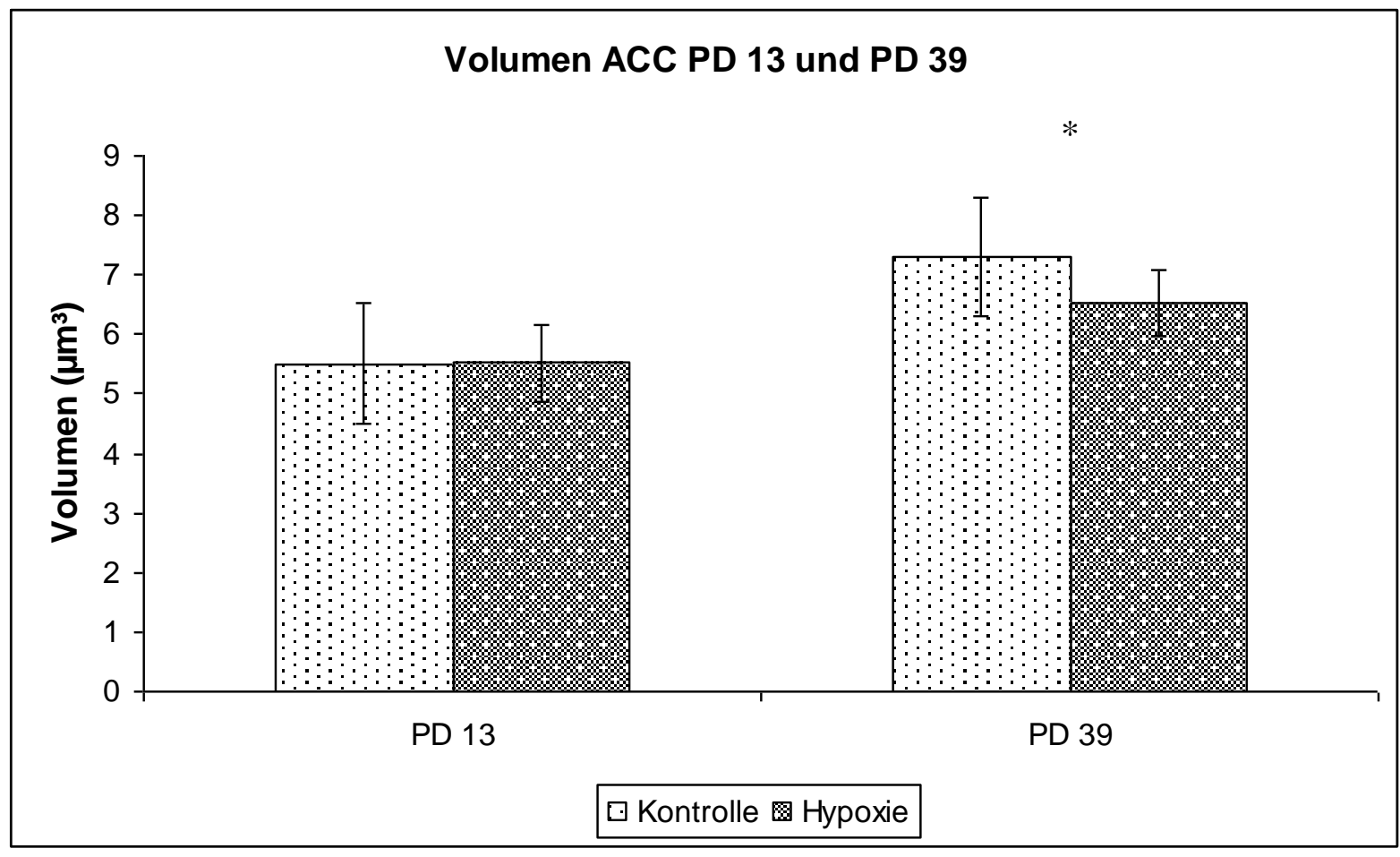

Abb. 28: Volumen ACC PD 13 und PD 39, Vergleich Hypoxie und Kontrolle ${ }^{*}(p<0,05)$

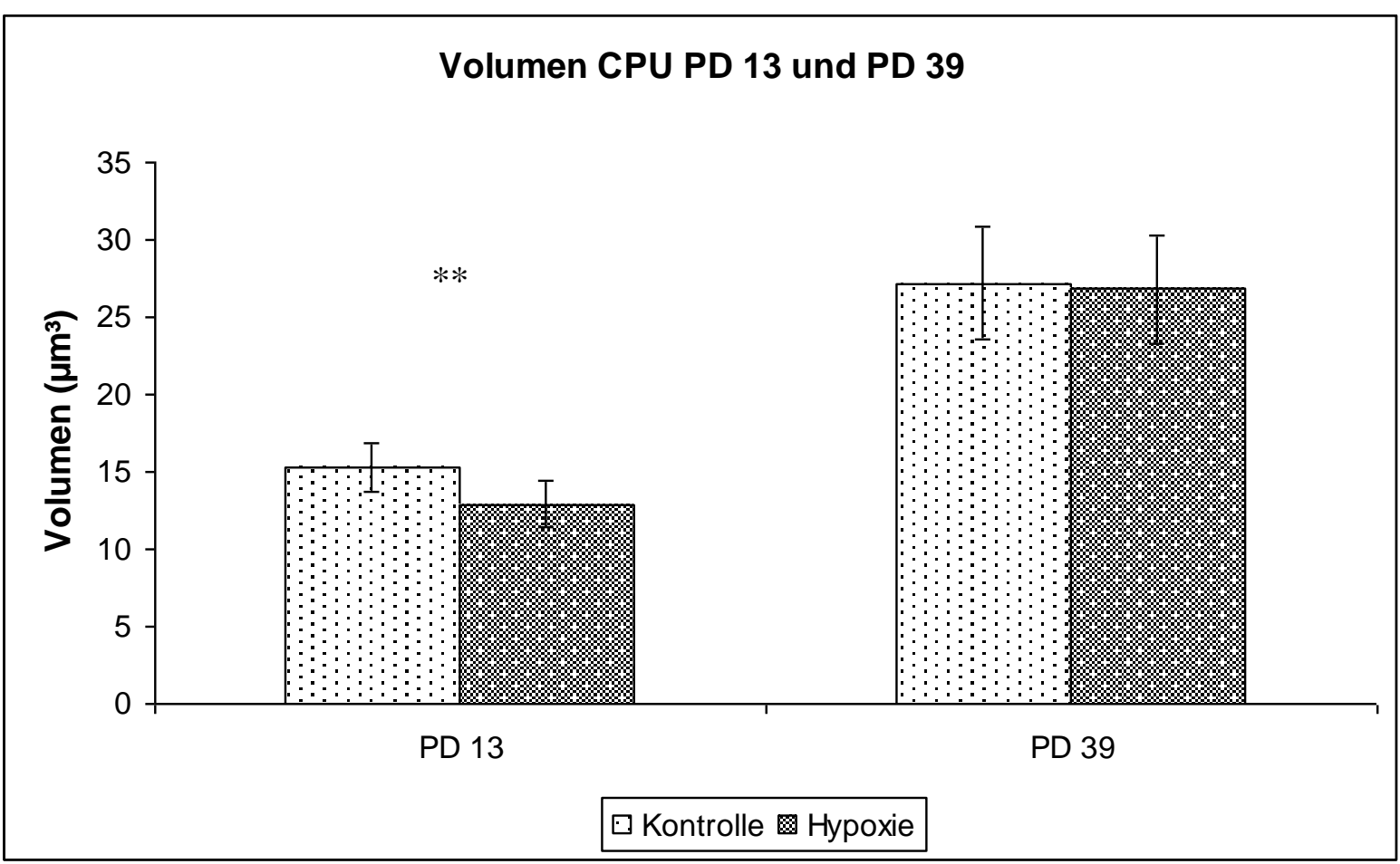

Abb. 29: Volumen CPU PD 13 und PD 39, Vergleich Hypoxie und Kontrolle ${ }^{* *}(p<0,01)$ 


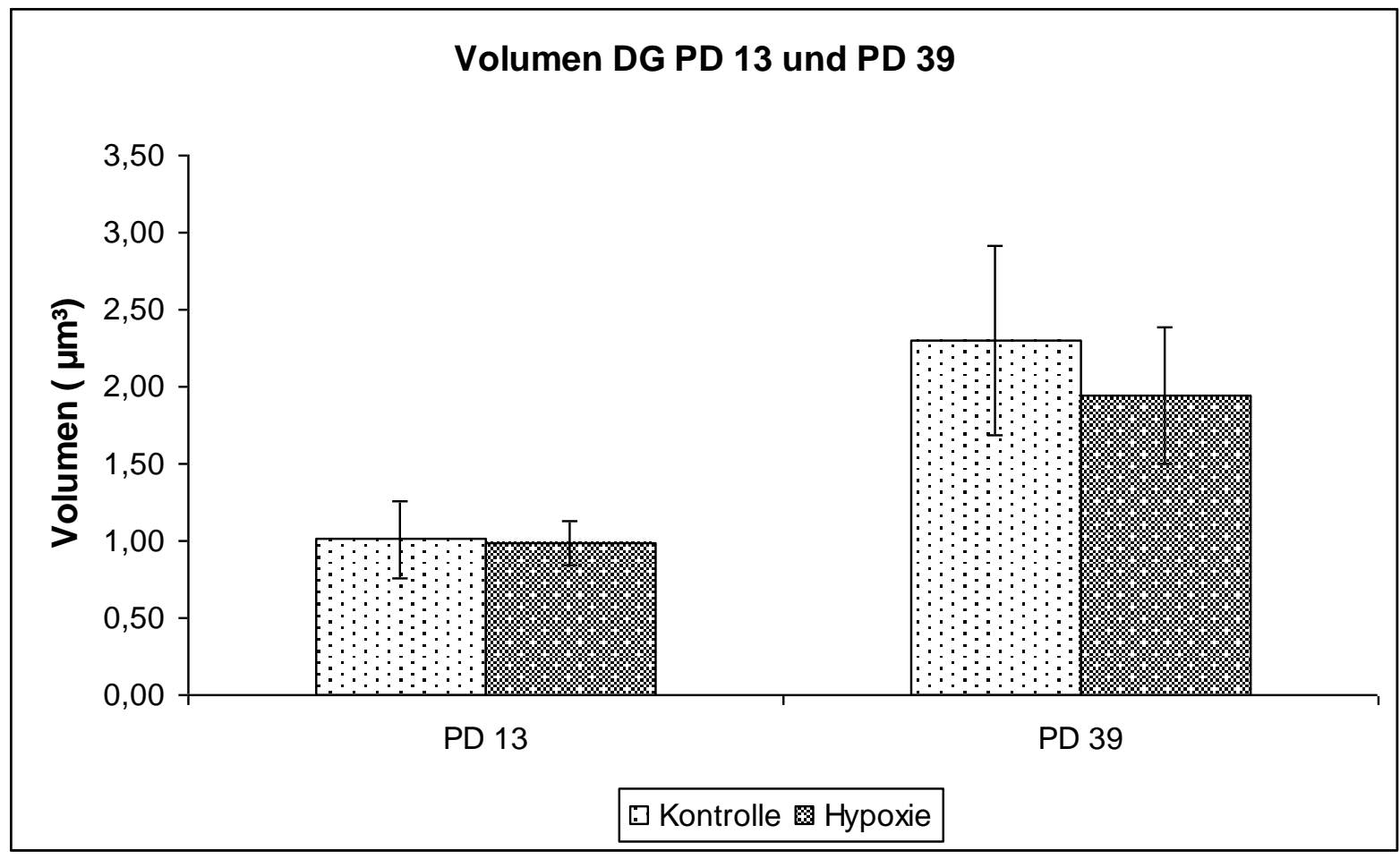

Abb. 30: Volumen DG PD 13 und PD 39, Vergleich Hypoxie und Kontrolle Es finden sich keine signifikanten Mittelwertdifferenzen

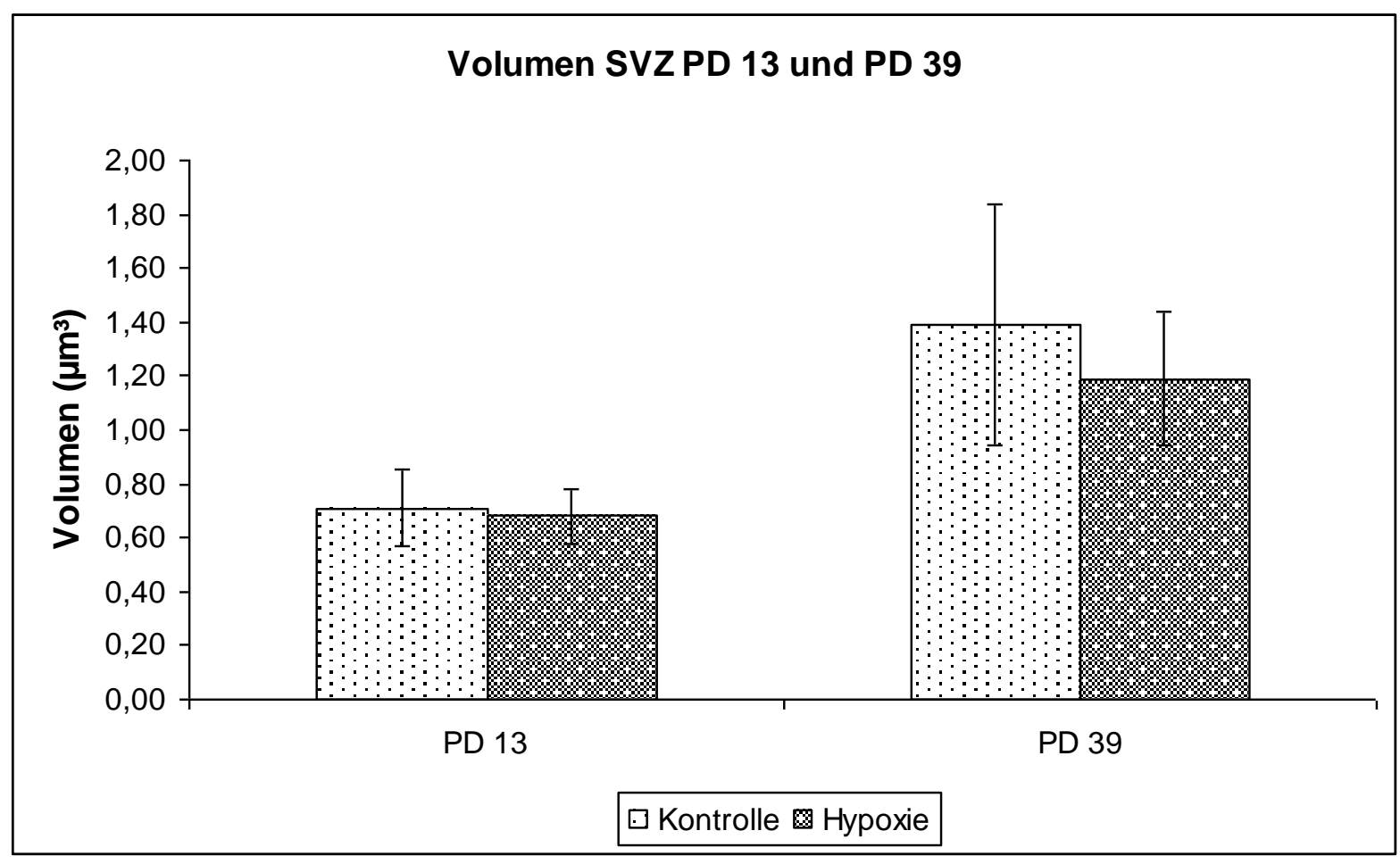

Abb. 31: Volumen SVZ PD 13 und PD 39, Vergleich Hypoxie und Kontrolle Es finden sich keine signifikanten Mittelwertdifferenzen 
3.3 Korrelationen zwischen Gewicht/Gewichtszunahme und absoluter Zellzahl/Zellvolumina

Die Korrelationen zwischen Gewicht/Gewichtszunahme und den abhängigen Variablen: absolute Zellzahl/Volumina (gepoolt und separat für Hypoxie/Kontrolle PD 13 und Hypoxie/Kontrolle PD 39) wurden mit der bivariaten Produkt-Moment-Korrelation nach Pearson berechnet.

\begin{tabular}{|l|c|c|}
\hline $\begin{array}{l}\text { Korrelation zwischen abso- } \\
\text { luter Zellzahl ACC } \\
\text { PD 13 und Gewicht/ Ge- } \\
\text { wichtszunahme }\end{array}$ & Korrelation r & Signifikanz ( $\mathbf{~ \leq ~ 0 . 0 5 ) ~}$ \\
\hline PD 4 & & 0.055 \\
\hline PD 8 & $-0,435$ & $\mathbf{0 . 0 0 9}$ \\
\hline PD 11 & $-0,569$ & $\mathbf{0 . 0 1 4}$ \\
\hline PD 13 & $-0,452$ & $\mathbf{0 . 0 0 5}$ \\
\hline Gewichtszunahme & $-0,598$ & $\mathbf{0 . 0 2 4}$ \\
\hline
\end{tabular}

Tab. 17: Korrelationen zwischen absoluter Zellzahl ACC PD 13 und Gewicht/Gewichtszunahme

Die Ergebnisse für Hypoxie- und Kontrolltiere PD 13 gepoolt ergaben signifikant negative Korrelationen zwischen den absoluten Zellzahlen im ACC und den Körpergewichten wie auch der Gewichtszunahme (Tab. 17).

\begin{tabular}{|l|c|c|}
\hline $\begin{array}{l}\text { Korrelation zwischen Vo- } \\
\text { lumen CPU } \\
\text { PD 13 und Gewicht/ Ge- } \\
\text { wichtszunahme }\end{array}$ & Korrelation r & Signifikanz ( $\mathbf{p} \leq \mathbf{0 . 0 5})$ \\
\hline PD 4 & & $\mathbf{0 . 0 0 1}$ \\
\hline PD 8 & 0,664 & $<\mathbf{0 . 0 0 0 5}$ \\
\hline PD 11 & 0,727 & $\mathbf{0 . 0 1}$ \\
\hline PD 13 & 0,562 & $\mathbf{0 . 0 0 9}$ \\
\hline Gewichtszunahme & 0,568 & 0.16 \\
\hline
\end{tabular}

Tab. 18: Korrelationen zwischen absolutem Volumen CPU PD 13 und Gewicht/Gewichtszunahme

Die Ergebnisse für Hypoxie- und Kontrolltiere PD 13 gepoolt ergaben signifikant positive Korrelationen zwischen dem Volumen im CPU und den Körpergewichten (Tab. 18). 
Die separate Berechnung für die Kontrolltiere PD 13 ergab eine signifikant negative Korrelation zwischen dem Gewicht und den absoluten Zellzahlen im ACC an PD 8 ( $r=-0,668$; $\mathrm{p}=0.035$ ). Auch die Korrelationen zwischen den Gewichten an den folgenden Tagen (PD 11, PD 13) wie auch der Gewichtszunahme und der absoluten Zellzahl im ACC war weiterhin negativ, bei der kleinen Fallzahl ergab sich aber keine Signifikanz. Die Korrelation zwischen Gewichtszunahme und Volumen im ACC war signifikant negativ ( $r=-0,660 ; p=0.038)$. Die Korrelation zwischen dem Gewicht an PD 4 und dem Volumen in der SVZ war signifikant positiv $(r=0,706 ; p=0.023)$.

Die separate Berechnung für die Hypoxietiere PD 13 ergab eine signifikant positive Korrelation zwischen dem Volumen im CPU und dem Gewicht an PD 8 ( $r=0,680 ; p=0.030)$. Auch die Korrelation zwischen dem Volumen des CPU und dem Gewicht an PD 13 bzw. der Gewichtszunahme war positiv, jedoch bei der kleinen Fallzahl nicht mehr signifikant.

Die Ergebnisse für Hypoxie- und Kontrolltiere PD 39 gepoolt ergaben eine signifikant positive Korrelation zwischen dem Volumen in der SVZ und der Gewichtszunahme $(r=0,452$; $\mathrm{p}=0.045)$.

Die separate Berechnung für die Kontrolltiere PD 39 ergab eine signifikant positive Korrelation zwischen der absoluten Zellzahl in der SVZ und dem Gewicht an PD 39 ( $r=0,740$; $\mathrm{p}=0.014$ ). Des Weiteren zeigte sich eine signifikant positive Korrelation zwischen der absoluten Zellzahl in der SVZ und der Gewichtszunahme ( $r=0,732 ; p=0.016)$.

Die separate Berechnung für die Hypoxietiere PD 39 ergab eine signifikant negative Korrelation zwischen der absoluten Zellzahl im ACC und dem Gewicht an PD 8 $(r=-0,693 ; p=0.026)$, dem Volumen im ACC und dem Gewicht an PD 39 ( $r=-0,761 ; p=0.011)$ bzw. dem Volumen im ACC und der Gewichtszunahme ( $r=-0,740 ; p=0.014)$. Außerdem zeigte sich eine signifikant negative Korrelation zwischen der absoluten Zellzahl im CPU und dem Gewicht an PD 11 ( $r=-0,733 ; p=0.016)$ und zwischen der absoluten Zellzahl im DG und dem Gewicht an PD $11 \quad(r=-0,821 ; p=0.004)$ und PD $39 \quad(r=-0,655 ; p=0.04)$. 


\section{Diskussion}

Neben der genetischen Prädisposition gibt es zahlreiche Umweltfaktoren in der Ätiologie der Schizophrenie, wobei die perinatale Hypoxie einen bedeutenden Einfluss auf die Pathophysiologie der Erkrankung hat.

Eine Hypothese geht davon aus, dass der Beginn einer abnormalen Hirnentwicklung perinatal liegt, wohingegen sich Symptome erst im frühen Erwachsenenalter manifestieren (Weinberger 1996). Störungen der Zellproliferation stellen möglicherweise einen wichtigen Faktor in der Pathogenese der Erkrankung dar und sind nach perinataler Hypoxie bislang unbekannt. Ziel der Arbeit war die Untersuchung der Zellproliferation im Gehirn am Tiermodell unter dem Einfluss von postnataler Hypoxie als Modell für Schwangerschafts- und Geburtskomplikationen.

Mögliche Veränderungen der Zellproliferation der Gehirnregionen ACC, CPU, SVZ und DG wurden über die Zeit (PD 13 bis PD 39) untersucht. Die Ergebnisse sollten im Anschluss kritisch auf das Krankheitsbild der Schizophrenie bezogen und deren Bedeutung für die Äthiopathogenese diskutiert werden.

\subsection{Gyrus cinguli}

Zusammenfassend konnte festgestellt werden, dass Ratten, die einer chronischen postnatalen Hypoxie ausgesetzt waren, eine um 20 \% signifikant erhöhte Zellzahl im ACC an PD 13 gegenüber den gleichaltrigen Kontrollen aufwiesen. An PD 39 zeigten sich allerdings keine signifikanten Unterschiede mehr.

Die Ergebnisse zeigen auf der einen Seite, dass ein vorübergehender Einfluss chronischer Hypoxie auf die Zellproliferation im ACC angenommen werden kann, auf der anderen Seite zeigt sich eine Normalisierung der Zellzahl mit zunehmendem Alter.

Die vorliegende Studie ist die erste, die eine erhöhte Zellproliferation im ACC nach neonataler Hypoxie mit der aufgezeigten Methodik nachweisen konnte.

Unsere Ergebnisse stimmen mit anderen Studien überein, die eine vermehrte kortikale Zellproliferation nach Hypoxie und/oder Ischämie feststellen konnten (z. B. Fagel et al. 2006, Zhang et al. 2001, Ikeda et al. 2005). Mäuse, die von PD 3 bis PD 11 einer chronischen Hypoxie (9,5-10,5\%iges Sauerstoffgemisch) ausgesetzt waren, zeigten an PD 49 eine um $40 \%$ höhere Anzahl BrdU-positiver Zellen im zerebralen Kortex im Vergleich zu den Kontrollen. Davon machten etwa $45 \%$ Oligodendrozyten, $35 \%$ Astrozyten und $10 \%$ Neurone aus. Die Darstellung von Neuronen erfolgte mit Hilfe der immunhistochemischen Doppelfärbung mit BrdU und Neuronen-spezifischem Protein (NeuN). Der an PD 49 erhöhten Zellzahl war eine verminderte Dichte proliferierender Zellen in der SVZ und im Hippocampus an PD 11 
vorausgegangen. An PD 18 konnte schon eine vermehrte Zellproliferation BrdU-positiver Zellen in den Neurogenesezentren, vor allem in der SVZ beobachtet werden (Fagel et al. 2006). Die Untersuchung der Neurogenese durch eine immunhistochemische Doppelfärbung erfolgte in der hier vorliegenden Arbeit nicht. Aus den genannten Ergebnissen von Fagel et al. (2006) kann jedoch geschlussfolgert werden, dass die erhöhte Anzahl von Neuronen im ACC Folge einer vorangegangenen verstärkten Zellproliferation (wie wir sie nachweisen konnten) sein könnte.

Des Weiteren zeigten sich in der Studie von Fagel et al. (2006) an PD 11 ein signifikanter Neuronenverlust von $30 \%$ und eine signifikante Volumenminderung im neonatalen Kortex, wobei es sich überwiegend um Pyramidenzellen handelte. An PD 18 wurde eine Neuroblastenmigration in den Kortex aus der SVZ nach vorangegangener Zellproliferation nachgewiesen und geschlussfolgert, dass die kortikale Neurogenese eine signifikante Rolle bei der Regeneration neuronaler Verluste nach neonataler Hypoxie im sich entwickelnden Gehirn spielt (Fagel et al. 2006). Eine erhöhte Anzahl an Zellen in der SVZ konnte durch uns nicht festgestellt werden, sodass von einer lokalen Zellproliferation bzw. Zelldifferenzierung im ACC infolge postnataler Hypoxie ausgegangen werden kann. Kortikale multipotente Vorläuferzellen wurden bereits in Anwesenheit von Wachstumsfaktoren aus dem adulten zerebralen Kortex isoliert (Palmer et al. 1999) und auch im Tiermodell konnte bereits adulte Neurogenese mittels immunhistochemischer Doppelfärbung aus lokalen Vorläuferzellen im Neokortex nachgewiesen werden (Dayer et al. 2005).

Im Ischämiemodell konnten nach Verschluss (Occlusion) einer der mittleren Gehirnschlagadern (Arteria cerebri media=ACM) der adulten Ratte ipsilateral infarktnah signifikant vermehrte Gruppen BrdU-positiver Zellen im Kortex gefunden werden und es wurde geschlussfolgert, dass Vorläuferzellen auch im Kortex vorhanden seien und die Zellteilung lokal erfolge. Die BrdU-positiven Zellen exprimierten jedoch keine neuronalen Marker wie NeuN, sodass die Ischämie keine Neurogenese in dieser Region induzierte (Zhang et al. 2001). Die Untersuchungen erfolgten allerdings am adulten Tier, eine erhöhte Neurogenese wäre nach postnataler Ischämie wahrscheinlicher gewesen.

In einem postnatalen Tiermodell erfolgte an PD 7 eine fokale Ischämie durch Ligatur einer der Halsschlagadern (Arteria carotis communis=ACCo) und anschließend akuter Hypoxie mit $8 \% \mathrm{O}_{2}$ für zwei Stunden. Es zeigte sich eine signifikant erhöhte Zahl BrdU-positiver Zellen im ipsilateralen Kortex an PD 14. Zwar konnten Neurone nachgewiesen werden, aber die intrinsische Aktivität zur Selbstheilung war begrenzt, denn nur $1 \%$ der neu generierten Zellen im Kortex exprimierten den neuronalen Marker NeuN (Ikeda et al. 2005). Dieses Ergebnis deutet darauf hin, dass proliferierende Zellen auch im sich entwickelnden Gehirn nach hypoxisch/ischämischer Schädigung nur begrenzt zu Neuronen differenzieren. 
Eine akute Vervielfachung neuronaler Vorläuferzellen nach Ischämie/Hypoxie bedeutet also nicht, dass alle Zellen die Differenzierung und Entwicklung überleben (Kadam et al. 2008).

Obwohl Vorläuferzellen bereits aus vielen Teilen des Gehirns isoliert wurden (Palmer et al. 1999) und damit belegt werden konnte, dass auch außerhalb der Neurogenesezentren im DG und der SVZ Vorläuferzellen potentiell zu Neuronen differenzieren könnten, fehlen möglicherweise lokal benötigte Faktoren, um die Differenzierung zu gewährleisten (Madsen et al. 2005). Bezieht man dieses Wissen auf unsere Ergebnisse, müsste weiterführend untersucht werden, ob und wie viele der neu generierten Zellen im ACC in der Lage wären, sich zu Neuronen zu differenzieren bzw. dauerhaft zu überleben. Es lässt sich zumindest schlussfolgern, dass die vermehrte Zellproliferation an PD 13 als regenerativer Prozess nach neonataler Hypoxie angesehen werden kann.

In unseren Untersuchungen normalisierte sich die Zellzahl im ACC über die Zeit (PD 39) wieder. Unsere Ergebnisse stimmen mit einem weiteren Tiermodell überein, in dem eine Normalisierung der neuronalen Zelldichte nach Hypoxie beobachtet werden konnte. Weibliche Ratten wurden am 20. Tag der Schwangerschaft für eine Stunde $7 \% \mathrm{O}_{2}$ ausgesetzt. Die Gehirne der Jungtiere wurden pränatal (Kaiserschnittgeburt am 20. bzw. 21. Tag der Schwangerschaft) und postnatal (drei Tage bis 21 Tage nach Hypoxie) untersucht. Nach Färbung neuronaler Zellen mit Toluidinblau unter dem Lichtmikroskop resultierte in den ersten Tagen eine signifikante Reduktion der Dichte neuronaler Zellen durch Zelldegeneration im ACC, gefolgt von einer Normalisierung an PD 7 in den Hypoxie-behandelten Tieren. In den ersten 14 Tagen nach Hypoxie zeigte sich zudem mittels monoklonalem Antikörper OX-42 eine Aktivierung von Mikroglia (Li et al. 1998).

Diesen Ergebnissen wurde entnommen, dass Mikroglia eine wichtige Rolle bei der Protektion und Regeneration neuronaler Zellen infolge neonataler Hypoxie spielt. Einschränkend muss gesagt werden, dass in der Studie von Li et al. (1998) keine immunhistochemische Färbung erfolgte und zu Stammzellen und deren Proliferationsverhalten keine Vergleiche gezogen werden können. Des Weiteren erfolgte die Zählung an $1 \mu \mathrm{m}$ dicken Schnitten nur im infragranulären Teil des ACC.

Unserer Studie und den bisher genannten (Fagel et al. 2006, Li et al. 1998, Ikeda et al. 2005, Zhang et al. 2001) ist die transiente verstärkte Proliferation von Zellen im ACC nach Hypoxie/Ischämie oder alleiniger Hypoxie gemeinsam. Als ursächlich könnte ein physiologischer Autoregulationsmechanismus diskutiert werden. Dieser führt zu einer Umverteilung des zerebralen Blutflusses zugunsten weiter posterior gelegener Regionen, um das Gehirn vor der akuten Hypoxie zu schützen (Bilger und Nehlig 1993). Die reaktiv verstärkte Zellproliferation könnte einer Apoptose oder Nekrose in der betroffenen Hirnregion entgegen wirken, wie sie bereits in anderen Studien festgestellt werden konnte (Fagel et al. 2006, Li et al. 1998). Hier war der frühe Zellverlust nach Hypoxie immer zeitlich begrenzt und führte über die Zeit wie- 
der zu einer Normalisierung der Zellzahl im Kortex. Des Weiteren spielt wahrscheinlich auch die Schwere und Dauer der Hypoxie eine entscheidende Rolle bei der Regenerationsfähigkeit und beeinflusst das Ausmaß des Zelluntergangs. Die verstärkte Zellproliferation an PD 13 unserer Studie ist möglicherweise auch Folge einer von uns nicht untersuchten vorangegangenen Zelldegeneration infolge chronischer Hypoxie $\left(11 \% \mathrm{O}_{2}\right)$. Die Zellproliferation zeigte sich an PD 39 wieder normalisiert, was auf einen stattgefundenen Regenerationsprozess hindeuten könnte. Des Weiteren ist bekannt, dass im gesunden Tier die höchste Anzahl proliferierender Zellen in der peri- und postnatalen Phase vorliegen und in der weiteren Hirnentwicklung abnehmen. Das sich entwickelnde Gehirn kann damit exogen induzierte Schäden besser ausgleichen als das adulte (Zhang et al. 2001). Neben der Regenerationsfähigkeit spielt auch die neuronale Plastizität eine entscheidende Rolle und könnte erklären, warum ein perinatal gesetzter Schaden nicht zwangsläufig zur Ausbildung einer schizophrenen Symptomatik führt. Diese Mechanismen könnten auch die hohe Variabilität in der Ausprägung von Symptomen, Chronifizierung, Krankheitsbeginn und Verlauf der Erkrankung erklären.

Unsere Ergebnisse stimmen nicht mit denen aus Post-mortem-Studien schizophrener Patienten überein, in denen eine geringere Dichte und Größe von Neuronen im ACC nachgewiesen werden konnten (Benes et al. 1986, Benes und Bird 1987). Diese Befunde sind aber wahrscheinlich nicht (alleinige) Folge einer veränderten Zellproliferation durch perinatale Hypoxie. Es wird angenommen, dass Störungen z. B. der Migration und Differenzierung in der perinatalen Periode eine Ursache für Alterationen intrinsischer Kreisläufe schizophrener Patienten darstellen. Viele dieser neuronalen Alterationen zeigten sich spezifisch für den ACC und nicht den gesamten Kortex, wodurch die Bedeutung dieser Region für das Krankheitsbild nochmal verdeutlicht wird. Weitere typische Post-mortem-Befunde sind eine reduzierte Zahl an Interneuronen, vermehrte GABA-A-Rezeptorbindung und eine erhöhte Anzahl vertikaler Axone (Benes 1993). Die neonatale Hypoxie als Umweltfaktor in der Äthiopathogenese der Schizophrenie könnte zwar hierfür ursächlich sein, derartige Veränderungen waren jedoch nicht Ziel der vorliegenden Arbeit.

Obwohl die neonatale Hypoxie als Umweltfaktor in der Pathogenese der Schizophrenie bekannt ist, bleibt zu klären, ob es sich bei diesen Post-mortem-Befunden ausschließlich um Folgen einer Hypoxie handelt oder z. B. auch durch genetische Effekte bedingt sind, denn letztendlich handelt es sich um ein multifaktorielles Krankheitsbild (Benes 1993), bei dem die Gen-Umwelt-Interaktion eine bedeutende Rolle spielt (Schmitt et al. 2014). Weitere Einflüsse in Post-mortem-Studien sind z. B. individuelle Krankheitsverläufe, Medikamenteneffekte, Post-mortem-Gewebefixierung und das Post-mortem-Intervall bis zur Asservierung des Gewebes (Benes und Bird 1987). Durch diese Faktoren und die Unterschiede zwischen Mensch 
und Nagetier könnten sich die Diskrepanzen zu den Ergebnissen aus tierexperimentellen Studien erklären.

Der ACC nimmt neben dem Hippocampus-Amygdala-Komplex eine entscheidende Rolle bei der Bildung von Emotionen ein. Des Weiteren ist er an der Verarbeitung von Informationen beteiligt. Er hilft bei der Modulation kognitiver Fähigkeiten (Aufmerksamkeit, Kontrolle, Arbeitsgedächtnis, Erwartungshaltung und zielgerichtetes Verhalten) und trägt zur Verhaltensbildung bei. Die Bedeutung des ACC für die Schizophrenie ergibt sich durch Symptome wie Störungen der kognitiven Fähigkeiten und emotionalen Verarbeitung. Anatomisch gesehen ist der ACC eine Untereinheit des ventromedialen frontalen Kortex, der neben dem Gyrus cinguli auch den Sulcus cinguli beinhaltet (Gasquoine 2013). Die Identifizierung abnormaler Veränderungen im ACC spielt eine wichtige Rolle in der klinischen Manifestationen der Erkrankung. Durch die anatomische und funktionelle Heterogenität dieser Hirnregion ist dies allerdings eine schwer umsetzbare Aufgabe (Fornito et al. 2008). So wurden bisher vor allem Volumenveränderungen ausreichend wissenschaftlich belegt und mit der Ausbildung von Negativsymptomen in Verbindung gebracht (Fornito et al. 2008). Es konnte festgestellt werden, dass schizophrene Patienten eine reduzierte kortikale Dicke aufwiesen (Cannon TD et al. 2002, Fornito et al. 2008, Lui et al. 2009) und es wurde geschlussfolgert, dass der Verlust von Neuronen nach Hypoxie hierfür ursächlich ist (Fagel et al. 2006). Das gemessene Volumen des ACC in unserer Studie erfolgte jedoch nicht anhand von anatomischen Grenzen, sondern war eine willkürliche Abgrenzung (area of interest) zur Untersuchung der Zellproliferation in dieser Region. Die im Alter von PD 39 gemessene Volumenminderung (siehe Kapitel 3.2.2 Absolute Zellzahlen und Volumina) bedeutet, dass wir einen kleineren Gewebeausschnitt als bei den Kontrolltieren gewählt haben. Dies könnte eine Ursache dafür sein, dass wir zum Zeitpunkt PD 39 keine erhöhte Zellproliferation im ACC nach perinataler Hypoxie gefunden haben. Deshalb ist eine Aussage unserer Ergebnisse über regenerative Mechanismen zu diesem Zeitpunkt nicht möglich.

Zusammenfassend weisen unsere Ergebnisse darauf hin, dass der ACC eine Rolle bei der Zellproliferation nach neonataler Hypoxie spielt. Ein möglicher zusätzlicher Einfluss von perinataler Hypoxie auf die neuronale Plastizität und Regenerationsfähigkeit kann jedoch nicht ausgeschlossen werden.

\subsection{Subventrikuläre Zone}

In unseren Untersuchungen konnten keine signifikanten Unterschiede bezüglich der Zellproliferation nach postnataler Hypoxie an PD 13 und PD 39 im Vergleich zu den gleichaltrigen Kontrollen festgestellt werden. 
Unsere Ergebnisse stimmen mit einer vergleichbaren Studie überein, bei der Ratten postnatal (PD 7) einer 90-minütigen Hypoxie mit $8 \% \mathrm{O}_{2}$ ausgesetzt waren. Es fanden sich keine signifikanten Veränderungen der Zellproliferation in der SVZ mittels immunhistochemischer BrdU-Färbung gegenüber den Kontrollen an PD 21 (Ong et al. 2005). Allerdings wurde in dieser Studie nur eine geringe Fallzahl $(n=3)$ untersucht.

Im Gegensatz zu unseren Ergebnissen konnte in der SVZ an postnatalen Mäusen unter alleiniger Hypoxie ( $10 \% \mathrm{O}_{2}$ über 45 Minuten an PD 10) eine doppelt so hohe Zellproliferation mittels immunhistochemischer BrdU-Peroxidasefärbung im Vergleich zu den Kontrollen nachgewiesen werden. Es zeigten sich aber weder eine vermehrte Neurogenese noch eine Migration neu generierter Zellen (Plane et al. 2004).

Ursache für die Diskrepanz zu unseren Ergebnissen könnten spezifische pathophysiologische Differenzen zwischen Ratte und Maus in Reaktion auf die Wirkung von Hypoxie sein (Ong et al. 2005, Yang and Levison 2007). So zeigt sich nach neonataler Hypoxie bzw.

Ischämie trotz gleichen Schädigungsmusters die Anzahl an Zellen in der Ratte nicht so ausgeprägt wie in der Maus (Maus 4-fach erhöht, Ratte 2-fach erhöht). Zwischen unterschiedlichen Spezies sind also auch unterschiedliche Reaktionen zu erwarten (Ong et al. 2005, Plane et al. 2004).

Hypoxische Episoden können innerhalb gewisser Grenzen auch als vorteilhaft angesehen werden, z. B. im Sinne einer Präkonditionierung (kurze Reize stoßen körpereigene Prozesse an, die dann vor den Auswirkungen eines späteren Schadens schützen). Ratten, die postnatal akut für fünf Minuten $100 \% \mathrm{~N}_{2}$ ausgesetzt wurden, zeigten über einen Zeitraum von drei Wochen eine erhöhte Zelldichte in der SVZ. Die Zellen waren in der Lage zu migrieren und exprimierten neuronale Marker (NeuN, Neuro D). Anzumerken ist, dass die akute Hypoxie von fünf Minuten nicht in einen nachweisbaren Zelltod mündete und es wurde geschlussfolgert, dass Hypoxie zu einer Generierung funktioneller Neurone führt (Pourié et al. 2006). Die Diskrepanz zu unseren Ergebnissen ergibt sich möglicherweise aus der kurzen schweren Anoxie im Vergleich zu der von uns eingesetzten chronischen und milderen Hypoxie (11\% $\left.\mathrm{O}_{2}\right)$.

In den bereits aufgeführten Studien von Ong et al. (2005) und Plane et al. (2004) wurden im Gegensatz zu unserer Studie auch Hypoxie (gleiche Bedingungen wie beschrieben) mit Ischämie (einseitige ACCo-Ligatur) kombiniert untersucht. Bei Ong et al. (2005) ergab sich eine um 80 \% erhöhte Zahl BrdU-positiver Zellen in der ipsilateralen SVZ sowie eine erhöhte Zahl neu generierter Neurone. Allerdings waren nach vier Wochen keine doppelgefärbten BrdU- und NeuN-positiven Zellen im Infarktbereich mehr nachweisbar. Bei Plane et al. (2004) zeigten sich die BrdU-positiven Zellen 4-fach erhöht und eine Neuroblastenmigration 
zum Infartkareal im Striatum sowie wenige doppelgefärbte Neurone konnten nachgewiesen werden.

Eine 4-fach erhöhte Zahl BrdU-positiver Zellen in der ipsi- und kontralateralen SVZ konnte auch bei Ratten an PD 7 infolge kombinierter Hypoxie/lschämie nachgewiesen werden (einseitige ACCo-Ligatur gefolgt von zwei Stunden $8 \% \mathrm{O}_{2}$ bei $33^{\circ} \mathrm{C}$ Umgebungstemperatur). An PD 21 normalisierte sich die Zellzahl in der SVZ, es konnte aber weiterhin eine 15-fach erhöhte Zellzahl entlang der oberen Wand des Seitenventrikels gefunden werden. Es wurde geschlussfolgert, dass Vorläuferzellen migirieren (Iwai et al. 2006). Eine offene Frage ist, ob die vermehrten Zellen, die in der SVZ der kontralateralen Seite nachgewiesen werden konnten, auf die ischämische Seite migrieren und an der Regeneration teilnehmen könnten (Ikeda 2008).

Der verstärkte Zelluntergang durch Apoptose, z. B. infolge einer Infarzierung könnte zu einer Stimulation der Zellproliferation und Neurogenese führen. Somit stellt die Ischämie wahrscheinlich einen stärkeren Induktor der Zellproliferation dar als die Induktion durch sauerstoffreduzierte Atemluft (Hypoxie) und erklärt die Diskrepanz zu unseren Ergebnissen. So konnte bereits nachgewiesen werden, dass das Fehlen von Apoptose-induzierendem Faktor zu einem verminderten Zelltod wie auch zu einer verminderten Zellproliferation in der SVZ führte (Osato et al. 2010).

Auch nach isolierter akuter Ischämie mittels einseitiger Occlusion der ACM in der adulten Ratte konnten nach sieben Tagen durch immunhistochemische Färbung erhöhte Zahlen an BrdU-positiven Zellen in der ipsilateralen SVZ und dem Bulbus olfactorius nachgewiesen werden (Zhang et al. 2001). Jedoch zeigte sich nur ein transienter Effekt, denn nach vier Wochen war die erhöhte Zellproliferation wieder um $90 \%$ reduziert (Zhang et al. 2001). Eine geringere oder fehlende Apoptose im Rahmen einer isolierten chronischen Hypoxie (11\% $\mathrm{O}_{2}$ ), wie sie von uns angewandt wurde, könnte somit erklären, warum sich keine Effekte auf die Zellproliferation in der SVZ zeigten. Akute Ischämie resultiert in einem rapiden Abfall der Sauerstoffverfügbarkeit und führt zu einem Neuronenuntergang (Apoptose) in verschiedenen Hirnregionen sowie einer Verlangsamung der Migration. Chronische Schädigungen, wie die von uns durchgeführte Hypoxie, führen eher zu einem Überleben von Neuronen bzw. sind diese deutlich weniger von Apoptose betroffen (Rees et al. 1999, Rees und Inder 2005). Im Gegensatz zu unserer Studie erfolgten die Untersuchungen am adulten (Zhang et al. 2001) und nicht postnatalen Rattenhirn. Bekanntermaßen befinden sich während der Embryonalperiode im Gegensatz zum adulten Gehirn die meisten der proliferierenden Vorläuferzellen in der SVZ, sodass das sich entwickelnde Gehirn exogen erzeugte Schäden besser und schneller kompensieren kann. In unserer Studie hätten Untersuchungen zu einem früheren 
Zeitpunkt als an PD 13, z. B. direkt nach Hypoxie möglicherweise andere Ergebnisse gezeigt, sodass wir nur Aussagen zu dem von uns untersuchten Zeitpunkt machen können.

Neben den eben genannten gibt es weitere Studien, die eine Stimulation der Zellproliferation in der SVZ infolge Hypoxie und/oder Ischämie nachweisen konnten (z. B. Kadam et al. 2008, Zhu et al. 2005, Felling et al. 2006).

Der Mechanismus, durch den die Proliferation und Differenzierung von Stammzellen in der SVZ getriggert wird, ist unverstanden. Wachstumsfaktoren wurden sowohl im adulten als auch neonatalen Gehirn mit der Regulation der Zellproliferation in der SVZ in Verbindung gebracht. Nach intraventrikulärer Infusion von Fibroblasten-Wachstumsfaktor konnte bereits eine erhöhte Neurogenese beobachtet werden (Sun et al. 2009). Daraus kann geschlussfolgert werden, dass endogene Wachstumsfaktoren eine mögliche Rolle bei der Regulierung der Zellproliferation nach neonataler Ischämie bzw. Hypoxie spielen (Ong et al. 2005).

Im Gegensatz dazu berichtete ein Tiermodell, dass durch einseitige Occlusion der Halsschlagader (ACCO) mit anschließender Hypoxie (8 \% $\mathrm{O}_{2}$ über 90 Minuten) an PD 7 eine anhaltende Zerstörung von Oligodendrozyten der weißen Substanz und Stammzellen in der ipsilateralen SVZ der Ratte nachweisbar war (Levison et al. 2001). Neben einer unbehandelten wurde auch eine allein mit Hypoxie ( $8 \% \mathrm{O}_{2}$ über 90 Minuten) behandelte Kontrollgruppe untersucht. Der Untersuchungszeitraum lag zwischen vier Stunden bis drei Wochen nach dem Versuchsereignis. Initial kam es in der Ischämie-/Hypoxiegruppe vor allem zu Nekrosen, im weiteren Verlauf aber auch zur Apoptose. Nach drei Wochen war die SVZ kleiner und wies weniger als $25 \%$ der normalen neuronalen Zellzahl im Vergleich zu den Kontrolltieren auf. Des Weiteren war die periventrikuläre weiße Substanz durch den Verlust von Oligodendrozyten nur wenig myelinisiert (Levison et al. 2001), was ein Hinweis für eine sich entwickelnde periventrikuläre Leukomalazie ist.

Der Studie konnte nicht entnommen werden, ob sich Unterschiede zwischen der allein mit Hypoxie behandelten Gruppe im Vergleich zu den gesunden Kontrollen zeigten. Wahrscheinlich weil kongruent zu unseren Ergebnissen die Effekte in der SVZ nicht signifikant waren. Des Weiteren erfolgte neben der immunhistochemischen BrdU-Färbung auch ein in situ endlabeling (ISEL) für die Markierung von DNA-Fragmenten in apoptotischen oder nekrotischen Zellen in Geweben. Es wurde geschlussfolgert, dass neuronale Stammzellen anfällig gegenüber Ischämie/Hypoxie sind und eine Dysregulation kognitive und motorische Defizite verursachen könnte (Levison et al. 2001). So konnte auch bereits an wenigen Kindern Postmortem nach schwerer perinataler Hypoxie/Ischämie eine Zerstörung der SVZ gezeigt werden (Takizawa et al. 2006). In Bezug auf die Schizophrenie könnte zusätzlich zur Hypoxie bei Schwangerschafts- und Geburtskomplikationen auch eine ischämische Komponente ur- 
sächlich sein, die wir in unserer Studie nicht untersucht haben. So korreliert Hypoxie signifikant mit einer Vergrößerung des zerebralen Ventrikelsystems, wie es auch bei der Schizophrenie nachgewiesen werden konnte. Die Ursache hierfür ist noch nicht abschließend geklärt (Cannon TD et al. 2002). In einer longitudinalen Untersuchung ersterkrankter schizophrener Patienten waren nach 10 Jahren die Seitenventrikel gegenüber dem ersten Untersuchungszeitpunkt vergrößert und korrelierten mit dem Alter der Ersterkrankung sowie der Zeitdauer stationärer Behandlungen (DeLisi et al. 2004). Der Befund vergrößerter Liquorräume schon bei Ersterkrankung ist vereinbar mit der Hypothese einer neuronalen Entwicklungsstörung, bei der möglicherweise schon während der Gehirnentwicklung Einflüsse auf das Volumen bestimmter Hirnregionen entstehen könnten. Ein möglicher Einflussfaktor ist die Proliferation von Zellen sowie deren Differenzierung in Neurone und Gliazellen. Deren Schädigung, z. B. infolge Ischämie/Hypoxie könnte die Minderung der Zellzahl in der SVZ erklären, was wiederum die Befunde der Volumenreduktion stützt (Schmitt et al. 2009a).

Weitere Faktoren, wie die genetische Prädisposition oder/und Schwere und Dauer der Hypoxie, spielen möglicherweise eine wichtige Rolle und erklären, warum über $90 \%$ aller fetalen Hypoxien nicht zum klinischen Erkrankungsbild einer Schizophrenie führen (Cannon TD et al. 2002). Dies bestätigen Zwillingsstudien, in denen gesunde Geschwister von an Schizophrenie Erkrankten gleiche anatomische Veränderungen nach fetaler Hypoxie zeigten, ohne dass es zu einer Manifestation der Erkrankung kam (Cannon TD et al. 2002).

\subsection{Gyrus dentatus}

In unseren Untersuchungen konnten keine signifikanten Effekte bezüglich der Zellproliferation infolge postnataler Hypoxie an PD 13 und PD 39 im Vergleich zu den gleichaltrigen Kontrollen festgestellt werden.

Unsere Ergebnisse stimmen nicht oder nur teilweise mit anderen Studien perinataler Hypoxie überein. Es konnte eine erhöhte Zellproliferation an PD 21 in der CA1-Region nachgewiesen werden, nachdem Ratten postnatal innerhalb der ersten 24 Stunden für fünf Minuten $100 \%$ $\mathrm{N}_{2}$ ausgesetzt waren. Mit Hilfe der immunhistochemischen Doppelfärbung (BrdU und NeuN bzw. Neuro D) konnte außerdem eine Differenzierung dieser Zellen zu Neuronen nachgewiesen werden, die in der Lage waren, zu migrieren (Pourié et al. 2006). Eine vermehrte Neurogenese in der CA1-Region bei gleicher Methodik konnte auch in einer weiteren Tierstudie nachgewiesen werden (Blaise et al. 2009).

Einschränkend muss gesagt werden, dass bei diesen Experimenten die Hypoxie-Induktion zu einem früheren Zeitpunkt (innerhalb der ersten 24 Stunden) als in unserer Studie erfolgte und die signifikant erhöhte Zahl BrdU-positiver Zellen in der CA1-Region nur an PD 21 nachweisbar war. Zellzählungen nach PD 21 erfolgten nicht, sodass keine Aussagen der 
Zellentwicklung über die Zeit möglich waren. Dagegen untersuchten wir die Tiere zu anderen Zeitpunkten und bis in die frühe Aldoleszenz (PD 13 bis PD 39). Des Weiteren könnte die von uns angewandte milde intermittierende chronische Hypoxie erklären, warum in unserer Studie keine Alterationen der Stammzellzahl nachweisbar waren.

Im Gegensatz dazu steht eine weitere Studie, bei der Ratten innerhalb der ersten 24 Stunden einer vergleichsweise längeren Hypoxie ausgesetzt waren (100\% $\mathrm{N}_{2}$ für 20 Minuten). Die immunhistochemische Doppelfärbung erfolgte mit BrdU und Neuro D bzw. Neuronenspezifischer Enolase (NSE). In der CA1-Region des Hippocampus zeigte sich ein massiver Verlust NSE-markierter neuronaler Zellen, die nach einer Woche ihren Peak mit $27 \%$ der Ausgangszellzahl erreichte. Zudem zeigte sich in der Pyramidenzellschicht der CA1-Region eine verminderte Zelldichte und typische Kernmorphologie sowie eine reduzierte NSE und vermehrte Expression von Apoptose-regulierenden Proteinen wie Bcl-2, Bax und Caspase-3. An PD 21 zeigte sich bezüglich der Zelldichte kein signifikanter Unterschied mehr zu den Kontrollen. Als Ursache wurde eine vermehrte Zellproliferation in der SVZ diskutiert, die sich um 225 \% erhöht zeigte (Daval et al. 2004). Die Zellen exprimierten neuronale Marker (Neuro D, NSE) und migrierten entlang der posterioren periventrikulären Zone zum Hippocampus (Daval et al. 2004, Pourié et al. 2006, Blaise et al. 2009). Einschränkend muss gesagt werden, dass die Zellzählung nur in der CA1-Region des Hippocampus erfolgte (Pourié et al. 2006, Blaise et al. 2009, Daval et al. 2004), wohingegen in unserer Studie die Zellzählung nur im DG des Hippocampus erfolgte. Möglicherweise erklären sich auch hierdurch Differenzen zu unseren Ergebnissen. Zelldifferenzierung, Migrationsverhalten und Zelluntergang wurden in unserer Studie nicht untersucht, sodass hierzu keine vergleichenden Aussagen gemacht werden können.

Darüber hinaus könnte eine fehlende ischämische Komponente in unseren Versuchen zu dem Ergebnis einer unveränderten neuronalen Zellproliferation geführt haben. Zellalterationen im Hippocampus nach kombinierter Ischämie mit Hypoxie konnten durch die immunhistochemische Doppelfärbung (BrdU und NeuN für Neurone) nachgewiesen werden. Mäuse erhielten an PD 7 eine einseitige Ligatur der ACCo mit folgender globaler Hypoxie $\left(8 \% \mathrm{O}_{2}\right)$ über 75 Minuten. Im Anschluss wurde die ischämie- und hypoxiebehandelte Hirnhälfte mit der kontralateralen Hirnhälfte, die nur Hypoxie ausgesetzt war, verglichen. Im Gegensatz zu alleiniger Hypoxie konnte in der Zielregion ein Gewebeschaden (Nekrose) durch die Ischämie festgestellt werden. Des Weiteren zeigte sich auf der ischämie- und hypoxiebehandelten Hirnseite eine signifikant erhöhte Zellproliferation sowie vermehrt Neurone, Glia- und Endothelzellen im DG (jedoch nicht in der CA1- oder CA3-Region). Im Vergleich konnten auf der allein mit Hypoxie behandelten Hirnseite keine signifikanten Effekte auf die Zellproliferation nachgewiesen werden. Es zeigte sich aber eine signifikant erhöhte Zahl an Oli- 
godendrozyten an PD 10 (Bartley et al. 2005). Die Ergebnisse bezüglich der Zellproliferation in der allein mit Hypoxie behandelten Hirnseite sind kongruent zu unseren Ergebnissen im DG. Jedoch erfolgte im Gegensatz zu unserer Studie kein Vergleich hypoxiebehandelter Tiere zu unbehandelten Kontrollen, wodurch sich möglicherweise signifikante Unterschiede offenbart hätten. Des Weiteren wurde durch uns keine Zelldifferenzierung mittels immunhistochemischer Doppelfärbung untersucht.

Es kann also angenommen werden, dass stärkere Effekte bei kombinierter Hypoxie/Ischämie zu erwarten sind als unter alleiniger Hypoxie. Aufgrund der nachgewiesenen erhöhten Oligodendrozytenzahl auf der allein durch Hypoxie behandelten Hirnseite wurde eine verminderte Synthese von Oligodenrozyten auf der ischämie- und hypoxiebehandelten Hirnseite angenommen (Bartley et al. 2005), was in der weiteren Entwicklung die Schädigung der weiBen Substanz und Oligodendrozytenzahl erklären könnte, wie sie bei der Schizophrenie bereits nachgewiesen werden konnte (Schmitt et al. 2009b).

Eine erhöhte Zellproliferation konnte mit der BrdU-Peroxidasefärbung im DG der Maus auch nach isolierter fokaler Ischämie (einseitige Ligatur der ACCo für 15 Minuten) nachgewiesen werden (Takagi et al. 1999). Darüber hinaus ist eine erhöhte Zellproliferation und Neurogenese durch immunhistochemische Doppelfärbung (BrdU und NeuN bzw. Doublecortin) im DG auch im adulten nicht-menschlichen Primaten nach einseitiger Occlusion der ACM belegt wurden. Hier zeigte sich ein längeres Überleben von Neuronen, denn 28 Tage nach Ischämie zeigte sich immer noch eine 4,7-fach erhöhte Zahl neu generierter Neurone, sowohl auf der Ischämieseite als auch im kontralateralen unbehandelten DG (Koketsu et al. 2006). Dieser Befund war bisher nur im Ischämiemodell des Nagetiers belegt worden (Iwai et al. 2006, siehe Kapitel 4.2 subventrikuläre Zone). Wachstumsfaktoren werden auch im DG als Ursache für die Zellproliferation angesehen (Koketsu et al. 2006). Während der hypoxischen Episode werden diese von Neuronen des Hippocampus exprimiert und könnten in die Regulation von Apoptose und Regeneration involviert sein (Kiessling et al. 1993). Außerdem spielen Veränderungen von NMDA-Rezeptoren bei der neuronalen Differenzierung im Hippocampus eine Rolle. Es konnte nachgewiesen werden, dass die NMDA-Rezeptorbindung nach Ischämie deutlich reduziert ist und mit massiver Zelldegeneration in der CA1-Region einhergeht (Westerberg et al. 1989). In anderen Tiermodellen konnte die direkte Stimulation der Neurogenese nach NMDA-Rezeptorblockung mittels Antagonisten (Ketamin) belegt werden (Keilhoff et al. 2004). Ein weiterer Trigger der neuronalen Zellproliferation und Neurogenese ist die Apoptose. Apoptose aktivierende Einflüsse, wie z. B. Hypoxie/lschämie, führen zu einer verstärkten Membranpermeabilität (reguliert durch pro- und antiapoptotische Proteine). Es kommt zu einer Freisetzung von Cytochrom $C$ und anderer proapoptotischer Faktoren in das Zytoplasma (Daval et al. 2004, Scheepens et al. 2003). Dies führt zu einer transienten Akti- 
vierung des Caspase-3-Enzyms, welches die Apoptose induziert. Gleichzeitig kommt es zu einer verstärkten Freisetzung antiapoptotischer Proteine (Yuan and Yankner 2000, Morales et al. 2008). In verschiedenen Studien konnte bereits eine vermehrte kompensatorische Neurogenese im Hippocampus nach vorangegangener Zelldegeneration nachgewiesen werden (z. B. Liu et al. 1998, Daval et al. 2004, Bartley et al. 2005, Scheepens et al. 2003). Weitere Mechanismen durch den die Zellproliferation in den Neurogenesezentren nach perinataler Hypoxie ausgelöst wird, sollte zukünftig noch Bestandteil der Forschung sein.

Im Gegensatz zu unseren und anderen Tiermodellen konnte eine verminderte hippocampale Zellproliferation in Post-mortem-Hirnschnitten schizophrener Patienten nachgewiesen werden (Reif et al. 2006). Da Alter, pH-Wert, Gewicht, Post-mortem-Intervall, Beginn und Dauer der Erkrankung sowie Medikamenteneinnahme keine signifikanten Effekte zeigten, könnte geschlussfolgert werden, dass Umweltfaktoren wie die Hypoxie einen Auslöser darstellen. Es wurde angenommen, dass Veränderungen der neuronalen Zellproliferation einen wichtigen Bestandteil in der Pathophysiologie der Erkrankung darstellen. Da die Schizophrenie mit kognitiven Defiziten einhergeht und der Hippocampus eine wichtige Gedächtnis- und Erinnerungsfunktion einnimmt, könnte eine gestörte Zellproliferation und Neurogenese die Ursache sein (Reif et al. 2006) und ist möglicherweise mit Positivsymptomen assoziiert (Bogerts 1997).

Einschränkend muss gesagt werden, dass der Nachweis von proliferierenden Zellen in der humanen Post-mortem-Studie von Reif et al. (2006) nicht wie bei uns mit Hilfe der immunhistochemischen BrdU-Peroxidasefärbung erfolgte, sondern mit dem Protein Ki-67, das sich im Gegensatz zu BrdU in allen Phasen der Zellteilung in die Zellen einlagern kann. Hierdurch entstehen unterschiedliche Ergebnisse in der Anzahl der Zellen, denn durch Ki-67 werden folglich mehr Zellen angefärbt als durch BrdU, welches sich nur in der S-Phase einlagert. Des Weiteren ist keine immunhistochemische Doppelfärbung von Ki-67 mit neuronalen (NeuN) oder glialen (saures Gliafaserprotein=GFAP) Markern möglich, sodass eine Zellquantifizierung der angefärbten Zellen nicht möglich ist. Eine zusätzliche Mitfärbung glialer Stammzellen, sofern sie sich in der Teilungsphase befanden, ist somit möglich, kann aber in unserer Studie auch nicht sicher ausgeschlossen werden, da auch durch uns keine weiterführende immunhistochemische Doppelfärbung zur Zellquantifizierung erfolgte.

\subsection{Striatum}

In unseren Untersuchungen konnten keine signifikanten Effekte bezüglich der Zellproliferation infolge postnataler Hypoxie an PD 13 und PD 39 im Vergleich zu den gleichaltrigen Kontrollen festgestellt werden. Des Weiteren zeigten die hypoxiebehandelten Tiere ein um $16 \%$ 
vermindertes Volumen im CPU an PD 13 im Vergleich zu den Kontrollen. An PD 39 zeigten sich allerdings keine signifikanten Unterschiede mehr.

Die Berechnung und statistische Auswertung des Volumens war nur im CPU möglich, da hier die komplette Struktur anhand anatomisch definierter Grenzen abgegrenzt wurde. Bei den übrigen Regionen wurde die Grenze anhand von Abschätzungen aus dem Gehirnatlas (Paxinos und Watson 1998) gezogen. Deshalb waren im ACC, in der SVZ und im DG keine Volumenberechnungen möglich. Die Ergebnisse zeigen auf der einen Seite, dass ein vorübergehender Einfluss chronischer Hypoxie auf das Volumen im CPU angenommen werden kann, auf der anderen Seite zeigt sich eine Normalisierung des Volumens mit zunehmendem Alter. Die vorliegende Studie ist die erste, die eine Volumenminderung im CPU nach neonataler Hypoxie mit der aufgezeigten Methodik nachweisen konnte.

Umstritten ist, ob neonatale Hypoxie/Ischämie eine transiente oder anhaltende Neurogenese im CPU initiiert und ob neu generierte Neurone aus lokalen Vorläuferzellen im CPU entstehen oder aus der angrenzenden SVZ migrieren (Yang und Levison 2007). Im Tiermodell konnte bereits mehrfach bewiesen werden, dass Vorläuferzellen infolge neonataler Hypoxie/Ischämie aus der SVZ in das CPU migrieren (z. B. Plane et al. 2004, Ong et al. 2005, Felling et al. 2006).

Auch in dieser Region könnte eine zusätzliche ischämische Komponente im Vergleich zur alleinigen Hypoxie eine Rolle spielen. Sechs Tage alte Jungtiere wurden einer einseitigen Ligatur der ACCo zugeführt und anschließend einer 80-minütigen Hypoxie mit $8 \% \mathrm{O}_{2}$ ausgesetzt. Mit Hilfe der immunhistochemischen Doppelfärbung (BrdU und NeuN) zeigten sich neu generierte Neurone im CPU. Ursache war eine über Monate anhaltende Migration dieser Zellen aus der SVZ in das geschädigte Gewebe des CPU (Yang und Levison 2007). Diese Ergebnisse sind auch zu Untersuchungen am adulten Rattenhirn nach isolierter Ischämie (einseitige Occlusion der ACM) kongruent (Parent et al. 2002, Arvidsson et al. 2002).

In unserer Studie erfolgte weder die Untersuchung der Zelldifferenzierung in Neurone noch die Untersuchung des Migrationsverhaltens von Zellen aus der SVZ. Eine vorangehende Erhöhung der Anzahl proliferierender Zellen konnte durch uns weder in der SVZ noch im CPU nachgewiesen werden. Möglicherweise liegt die Ursache in der unterschiedlichen Methodik, denn eine Gewebeschädigung durch Ischämie wurde durch uns nicht induziert.

Im Vergleich zum adulten Tier scheint die Regeneration im sich entwickelnden Gehirn aber robuster zu sein, denn bei den Jungtieren fanden sich fünf Wochen nach Ischämie noch 400 BrdU- und NeuN-positive Zellen/mm³ (Yang und Levison 2007), bei den adulten Tieren nur 136 BrdU- und NeuN-positive Zellen/mm $\mathrm{mm}^{3}$ (Arvidsson et al. 2002) bei vergleichbarer vorangegangener intraperitonealer BrdU-Gabe (sechs Mal über drei Tage). Damit wird die An- 
nahme bestätigt, dass das sich entwickelnde Gehirn eine höhere Kapazität besitzt, sich von Hirnschädigungen zu erholen als das reife (Yang und Levison 2007). Bezogen auf unsere Ergebnisse konnten möglicherweise aufgrund der perinatal maximal aktivierten Zellproliferation keine relevanten Veränderungen in der Zellzahl infolge perinataler Hypoxie im Vergleich zu den unbehandelten Kontrollen an PD 13 festgestellt werden. Das sich entwickelnde Gehirn zeigte sich tolerant gegenüber exogener Schädigung wie Hypoxie. Möglicherweise hätten sich signifikante Unterschiede bei Untersuchungen am adulten Tier gezeigt, dies war jedoch nicht Ziel der vorliegenden Arbeit.

Yang und Levison (2007) konnten außerdem nachweisen, dass Zellen in geschädigte Areale des Neokortex migrierten, was wiederrum die Annahme stützt, dass die Zellproliferation im ACC, wie wir sie nachweisen konnten, ihren Ursprung in der SVZ hat und Zellen nicht lokal proliferieren. Allerdings konnten die Autoren auch nicht sicher ausschließen, dass ein Teil neu generierte Neurone aus lokalen kortikalen Vorläuferzellen hervorgehen (Yang und Levison 2007).

Die bereits aufgeführten Tierstudien von Ong et al. (2005) und Plane et al. (2004) (siehe Kapitel 4.2 Subventrikuläre Zone) beispielsweise konnten eine Proliferation von BrdU- positiven Vorläuferzellen im CPU (sowie der SVZ) nach Ischämie mit kombinierter Hypoxie nachweisen. Diese exprimierten nach immunhistochemischer Doppelfärbung zwar neuronale Marker wie NeuN, waren aber nach Tagen bzw. wenigen Wochen nicht mehr nachweisbar. Es wurde geschlussfolgert, dass das kurze Überleben von Neuronen im CPU auf einen Mangel an trophischen Faktoren beruhte und die erhöhte Zellzahl zu einer verbesserten neuronalen Regeneration nach Hirnschädigung führte (Plane et al. 2004).

Da wir, wie bereits erwähnt, keine Zellproliferation in der SVZ nachweisen konnten, scheint es aufgrund der aufgeführten Studien (z. B. Plane et al. 2004, Ong et al. 2005, Yang und Levison 2007) möglich, dass auch keine Zellproliferation im CPU nachgewiesen werden konnte. Sollte auch nur ein kleiner Teil an Vorläuferzellen im CPU in der Lage sein, infolge perinataler Hypoxie zu proliferieren, würden sich wahrscheinlich keine signifikanten Unterschiede zu den Kontrollen ergeben und könnten somit statistisch auch nicht erfasst werden.

In einer Post-mortem-Studie konnte adulte Neurogenese erstmals auch im CPU des Menschen nachgewiesen werden (Ernst et al. 2014). Die Differenzierung von Vorläuferzellen (Neuroblasten) scheint dabei vornehmlich auf Interneurone beschränkt zu sein. Hinweise für Migrationsströme aus der angrenzenden SVZ zeigten sich nicht, sodass eine ortsständige Neurogenese angenommen werden konnte (Ernst et al. 2014). Diese Erkenntnis könnte auch auf das Tiermodell übertragen werden. Hier ist eine lokale Zellproliferation und -differenzierung im postnatalen CPU vor allem reaktiv nach einer vorangegangenen Schädigung wie Hypoxie/Ischämie denkbar, konnte durch uns aber nicht belegt werden. Der Nach- 
weis humaner adulter Neurogenese im CPU gelang unter anderem durch den Nachweis von Neuroblasten mittels Doublecortinfärbung sowie mit radioaktiv markiertem lododeoxyuridine, einem Thymidinanalogon wie BrdU, das sich teilende Zellen im CPU nachweisen konnte, die im Anschluss auch neuronale Marker (vor allem Calretinin) exprimierten (Ernst et al. 2014). Für die Beurteilung der Zelldifferenzierung wäre in unserer Studie eine immunhistochemische Doppelfärbung notwendig gewesen. Die Aussagekraft im Gesamtkontext der Schizophrenie wäre durch den Nachweis von Veränderungen in der Neurogenese deutlich höher gewesen als die alleinige Beurteilung der Zellproliferation. Jedoch sollten auch die Unterschiede zwischen den Spezies Mensch und Nagetier beachtet werden, denn im Nagetier exprimieren deutlich weniger als $1 \%$ der striatalen Neurone Calretinin im Vergleich zum Menschen mit $10 \%$ (Ernst et al. 2014). Im adulten Kaninchen konnten bereits unter physiologischen Bedingungen Calretinin-positive Interneurone im CPU (Nucleus caudatus) nachgewiesen werden, die aus lokalen BrdU-positiven Zellen hervorgingen. Allerdings exprimierten nur 0,7 \% der überlebenden BrdU-positiven Zellen nach zwei Monaten neuronale Marker, was darauf hindeutet, dass der größte Teil neu generierter Zellen zugrunde geht (Luzzati et al. 2006).

Das CPU besteht aus dem Nucleus caudatus, dem Putamen und dem Nucleus accumbens und gehört zu den Basalganglien. Veränderungen dieser Strukturen wurden mit Erkrankungen wie der Schizophrenie assoziiert. Pathologische striatale Veränderungen zeigten demnach charakteristische Symptome wie kognitive Defizite oder Psychosen (Heimer et al. 1991).

Viele MR-volumetrische Studien, die das CPU chronisch erkrankter schizophrener Patienten untersuchten, konnten ein erhöhtes Volumen nachweisen (z. B. Breier et al. 1992, Buchanan et al. 1993, Hokama et al. 1995) und es wurde angenommen, dass dies Folge einer medikamentösen Behandlung mit Antipsychotika war. So wurde gezeigt, dass sich das CPU unter Therapie mit typischen Antipsychotika vergrößerte, während es sich nach Behandlung mit Atypika (Clozapin) wieder verkleinerte (Chakos et al. 1995). Im Vergleich zu gesunden Kontrollen zeigten volumetrische MR-Messungen erstdiagnostizierter schizophrener Patienten entweder keine oder signifikant erniedrigte Volumina in den Basalganglien. Unsere Ergebnisse reduzierten striatalen Volumens an PD 13 sind damit kongruent mit zahlreichen anderen Studien, die Volumendefizite mittels hochauflösender MRT in den Basalganglien schizophrener Ersterkrankter nachweisen konnten (z. B. Corson et al. 1999, Watson et al. 2012, Chua et al. 2006). Einflussfaktoren wie Dauer der Erkrankung, Chronifizierung, Medikation und Outcome sind bei der Untersuchung ersterkrankter Patienten reduziert bzw. können weitestgehend ausgeschlossen werden (Kaspárek et al. 2006) und sind deshalb vergleichbar mit unseren Ergebnissen. MR-morphologisch konnte ein Volumendefizit von $5 \%$ im Nucleus 
caudatus Ersterkrankter im Vergleich zu gesunden Kontrollen nachgewiesen werden (Corson et al. 1999). Eine Volumenreduktion im Nucleus caudatus war auch bei Patienten mit vorherrschender Negativsymptomatik nachweisbar (Young et al. 1991). Mit der Volume of interest-Methode konnten magnetresonanztomografisch Volumendefizite in Strukturen wie dem Hippocampus, Thalamus, CPU und Cerebellum bestätigt werden (Watson et al. 2012). Außerdem konnten mit dieser Methode ein 11 bis $13 \%$ reduziertes Volumen im Nucleus caudatus bihemispheriell Ersterkrankter mit Psychosen im Vergleich zu gesunden Kontrollen sowie um $26 \%$ vergrößerte Seitenventrikel nachgewiesen werden. Volumendefizite der grauen und weißen Substanz zeigten sich periventrikulär und umfassten neben dem Nucleus caudatus, den ACC, den Gyrus temporalis superior, den medialen frontalen Cortex sowie das Corpus callosum und die Capsula interna (Chua et al. 2006). Die neuronale Entwicklungshypothese besagt, dass die abnormale Hirnentwicklung lange vor Ausbruch der Erkrankung, möglicherweise während der Schwangerschaft, ihren Ursprung hat und zu pathologischen Veränderungen von Neuronen und neuronaler Kreisläufe führt (Weinberger 1987). Im Gegensatz zu anderen Erkrankungen kommt es aber nicht sofort zu Symptomen, sondern erst mit einer zeitlichen Latenz von einer bis drei Dekaden zu einer Krankheitsmanifestation. Faktoren, die den Ausbruch der Erkrankung triggern, sind noch weitgehend unbekannt. Es wird angenommen, dass neurobiologische Entwicklungsprozesse, wie Neuronenund Gliazellproliferation und deren Migration, axonale und dendritische Proliferation, programmierter Zelltod sowie Interaktionen mit Umweltfaktoren wie Trauma, psychischer Stress und Substanzmissbrauch, eine Rolle spielen (Liebermann et al. 2001). Dies könnte erklären, warum typische hirnstrukturelle Veränderungen schon bei Ersterkrankten unbehandelten Patienten nachweisbar sind.

In Studien über eineiige Zwillinge konnten signifikante Zusammenhänge zwischen Geburtskomplikationen wie Hypoxie und der Größe verschiedener Hirnstrukturen nachgewiesen werden, wobei pathologische hirnstrukturelle Veränderungen bei dem erkrankten Zwilling stärker ausgeprägt waren (McNeil et al. 2000, vanErp et al. 2002).

Auch die Volumenreduktion von $16 \%$ im CPU der hypoxiebehandelten Tiere an PD 13 unserer Studie ist mit der Hypothese der frühen gestörten Hirnentwicklung und der Wirkung von perinataler Hypoxie auf das Volumen des CPU vereinbar.

Unsere Ergebnisse sind außerdem kongruent zu Studien, die Volumenminderungen in anderen Hirnregionen im Tiermodell nach perinataler Hypoxie feststellen konnten (z. B. Levison et al. 2001, Fagel et al. 2006). Die Normalisierung des Volumens im CPU an PD 39 in unserer Studie könnte, kongruent zu der Normalisierung der Zellzahl im ACC an PD 39, auf einen stattgefundenen Regenerationsprozess hindeuten und spiegelt das hohe Potential des sich entwickelnden Gehirns wieder auf exogene Schädigung, wie die perinatale Hypoxie, zu reagieren. Außerdem bestätigt sich die multifaktorielle Genese der Schizophrenie, denn erst die 
Interaktion von genetischen Faktoren und Umweltfaktoren (Schmitt et al. 2014) könnte wahrscheinlich in unserem Tiermodell zu dauerhaften Veränderungen des Volumens verschiedener Hirnstrukturen führen. Die transiente Volumenminderung im CPU könnte sich auch durch die von uns angewandte chronische, eher milde Hypoxie $\left(11 \% \mathrm{O}_{2}\right)$ erklären.

\subsection{Weitere hypoxieassoziierte Tiermodelle und deren Auswirkungen auf die Zellproliferation und Neurogenese}

Die Schizophrenie ist in rund $20 \%$ der Fälle mit Geburtskomplikationen assoziiert (Lewis und Murray 1987). Populationsbezogene Metaanalysen zeigten neben der Hypoxie signifikante Hinweise für Asphyxie, Uterusatonie und Notfallkaiserschnitte als ursächlich (z. B. Cannon M et al. 2002). Individuen mit einer entsprechenden Vorgeschichte haben demnach ein 2-fach erhöhtes Risiko, an einer Schizophrenie zu erkranken (Geddes und Lawrie 1995).

Die Maximalform des Sauerstoffmangels ist die globale Asphyxie. Infolge der Erhöhung des $\mathrm{CO}_{2}$-Partialdrucks im Blut (Hyperkapnie) kommt es zu einer Bewusstlosigkeit mit anschlieBendem Herz-Kreislauf-Versagen und Atemstillstand (Pschyrembel 2002). Rattenjunge wurden im Rahmen des normalen Geburtsvorgangs intrauterin für 19 Minuten im Wasserbad einer Asphyxie ausgesetzt, im Anschluss erfolgte die Kaiserschnittgeburt. Es konnte eine signifikant erhöhte Zellproliferation (60\%) im Hippocampus ab PD 5 festgestellt werden, die mit einer Massenzunahme des Hippocampus einherging und sich bis PD 11 wieder normalisierte. In anderen Hirnregionen, z. B. der SVZ, konnten keine Veränderungen dokumentiert werden (Scheepens et al. 2003). Diese Erkenntnis ist in Übereinstimmung mit unseren Ergebnissen einer unveränderten Zellproliferation an PD 13 in der SVZ. Es ist möglich, dass sich in unseren Ergebnissen, aufgrund der im Vorfeld maximal aktivierten Zellproliferation und anschließenden Normalisierung, perinatal keine signifikanten Effekte im Hippocampus an PD 13 zeigten. Einschränkend muss gesagt werden, dass in der Studie von Scheepens et al. (2003) keine immunhistochemische Doppelfärbung erfolgte. Die Zellproliferation wurde mittels radioaktiv markiertem ${ }^{3} \mathrm{H}$-Thymidin untersucht, welches sich wie $\mathrm{BrdU}$ in der S-Phase teilungsfähiger Zellen einlagert (Scheepens et al. 2003). Des Weiteren wurde kongruent zu uns nicht die Differenzierung zu Neuronen untersucht, jedoch wurde angenommen, dass die Zellproliferation neurogen war (Scheepens et al. 2003). Außerdem beschrieben Scheepens et al. (2003) nicht, welche Subregionen des Hippocampus untersucht wurden, hierdurch hätten sich möglicherweise auch Unterschiede ergeben.

Die Plazentainsuffizienz stellt einen weiteren Risikofaktor für eine Sauerstoffminderversorgung im Sinne einer chronischen Hypoxie des Fötus und der Entwicklung einer Schizophrenie dar (Cannon M et al. 2002). Im Tiermodell konnten verminderte dendritische Fortsätze im DG nachgewiesen werden (Dieni und Rees 2003). Meerschweinchen, die einer plazentaren 
Insuffizienz in der Schwangerschaft ausgesetzt waren, zeigten 12 Wochen postnatal neben der Ventrikulomegalie auch ein reduziertes Volumen in den Basalganglien. Es wurden Parallelen zu den pathoanatomischen Veränderungen wie bei der Schizophrenie gezogen (Rehn et al. 2004). Der Befund einer Volumenreduktion ist kongruent zu unseren Ergebnissen im CPU an PD 13 nach chronischer Hypoxie. Weitere tierexperimentelle Studien, die die Plazentainsuffizienz im Tiermodell untersuchten (z. B. Mallard et al. 1999, Mallard et al. 2000, Dieni und Rees 2003, Rehn et al. 2004), bewiesen hirnstrukturelle Veränderungen infolge der perinatalen chronischen Hypoxie wie sie bei der Schizophrenie gefunden wurden und belegen damit die frühe Schädigung in der Hirnentwicklung durch Schwangerschafts- und Geburtskomplikationen. Wir waren mit unserer Studie nicht in der Lage, typische Zellproliferationsveränderungen, wie sie in der Pathogenese der Schizophrenie vermutet werden, zu beweisen. Vielmehr verdeutlicht unsere Studie, dass das Gehirn innerhalb gewisser Grenzen tolerant gegenüber Hypoxie ist. Im Vergleich zu den in diesem Kapitel aufgeführten Tierstudien beruhen die Unterschiede zu unseren Experimenten in der Schwere des Sauerstoffmangels (Hypoxie bzw. Asphyxie) und in der Dauer der Hypoxie (chronisch bzw. akut). So besteht die Plazentainsuffizienz im Vergleich zu postnataler Hypoxie über mehrere Wochen (i. d. R. ab der zweiten Schwangerschaftshälfte) und in einem früheren Entwicklungsstadium und geht neben einer verminderten Sauerstoffversorgung des Fetus mit anderen Einflussfaktoren wie Nährstoffmangel (z. B. Glucose), Wachstumsretardierung und niedrigem Geburtsgewicht einher (Meyer und Feldon 2010).

\subsection{Neurobiologische Tiermodelle der Gen-Hypoxie-Interaktion und in- re Relevanz für die Schizophrenie}

Zwillingsstudien zeigen, dass genetische Faktoren einen Anteil von bis zu $80 \%$ bei der Entstehung der Schizophrenie ausmachen (Sullivan et al. 2003, Cannon TD et al. 1998).

Der Umweltfaktor Hypoxie wiederum spielt zwar bei verschiedenen Schwangerschafts- und Geburtskomplikationen eine bedeutende Rolle (siehe Kapitel 1.3.1 Gene und Umweltfaktoren), jedoch entwickeln mehr als $97 \%$ der hypoxie-assoziierten Geburtskomplikationen keine Psychosen (Buka et al. 1993). An Schizophrenie erkrankte Probanden und deren gesunde Geschwister zeigten nach perinataler Hypoxie stärkere hirnstrukturelle Veränderungen als gesunde Kontrollen, die auch einer perinatalen Hypoxie ausgesetzt waren, aber keine Eigenoder Familienanamnese für Psychosen aufwiesen (Cannon TD et al. 2002). Es stellt sich also die Frage, wie die Entstehung der Schizophrenie durch die Interaktion von Umweltfaktoren -wie der perinatalen Hypoxie- und Genen begünstigt wird. Ursache ist die multifaktorielle Genese der Erkrankung, die erst durch die Interaktion von prädisponierenden Genen (G) und Umweltfaktoren (E) in einem Gen-Umwelt-Interaktionsmodell (GxE) entsteht (Mittal et al. 2008). Dieses besagt, dass sich der Einfluss von Umweltfaktoren mit dem Vorhandensein 
von Promotorgenen multipliziert (Schmidt-Kastner et al. 2012). In Assoziation stehen früherer Krankheitsbeginn und stärkere hirnstrukturelle Veränderungen (van Erp 2002). Je häufiger dabei ein Gen mit der Schizophrenie assoziiert ist, desto wahrscheinlicher ist auch ein Zusammenhang mit Hypoxie und Ischämie, nämlich 55 \% (Schmidt-Kastner et al. 2012).

Tierexperimentelle Studien mit prä- und postnataler Hypoxie untersuchen zunehmend auch Schizophrenie-relevante Gene und deren Auswirkungen auf die Stammzellproliferation und Neurogenese, wobei diesem Forschungszweig noch deutlich mehr Beachtung geschenkt werden muss. Trotz der Entdeckung vieler Suszeptibilitätsgene (siehe Kapitel 1.3.1 Gene und Umweltfaktoren) sind die zugrunde liegenden neurobiologischen Mechanismen in der Interaktion mit Umwelteinflüssen weitgehend unbekannt und die Studienlage spärlich. So könnte die Entwicklung valider Tiermodelle als Hilfestellung für verbesserte Therapiemöglichkeiten dienen.

Eine experimentelle Studie zeigte, dass z. B. Neuregulin 1 (NRG1) im Rattenhirn durch Hypoxie reguliert wird (Nadri et al. 2007). NRG1 fungiert als systemischer endogener Schutz gegen perinatale Hirnschädigung und spielt eine bedeutende Rolle bei Zelldifferenzierung, Migration, Apoptose, Myelinisierung und Differenzierung von Neuronen und Oligodendrozyten (Falls 2003). Nach Hypoxie bei Ratten an PD 7 zeigte sich im Erwachsenenalter ein um $32 \%$ erhöhtes NRG1 Alpha-Protein im frontalen Kortex im Vergleich zu den Kontrollen (Nadri et al. 2007). Im Vergleich waren in Post-mortem-Studien schizophrener Patienten verminderte NRG1 Alpha-Proteinspiegel im frontalen Kortex nachweisbar (Bertram et al. 2007), was wiederum die Hypothese der neurobiologischen Veränderungen in der Ätiologie der Schizophrenie stützt. Der Nachweis von zumindest transient erhöhtem NRG1 wie in der Studie von Nadri et al. (2007) ist demnach als neuroprotektiver Mechanismus infolge perinataler Hypoxie zu verstehen und könnte in Zukunft als Ziel therapeutischer tierexperimenteller Studien genutzt werden (Schmitt et al. 2008).

Reelin ist eine extrazelluläre Matrixprotease, die im sich entwickelnden Gehirn in die neuronale Migration involviert ist (Tissir und Goffinet 2003). Pränatale maternale Hypoxie (zwei Stunden $9 \% \mathrm{O}_{2}, 3 \% \mathrm{CO}_{2}$ ) in Mäusen am 17. Tag der Schwangerschaft führte innerhalb der ersten 24 Stunden zu verminderter neuronaler Migration im fetalen Hirn und war bis 20 Tage nach Hypoxie nachweisbar. Ursache waren verminderte Reelin-Signale im Hippocampus. Gerade in dieser kritischen Phase erfolgt die Synaptogenese in Kortex und Hippocampus sowie die finale Migration von Neuronen aus dem Hippocampus (Golan et al. 2009). Passend hierzu konnte bereits Post-mortem vermindertes Reelinprotein und Reelin-mRNA (bis $50 \%)$ schizophrener Patienten in zahlreichen Hirnregionen wie dem Hippocampus nachgewiesen werden (Impagnatiello et al. 1998). In Reelin-defizienten Mäusen zeigte sich eine größere Infarktzone nach einseitiger Occlusion der ACM im Vergleich zum Wildtyp sowie eine deutlich eingeschränkte Neurogenese im DG und der SVZ nach immunhistochemischer 
Färbung mit BrdU und Doublecortin und war unter anderem auf eine gestörte Zellmigration über den rostralen Migrationsstrom zurückzuführen (Won et al. 2006).

Hypoxie-induzierte Transkriptionsfaktoren (HIF1/HIF2) sind die wichtigsten Regulatoren sauerstoffabhängiger Gentranskription während einer Hypoxie. Sie sind Heterodimere der HIF-aund HIF-ß-Untereinheiten und gehören zur PAS-Familie. Unter physiologischen Bedingungen wird die HIF- $\alpha$-Untereinheit schnell abgebaut und hydroxyliert. Unter Hypoxie ist aber die Aktivität der Hydroxylasen reduziert und die HIF-a-Untereinheit bleibt stabil und bindet an hypoxieregulierte spezifische Zielgene. Diese HIF-Zielgene modifizieren Sauerstoff- und Energieverfügbarkeit $u$. a. durch Beeinflussung des Überlebens von Zellen. (Trollmann und Gassmann 2009). Während der Embryo- und Organogenese stimuliert physiologische Hypoxie über die HIF-Kaskade die Angiogenese und metabolische Anpassung (Lee et al. 2001). Verschiedene neonatale Säugetiermodelle zeigten, dass HIF-Proteine unter hypoxischischämischen Bedingungen erhöht sind (z. B. Bergeron et al. 2000, Van den Tweel et al. 2006, Trollmann et al. 2008). HIF-Proteine akkumulieren dabei in hypoxievulnerablen Hirnregionen wie Cortex, Hippocampus und SVZ (Trollmann et al. 2008, Northington et al. 2001) und sind unter anderem in Neuronen und Astrozyten aktiviert (Chavez et al. 2006, Stroka et al. 2001). Folglich kann hierdurch die Entwicklung und Differenzierung von Zellen beeinträchtigt sein, wodurch sich wieder die Relevanz für die Schizophrenie verdeutlicht.

Daneben gibt es noch zahlreiche weitere Hypoxie-regulierte Gene, z. B. Cholezystokinin-ARezeptor (CCKAR), Cannabinoidrezeptor 1 (CNR1) oder Phospholipase A2 (PLA2G4A) (Schmidt-Kastner et al. 2006). Zukünftige Studien sollten intensiv deren neurobiologische Auswirkungen in Kombination mit perinataler Hypoxie in solchen transgenen Tiermodellen untersuchen.

\subsection{Methodenkritik}

\subsubsection{Das Tiermodell}

Das Tiermodell, insbesondere Untersuchungen in der Ratte, ist ein hilfreiches Werkzeug zur Detektierung von Störungen der Hirnfunktion und des Verhaltens in Bezug auf die Schizophrenie (siehe Kapitel 1.4.2 Tiermodelle in der Schizophrenie). Der Wunsch, Ursachen der Schizophrenie mit Hilfe von Tiermodellen umfassend zu erklären, ist dennoch durch das noch unzureichende Verständnis pathologischer Veränderungen, die zur Erkrankung führen, limitiert. Der Versuch das volle Syndrom, das spezifisch für den Menschen ist, auf eine niedere Tierspezies zu übertragen, ist offensichtlich nicht möglich, weshalb jeweils nur Endpunkte wie Hirnmorphologie, Neurochemie oder Verhalten untersucht werden können (Boksa 2004).

Ein Tiermodell, dass in der Lage ist, Symptome, wie sie im Menschen vorkommen, zu reproduzieren, ist in der Schizophrenie nur sehr schwer umsetzbar (Boksa 2004). Denn die Schi- 
zophrenie ist eine kognitive Erkrankung, die in weniger kognitiv entwickelten Tieren erfolgreich reproduziert werden soll. Des Weiteren handelt es sich um ein multifaktorielles (Genetik, Umweltfaktoren) und sehr heterogenes Krankheitsbild mit einer Kombination aus positiven, negativen und kognitiven Symptomen und großer Variabilität des Verlaufs (Marcotte et al. 2001).

Die alleinige Hypoxie als Untersuchungskriterium ist deshalb kein suffizienter Faktor, um die Entwicklung einer Schizophrenie vorherzusagen, denn die Mehrheit der Individuen, die Hypoxie-assoziierte Schwangerschafts- und/oder Geburtskomplikationen erleiden, entwickeln die Erkrankung nicht (Zornberg et al. 2000). Effekte eines wie von uns untersuchten unifaktoriellen Tiermodells (Hypoxie) scheinen durch das Fehlen anderer prädisponierender Faktoren, wie der genetischen Komponente nur sehr subtile Veränderungen zu bewirken (Boksa 2004) und könnten erklären, warum sich keine dauerhaften signifikanten Effekte in der Zellproliferation oder des Volumens, wie sie bei der Schizophrenie bekannt sind, zeigten. Vor allem in den hypoxieanfälligen postnatalen und adulten Neurogenesezentren (SVZ, DG) fanden wir keine signifikanten Veränderungen in der Zellproliferation. Die Ergebnisse unserer Studie spiegeln nur einen kurzen Untersuchungszeitraum von circa einem Monat nach Hypoxie wider. Die Langzeitfolgen postnataler Hypoxie bis in das Erwachsenenalter und somit den Zeitraum, in dem Symptome der Schizophrenie auftreten, sind demnach noch unklar.

\subsubsection{Grenzen der Methodik}

Die Hypoxie scheint abhängig von Schwere und Dauer zu einer Aktivierung der Apoptose zu führen. Eine fünfminütige Hypoxie führt nicht zu einer Apoptose (Blaise et al. 2009, Pourié et al. 2006), wohingegen bei 20-minütiger schwerer Hypoxie eine Apoptose induziert werden kann (Daval et al. 2004). Apoptose oder Nekrose wurden in der vorliegenden Studie nicht untersucht, könnten aber einen nicht unerheblichen hypoxieassoziierten Zelluntergang erklären, der unsere Ergebnisse beeinflussen könnte.

Möglicherweise war die von uns durchgeführte Hypoxie mit $11 \% \mathrm{O}_{2}$ zu mild, um Zellalterationen zu provozieren. Andere Studien, die Jungtiere einer vergleichbar schwereren Hypoxie (z. B. Li et al. $19987 \% \mathrm{O}_{2}$, Fagel et al. 20069,5 bis 10,5\% $\mathrm{O}_{2}$ ) oder einer globalen Hypoxie mit kombinierter Ischämie (z. B. Ikeda et al. 2005, Ong et al. 2005, Iwai et al. 2008, Felling et al. 2006) bzw. einer Asphyxie (z. B. Scheepens et al. 2003, Morales et al. 2008) aussetzten, konnten Zellveränderungen auch in anderen Hirnregionen wie der SVZ, dem CPU und dem Hippocampus nachweisen. Dagegen fanden wir keine aberante Zellproliferation in den Neurogenesezentren. Auch Ischämie im Tiermodell wurde durch uns nicht untersucht.

Des Weiteren erscheint eine Untersuchung der Zelldifferenzierung in Neurone mittels immunhistochemischer Doppelfärbung sinnvoll. Hierdurch könnten wichtige Aussagen zur Effektivität der Neurogenese möglich sowie das Überleben neu generierten Zellen über die Zeit 
beurteilt werden. Eine Mitfärbung von Gliazellen durch BrdU kann nicht sicher ausgeschlossen werden und die erhöhte Zellproliferation im ACC könnte durch eine mikrogliale Reaktion beeinflusst und damit falsch positiv sein.

BrdU-Konzentrationen über $50 \mathrm{mg} / \mathrm{kg}$ Körpergewicht können zudem die Entwicklung von Neuronen beeinflussen (Taupin 2007). Die von uns verwendete BrdU-Konzentration von 75 mg/kg Körpergewicht könnte also die Zellproliferation durch einen induzierten Zelluntergang beeinträchtigt haben.

Um die neurobiologischen Auswirkungen von Hypoxie in Zusammenhang mit der Schizophrenie zu bewerten, ist es zudem sinnvoll, das Verhalten auf Auffälligkeiten zu untersuchen (z. B. PPI, Motorik, soziale Interaktion). Dies erfolgte in unserer Studie nicht, allerdings wurde in dem hier verwendeten Tiermodell in einer früheren Studie ein PPI-Defizit im jungen Erwachsenenalter festgestellt (Fendt et al. 2008), wodurch die Validität des Tiermodells gestärkt wurde. Zudem beeinflusst Stress, dem die Tiere während einer solchen Testung ausgesetzt wären, die Zellproliferation (Jayatissa et al. 2010, siehe Kapitel 1.5.3 Einfluss von Stress auf die Neurogenese) und könnte zu verfälschten Ergebnissen führen.

In den Ergebnissen zeigten sich aus der MANOVA für absolute Zellzahlen und Volumen im ACC ein nicht signifikanter Trend zu Gruppeneffekten (siehe Kapitel 3.2.2 Absolute Zellzahlen und Volumina). Die signifikante Volumenminderung in der angeschlossenen ANOVA von $11 \%$ im ACC der Hypoxietiere an PD 39 im Vergleich zu den Kontrollen ist als Fehlerquelle zu werten. Ursache ist eine durch uns nicht einheitliche Abgrenzung anatomisch definierter, sondern willkürlich festgelegter Grenzen der Hirnregionen ACC, SVZ und DG des Hippocampus. Eine einheitliche Abgrenzung aller Hirnregionen und Volumenbestimmungen im Kontext mit der Bestimmung und Auswertung der Zellzahlen erscheint sinnvoller, um die Befunde für das Krankheitsbild der Schizophrenie zu verdeutlichen.

\subsection{Ausblick}

In der vorliegenden Arbeit wurde erstmals eine Zellproliferation an PD 13 im ACC infolge postnataler Hypoxie mit Hilfe der immunhistochemischen BrdU-Färbung untersucht.

Zukünftige Studien sollten mit Hilfe immunhistochemischer Doppelfärbung die Zelldifferenzierung zu Neuronen bzw. Gliazellen in dieser Hirnregion untersuchen, um die Ausdifferenzierung und Überlebensrate der proliferierenden Zellen zu beurteilen. Des Weiteren müsste untersucht werden, ob die Proliferation lokal oder durch Migration aus der subventrikulären Zone entstanden ist. Eine lokale kortikale Zellproliferation und Neurogenese würde die Annahme der Zellregeneration auch außerhalb der Neurogenesezentren infolge Hypoxie bestätigen.

Zur Detektierung von Schizophrenie-relevanten Verhaltensauffälligkeiten infolge einer gestörten Zellentwicklung empfehlen sich zukünftig Verhaltenstests wie die PPI in Kombination 
mit Untersuchungen zur Zellproliferation und Neurogenese. Zur Erhöhung der Sensitivität wäre die Kombination von Risikogenen und Umweltfaktoren in einem multifaktoriellen Tiermodell sinnvoll. Hierdurch wären die Ergebnisse besser im Kontext mit der Entstehung einer Schizophrenie einzuordnen. Vor allem Untersuchungen von Risikogenen sind erst im Ansatz verstanden und könnten einen Einstieg in kausale Therapieoptionen der Schizophrenie ermöglichen (Schmitt et al. 2009a).

Die detailierte Erforschung der Schizophrenie auf molekularbiologischer und morphologischer Ebene könnte in Zukunft zu einer Früherkennung der Erkrankung beitragen und somit eine frühzeitige Behandlung ermöglichen, die behindernde Symptome wie kognitive Defizite sowie Positiv- und Negativsymptome vermeiden helfen könnte (Schmitt et al. 2009a). Hierzu gehört auch die verstärkte Untersuchung von Zellalterationen in Post-mortem-Studien sowie die Untersuchung von Langzeitfolgen schizophrenieauslösender Risikofaktoren wie der Hypoxie bis zum Ausbruch der Erkrankung.

Mit der genauen Kenntnis zu den Mechanismen der Neurogenese sowie neuronaler Migration könnte das Wissen über autoreperative Mechanismen des Gehirns deutlich erweitert und dadurch die Tür für eine Stammzelltherapie bei schizophrenen Patienten nach exogener Schädigung geöffnet werden. Die Transplantation neuraler Stammzellen in das hypoxischischämisch geschädigte Gehirn konnte bereits im lebenden Organismus wie Maus und Ratte erfolgreich getestet werden (z. B. Zheng et al. 2006, Park et al. 2006). 


\section{$5 \quad$ Zusammenfassung}

Die Ätiologie der Schizophrenie ist noch weitgehend unverstanden und man geht davon aus, dass genetische Faktoren und Umweltfaktoren zusammenwirken. Die Hypoxie stellt von den bekannten Schwangerschafts- und Geburtskomplikationen den stärksten prädisponierenden Faktor in der Äthiopathogenese der Erkrankung dar und korreliert signifikant mit dem Erkrankungsbeginn.

Replizierbare Befunde perinataler Hypoxie und Schizophrenie sind strukturelle Aberrationen (z. B. Ventrikulomegalie, Volumenminderung in Gehirnarealen), Verhaltensdefizite sowie neurochemische Veränderungen, wobei die gestörte Zellentwicklung möglicherweise einen wichtigen Faktor bei der frühen Hirnentwicklungsstörung darstellt. Hierzu zählen Zellproliferation, -migration, Proliferation von Dendriten und Axonen, Myelinisierung, synaptic pruning und programmierter Zelltod.

Ziel der Arbeit war die Untersuchung der Zellproliferation im Gehirn am Tiermodell unter dem Einfluss von postnataler Hypoxie. Veränderungen der Zellzahl hypoxievulnerabler Hirnregionen sollten über einen Zeitraum von vier Wochen untersucht und die Ergebnisse im Kontext der Pathophysiologie der Schizophrenie bewertet werden.

20 männliche Wistar-Ratten wurden an PD 4 bis 8 einer sechsstündigen Hypoxie aus $11 \%$ $\mathrm{O}_{2}$ und $89 \% \mathrm{~N}_{2}$ ausgesetzt. Als Vergleich diente eine unbehandelte Kontrollgruppe aus 20 weiteren Versuchstieren. Alle Tiere erhielten an PD 11 eine viermalige intraperitoneale BrdUInjektion. An PD 13 bzw. PD 39 erfolgte die Sakrifizierung von jeweils 10 hypoxiebehandelten Tieren und 10 Kontrollen. Am Gefriermikrotom wurden die tiefgefrorenen Gehirne in $60 \mu \mathrm{m}$ dicke Schnitte präpariert, wobei jeder 10. Schnitt verwendet wurde. Die immunhistochemische Darstellung proliferierender Zellen erfolgte mit Hilfe der BrdU-Peroxidasefärbung. Die Zellzählung erfolgte blind mit der Optical Fractionator-Methode durch das Stereologiemikroskop in folgenden Hirnregionen: ACC, CPU, DG des Hippocampus und die SVZ der Seitenventrikel. Die statistische Auswertung erfolgte mittels parametrischer Verfahren.

Zusammenfassend konnte festgestellt werden, dass Ratten, die einer chronischen Hypoxie ausgesetzt waren, eine um 20 \% erhöhte Zellzahl im ACC an PD 13 sowie ein um

$16 \%$ reduziertes Volumen im CPU an PD 13 gegenüber den gleichaltrigen Kontrollen aufwiesen. An PD 39 zeigten sich keine signifikanten Unterschiede zu den Kontrollen mehr.

Mit der vorliegenden Studie konnte erstmals eine erhöhte Hypoxie-induzierte Zellproliferation im ACC sowie ein vermindertes Volumen im CPU belegt werden. Die Ergebnisse zeigen, dass ein vorübergehender Einfluss chronischer Hypoxie auf die Zellproliferation und das Volumen angenommen werden kann und bekräftigen, dass das Gehirn innerhalb gewisser 
Grenzen tolerant gegenüber dem Einfluss exogener Noxen wie der Hypoxie ist. Sie bestätigen auch die Erkenntnis, dass nur ein kleiner Teil der Hypoxie-assoziierten Geburtskomplikationen zu einer Schizophrenie führen und der Erkrankung eine multifaktorielle GenUmwelt-Ätiologie zugrunde liegt. Wir waren nicht in der Lage, dauerhafte Zellveränderungen im ACC sowie dauerhafte Volumenalterationen im CPU zu demonstrieren, wie sie bei der Schizophrenie bereits nachweisbar waren.

Die Zellproliferation postmortem, Langzeitfolgen perinataler Hypoxie bis zum Ausbruch der Erkrankung (Verhalten, Zellalterationen) sowie In-vivo-Techniken sollten wesentlicher Bestandteil der zukünftigen Forschung sein. 


\section{$6 \quad$ Anhang}

6.1 Systematik der Symptome ersten und zweiten Ranges nach Kurt Schneider (1938)

Symptome ersten Ranges:

- $\quad$ dialogische und kommentierende Stimmen

- Gedankenlautwerden

- $\quad$ leibliche Beeinflussungserlebnisse

- Gedankeneingebung, -entzug, -ausbreitung

- $\quad$ Gefühl des Gemachten

- Wahnwahrnehmung

Symptome zweiten Ranges:

- $\quad$ sonstige akustische Halluzinationen

- Halluzinationen auf anderen Sinnesgebieten

- Wahneinfälle

- Ratlosigkeit

- Verstimmungen

- $\quad$ erlebte Gefühlsverarmung

(Wobrock et al. 2004a)

6.2 Anzahl (n) der ausgewerteten Schnitte je Hirnregion und Gehirn

\begin{tabular}{|l|c|c|c|c|}
\hline Gehirn & ACC & CPU & SVZ & DG \\
\hline $\mathbf{1}$ & 7 & 6 & 4 & 5 \\
\hline $\mathbf{2}$ & 7 & 5 & 4 & 6 \\
\hline $\mathbf{3}$ & 7 & 6 & 5 & 7 \\
\hline $\mathbf{4}$ & 7 & 6 & 5 & 5 \\
\hline $\mathbf{5}$ & 7 & 6 & 5 & 5 \\
\hline $\mathbf{6}$ & 7 & 6 & 4 & 6 \\
\hline $\mathbf{7}$ & 6 & 5 & 4 & 5 \\
\hline $\mathbf{8}$ & 7 & 5 & 4 & 7 \\
\hline $\mathbf{9}$ & 6 & 5 & 5 & 6 \\
\hline $\mathbf{1 0}$ & 6 & 5 & 4 & 6 \\
\hline
\end{tabular}

Tab. 19: Anzahl (n) der ausgewerteten Schnitte je Hirnregion und Gehirn PD 13 Kontrolle 


\begin{tabular}{|l|c|c|c|c|}
\hline Gehirn & ACC & CPU & SVZ & DG \\
\hline $\mathbf{1}$ & 8 & 6 & 5 & 6 \\
\hline $\mathbf{2}$ & 8 & 6 & 5 & 5 \\
\hline $\mathbf{3}$ & 7 & 6 & 5 & 5 \\
\hline $\mathbf{4}$ & 6 & 5 & 4 & 6 \\
\hline $\mathbf{5}$ & 8 & 6 & 5 & 6 \\
\hline $\mathbf{6}$ & 8 & 7 & 6 & 5 \\
\hline $\mathbf{7}$ & 7 & 5 & 4 & 6 \\
\hline $\mathbf{8}$ & 6 & 6 & 4 & 5 \\
\hline $\mathbf{9}$ & 6 & 6 & 5 & 5 \\
\hline $\mathbf{1 0}$ & 6 & 5 & 4 & 6 \\
\hline
\end{tabular}

Tab. 20: Anzahl (n) der ausgewerteten Schnitte je Hirnregion und Gehirn PD 13 Hypoxie

\begin{tabular}{|l|c|c|c|c|}
\hline Gehirn & ACC & CPU & SVZ & DG \\
\hline $\mathbf{1}$ & 8 & 5 & 6 & 7 \\
\hline $\mathbf{2}$ & 7 & 6 & 5 & 8 \\
\hline $\mathbf{3}$ & 7 & 6 & 5 & 7 \\
\hline $\mathbf{4}$ & 8 & 6 & 5 & 5 \\
\hline $\mathbf{5}$ & 7 & 6 & 5 & 8 \\
\hline $\mathbf{6}$ & 7 & 5 & 5 & 7 \\
\hline $\mathbf{7}$ & 9 & 7 & 7 & 7 \\
\hline $\mathbf{8}$ & 8 & 7 & 6 & 8 \\
\hline $\mathbf{9}$ & 9 & 6 & 6 & 7 \\
\hline $\mathbf{1 0}$ & 8 & 6 & 6 & 6 \\
\hline
\end{tabular}

Tab. 21: Anzahl (n) der ausgewerteten Schnitte je Hirnregion und Gehirn PD 39 Kontrolle 


\begin{tabular}{|l|c|c|c|c|}
\hline Gehirn & ACC & CPU & SVZ & DG \\
\hline $\mathbf{1}$ & 8 & 7 & 5 & 7 \\
\hline $\mathbf{2}$ & 8 & 7 & 6 & 6 \\
\hline $\mathbf{3}$ & 8 & 6 & 5 & 6 \\
\hline $\mathbf{4}$ & 7 & 5 & 5 & 7 \\
\hline $\mathbf{5}$ & 7 & 7 & 6 & 6 \\
\hline $\mathbf{6}$ & 8 & 6 & 5 & 7 \\
\hline $\mathbf{7}$ & 8 & 6 & 6 & 6 \\
\hline $\mathbf{8}$ & 8 & 7 & 6 & 7 \\
\hline $\mathbf{9}$ & 8 & 7 & 5 & 7 \\
\hline $\mathbf{1 0}$ & 8 & 6 & 5 & 8 \\
\hline
\end{tabular}

Tab. 22: Anzahl (n) der ausgewerteten Schnitte je Hirnregion und Gehirn PD 39 Hypoxie 


\section{$7 \quad$ Literaturverzeichnis}

Allan CL, Cardno AG, McGuffin P (2008): Schizophrenia: From genes to phenes to disease. Curr Psychiatry Rep 10(4), 339-43

Altman J, Das GD (1965): Postnatal origin of microneurons in the rat brain.

Nature 207(5000), 953-6

American Psychiatric Association: Diagnostic and Statistical Manual of Mental Disorders. $5^{\text {th }}$ edition; American Psychiatric Publishing, Arlington (Virginia) 2013

Andreasen NC, Carpenter WT Jr (1993): Diagnosis and classification of schizophrenia. Schizophr Bull 19(2), 199-214

Arnedo J, Svrakic DM, Del Val C, Romero-Zaliz R, Hernández-Cuervo H, Molecular Genetics of Schizophrenia Consortium, Fanous AH, Pato MT, Pato CN, de Erausquin GA (2015): Uncovering the hidden risk architecture of the schizophrenias: Confirmation in three independent genome-wide association studies. Am J Psychiatry 172(2), 139-53

Arvidsson A, Collin T, Kirik D, Kokaia Z, Lindvall O (2002): Neuronal replacement from endogenous precursors in the adult brain after stroke. Nat Med $\underline{8}(9), 963-70$

Bartley J, Soltau T, Wimborne H, Kim S, Martin-Studdard A, Hess D, Hill W, Waller J, Carroll J (2005): BrdU-positive cells in the neonatal mouse hippocampus following hypoxicischemic brain injury. BMC Neurosci $\underline{6}, 15$

Becker A, Grecksch G, Bernstein HG, Höllt V, Bogerts B (1999): Social behaviour in rats lesiones with ibotenic acid in the hippocampus: quantitative and qualitative analysis. Psychopharmacology (Berl) 144(4), 333-8

Benes FM (1993): Neurobiological investigations in cingulated cortex of schizophrenic brain. Schizophr Bull 19

Benes FM, Bird ED (1987): An Analysis of the arrangement of neurons in the cingulated cortex of schizophrenic patients. Arch Gen Psychiatry 44(7), 608-16 
Benes FM, Paskevich PA, Davidson J, Domesick VB (1985): The effects of haloperidol on synaptic patterns in the rat striatum. Brain Res $\underline{329}(1-2), 265-73$

Benes FM, Davidson J, Bird ED (1986): quantitative cytoarchitectural studies of the cerebral cortex of schizophrenics. Arch Gen Psychiatry $\underline{43}(1), 31-5$

Berger M: Psychische Erkrankungen Klinik und Therapie. 3. Auflage; Urban und Fischer Verlag, München 2009

Bergeron M, Gidday JM, Yu AY, Semenza GL, Ferriero DM, Sharp FR (2000): Role of hypoxia-inducible factor-1 in hypoxia-induced ischemic tolerance in neonatal rat brain.

Ann Neurol $\underline{48}(3), 285-96$

Bertram I, Bernstein HG, Lendeckel U, Bukowska A, Dobrowolny H, Keilhoff G, Kanakis D, Mawrin C, Bielau H, Falkai P (2007): Immunohistochemical evidence for impaired neuregulin-1 signaling in the prefrontal cortex in schizophrenia and in unipolar depression. Ann N Y Acad Sci 1096, 147-56

Besnier N, Gavaudan G, Navez A, Adida M, Jollant F, Courtet P, Lançon C (2009): Clinical features of suicide occurring in schizophrenia (I). Risk-factors identification.

Encephale 35 (2), 176-81

Bilger A, Nehlig A (1993): Regional cerebral blood flow response to acute hypoxia changes with postnatal age in the rat. Brain Res Dev Brain Res $\underline{76}$ (2), 197-205

Björkman ST, Miller SM, Rose SE, Burke C, Colditz PB (2010): Seizures are associated with brain injury severity in a neonatal model of hypoxia-ischemia.

Neuroscience 166(1), 157- 167

Blaise SA, Nédélec E, Alberto JM, Schroeder H, Audonnet S, Bossenmeyer-Pourié C, Guéant JL, Daval JL (2009): Short hypoxia could attenuate the adverse effects of hyperhomocysteinemia on the developing rat brain by inducing neurogenesis.

Exp Neurol 216(1), 231-8

Blomgren K, Hagberg H (2006): Free radicals, mitochondria, and hypoxia- ischemia in the developing brain. Free Radic Biol Med $\underline{40}(3)$, 388-97 
Bogerts B (1997): The temporolimbic system theory of positive schizophrenic symptoms. Schizophr Bull 23(3), 423-35

Boksa P (2004): Animal models of obstetric complications in relation to schizophrenia. Brain Res Brain Res Rev $\underline{45}(1), 1-17$

Braff DL, Swerdlow NR, Geyer MA (1999): Symptom correlates of prepulse inhibition deficits in male schizophrenic patients. Am J Psychiatry 156(4), 596-602

Braff DL, Geyer MA, Swerdlow NR (2001): Human studies of prepulse inhibition of startle: normals subjects, patient groups, and pharmacological studies.

Psychopharmacology (Berl) 156(2-3), 234-58

Breier A, Buchanan RW, Elkashef A, Munson RC, Kirkpatrick B, Gellad F (1992):

Brain morphology and schizophrenia. A magnetic resonance imaging study of limbic, prefrontal cortex, and caudate structures. Arch Gen Psychiatry $\underline{49}(12), 921-6$

Brown AS, Bottiglieri T, Schaefer CA, Quesenberry CP Jr, Liu L, Bresnahan M, Susser ES (2007): Elevated prenatal homocysteine levels as a risk factor for schizophrenia.

Arch Gen Psychiatry 64(1), 31-9

Buchanan RW, Breier A, Kirkpatrick B, Elkashef A, Munson RC, Gellad F, Carpenter WTJr (1993): Structural abnormalities in deficit and nondeficit schizophrenia. Am J Psychiatry 150(1), 59-65

Buka SL, Tsuang MT, Lipsitt LP (1993): Pregnancy/delivery complications and psychiatric diagnosis: a prospective study. Arch Gen Psychiatry $\underline{50}(2), 151-6$

Butelmann ER (1989): A novel NMDA antagonist, MK-801, impairs performance in a hippocampal-dependent spatial learning task. Pharmacol Biochem Behav 34(1), 13-6

Caldwell CB, Gottesmann II (1992): Schizophrenia- a high risk factor for suicide: clues to risk reduction. Suicide Life Threat Behav 22(4), 479-93

Cameron HA, Woolley CS, McEwen BS, Gould E (1993): Differentiation of newly born neurons and glia in the dentate gyrus of the adult rat. Neuroscience $\underline{56}(2), 337-44$ 
Cameron HA, McEwen BS, Gould E (1995): Regulation of adult neurogenesis by excitatory input and NMDA receptor activation in the dentate gyrus. J Neurosci 15(6), 4687-92

Cannon M, Jones PB, Murray RM (2002): Obstetric complications and schizophrenia: historical and metaanalytic review. Am J Psychiatry 159(7), 1080-92

Cannon TD (1997): On the nature and mechanism of obstetric influences in schizophrenia: a review and synthesis of epidemiologic studies. Int Rev Psychiatry $\underline{9}(4)$, 387-98

Cannon TD, Kaprio J, Lönnqvist J, Huttunen M, Koskenvuo M (1998): The genetic epidemiology of schizophrenia in a Finnish twin cohort. A population-based modeling study. Arch Gen Psychiatry $\underline{55}(1), 67-74$

Cannon TD, Rosso IM, Bearden CE, Sanchez LE, Hadley T (1999): A prospective cohort study of neurodevelopmental processes in the genesis and epigenesis of schizophrenia. Dev Psychopathol 11(3), 467-85

Cannon TD, van Erp TG, Rosso IM, Huttunen M, Lönnqvist J, Pirkola T, Salonen O, Valanne L, Poutanen VP, Standertskjöld-Nordenstam CG (2002): Fetal hypoxia and structural brain abnormalities in schizophrenic patients, their siblings and controls. Arch Gen Psychiatry $\underline{59}(1), 35-41$

Chakos MH, Lieberman JA, Alvir J, Bilder R, Ashtari M (1995): Caudate nuclei volumes in schizophrenic patients treated with typical antipsychotics or clozapine.

Lancet $\underline{345}(8947)$, 456-7

Chavez JC, Baranova O, Lin J, Pichiule P (2006): The transcriptional activator hypoxia inducible factor 2 (HIF-2/EPAS-1) regulates the oxygen-dependent expression of erythropoietin in cortical astrocytes. J Neurosci 26(37), 9471-81

Chua SE, Cheung C, Cheung V, Tsang JT, Chen EY, Wong JC, Cheung JP, Yip L, Tai KS, Suckling J (2006): Cerebral grey, white matter and csf in never-medicated, first-episode schizophrenia. Schizophr Res $\underline{89}(1-3), 12-21$

Corcoran C, Mujica-Parodi L, Yale S, Leitman D, Malaspina D (2002): Could stress cause psychosis in individuals vulnerable to schizophrenia? CNS Spectr $\underline{7}(1)$, 33-8 
Corcoran C, Walker E, Huot R, Mittal V, Tessner K, Kestler L, Malaspina D (2003): The stress cascade and schizophrenia: etiology and onset. Schizophr Bull 29 $\underline{2}(4), 671-92$

Corson PW, Napoulos P, Andreasen NC, Heckel D, Arndt S (1999): Caudate size in firstepisode neuroleptic-naive schizophrenic patients measured using an artificial neural network. Biol Psychiatry 46 (5), 712-20

Czéh B, Lucassen PJ (2007): What causes the hippocampal volume decrease in depression? Are neurogenesis, glial changes and apoptosis implicated?

Eur Arch Psychiatry Clin Neurosci 257(5), 250-60

Dalman C, Allebeck P, Cullberg J, Grunewald C, Koester M (1999): Obstetric complications and the risk of schizophrenia: a longitudinal study of national birth cohort.

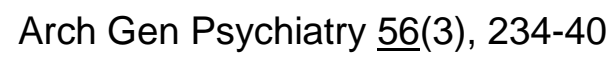

Daval JL, Pourié G, Grojean S, Lièvre V, Strazielle C, Blaise S, Vert P (2004): Neonatal hypoxia triggers transient apoptosis followed by neurogenesis in the rat CA1 hippocampus. Pediatr Res $\underline{55}(4), 561-7$

Dawirs RR, Hildebrandt K, Teuchert-Noodt G (1998): Adult treatment with haloperidol increases dentate granule cell proliferation in the gerbil hippocampus.

J Neural Transm 105(2-3), 317-27

Dayer AG, Ford AA, Cleaver KM, Yassaee M, Cameron HA (2003): Short-term and longterm survival of new neurons in the rat dentate gyrus. J Comp Neurol $\underline{460}(4), 563-72$

Dayer AG, Cleaver KM, Abouantoun T, Cameron HA (2005): New GABAergic interneurons in the adult neokortex and striatum are generated from different precursors.

J Cell Biol 168(3), 415-27

DeLisi LE, Sakuma M, Maurizio AM, Relja M, Hoff AL (2004): Cerebral ventricular change over the first 10 years after the onset of schizophrenia. Psychiatry Res $\underline{130}(1), 57-70$

Dieni S, Rees S (2003): Dendritic morphology is altered in hippocampal neurons following prenatal compromise. J Neurobiol $\underline{55}(1), 41-52$ 
Dilling H, Mombour W, Schmidt MH: Internationale Klassifikation psychischer Störungen. 9. Auflage; Verlag Hans Huber, Bern 2014

Dobbing J, Sands J (1979): Comparative aspects of the brain growth spurt.

Early Hum Dev $\underline{3}(1), 79-83$

El-Khodor BF, Boksa P (2000): Transient birth hypoxia increases behavioral responses to repeated stress in the adult rat. Behav Brain Res $\underline{107}(1-2), 171-5$

El-Khodor BF, Boksa P (2003): Differential vulnerability of male versus female rats to longterm effects of birth insult on brain catecholamine levels. Exp Neurol 182(1), 208-19

Encinas JM, Vaahtokari A, Enikolopov G (2006): Fluoxetine targets early progenitor cells in the adult brain. Proc Natl Acad Sci USA $\underline{103}(21)$, 8233-8

Ernst A, Alkass K, Bernard S, Salehpour M, Perl S, Tisdale J, Possnert G, Druid H, Frisén $\mathbf{J}$ (2014): Neurogenesis in the striatum of the adult human brain. Cell 156(5), 1072-83

Fagel DM, Ganat Y, Silbereis J, Ebbitt T, Stewart W, Zhang H, Ment LR, Vaccarino FM (2006): Cortical neurogensis enhanced by chronic perinatal hypoxia.

Exp Neurol 199(1), 77-91

Falkai P, Parlapani E, Gruber O, Schmitt A: The neuropathology of schizophrenia: Centrale role for the hippocampus? In: Advances in schizophrenia Research 2009; hrsg. v. Gattaz WF, Busatto G.1. Auflage; Springer Science and Business Media, New York 2010, S. 14966.

Falls DL (2003): Neuregulins: functions, forms, and signalling strategies.

Exp Cell Res $\underline{284}(1), 14-30$

Fanous AH, Neale MC, Webb BT, Straub RE, Amdur RL, O’Neill FA, Walsh D, Riley BP, Kendler KS (2007): A genom-wide scan for modifier loci in schizophrenia.

Am J Genet B Neuropsychiatr Genet 144B(5), 589-95

Feinberg I (1983): Schizophrenia: caused by a fault in programmed synaptic elimination during aldolescence? J Psychiatr Res 17(4), 319-34 
Felling RJ, Snyder MJ, Romanko MJ, Rothstein RP, Ziegler AN, Yang Z, Givogri MI, Bongarzone ER, Levison SW (2006): Neural stem/progenitor cells participate in the regenerative response to perinatal hypoxia/ischemia. J Neurosci 26(16), 4359-69

Fendt M, Lex A, Falkai P, Henn FA, Schmitt A (2008): Behavioural alterations in rats following neonatal hypoxia and effects of clozapine: Implications for schizophrenia. Pharmacopsychiatry $\underline{41}(4), 138-145$

Fornito A, Yücel M, Wood SJ, Adamson C, Velakoulis D, Saling MM, McGorry PD, Pantelis C (2008): Surface-based morphometry of the anterior cingulate cortex in first episode schizophrenia. Hum Brain Mapp 29 (4), 478-89

Freeman H (1994): Schizophrenia and city residence. Br J Psychiatry Suppl 23, 39- 50

Fruntes V, Limosin F (2008): Schizophrenia and viral infection during neurodevelopment: a pathogenesis model? Med Sci Monit 14(6), RA71-7

Fuchs E (2007): Neurogenesis in the adult brain: is there an association with mental disorders? Eur Arch Psychiatry Clin Neurosci 257(5), 247-9

Garcia-Verdugo JM, Doetsch F, Wichterle H, Lim DA, Alvarez-Buylla A (1998): Architecture and cell types of the adult subventricular zone: in search of the stem cells. J Neurobiol $\underline{36}(2), 234-48$

Gasquoine PG (2013): Localization of function in anterior cingulate cortex: from psychosurgery to functional neuroimaging. Neurosci Biobehav Rev $\underline{37}(3)$, 340-8

Geddes JR, Lawrie SM (1995): Obstetric complications and schizophrenia: a meta-analysis. Br J Psychiatry 167(6), 786-93

Ghiani CA, Beltran-Parrazal L, Sforza DM, Malvar JS, Seksenyan A, Cole R, Smith DJ, Charles A, Ferchmin PA, de Vellis J (2007): Genetic program of neuronal differentiation and growth induced by specific activation of NMDA receptors. Neurochem Res $\underline{32}(2), 363-76$

Giovannini MG, Camilli F, Mundula A, Pepeu G (1994): Glutamatergic regulation of acetylcholine output in different brain regions: a microdialysis study in the rat.

Neurochem Int 25 (1), 23-6 
Girlovanu M, Susman S, Soritau O, Rus-Ciuca D, Melincovici C, Constantin AM, Mihu CM (2015): Stem cells - biological update and cell therapy progress.

Clujul Med 88(3), 265-71

Gleixner C, Müller M, Wirth S: Neurologie und Psychiatrie für Studium und Praxis. 6. Auflage; Medizinische Verlags- und Informationsdienste, Breisach 2007

Golan MH, Mane R, Molczadzki G, Zuckerman M, Kaplan-Louson V, Huleihel M, PerezPolo JR (2009): Impaired migration signaling in the hippocampus following prenatal hypoxia. Neuropharmacology $\underline{57}(5-6), 511-22$

Goldman JE (1995): Lineage, migration, and fate determination of postnatal subventricular zone cells in the mammalian CNS. J Neurooncol 24 (1), 61-4

Gould E (2007): How widespread is adult neurogenesis in mammals?

Nat Rev Neurosci $\underline{8}(6), 481-8$

Gould E, Tanapat P (1999): Stress and hippocampal neurogenesis.

Biol Psychiatry $\underline{46}(11), 1472-9$

Gould E, McEwen BS, Tanapat P, Galea LA, Fuchs E (1997): Neurogenesis in the dentate gyrus of the adult tree shrew is regulated be psychosocial stress and NMDA receptor activation. J Neurosci 17(7), 2492-8

Granger B (1996): Synaptogenesis and synaptic pruning: role triggering schizophrenia. Presse Med 25(33), 1595-8

Häfner H, an der Heiden W (1997): Epidemiology of schizophrenia.

Can J Psychiatry $\underline{42(2), 139-51}$

Häfner H, Reimann H, Immich H, Martini H (1969): Inzidenz seelischer Erkrankungen in Mannheim 1965. Social Psychiatry $\underline{4}(3), 126-35$

Häfner H, an der Heiden W, Behrens S, Gattaz WF, Hambrecht M, Löffler W, Maurer K, Munk- Jørgensen P, Nowotny B, Riecher- Rössler A, Stein A (1998): Causes and consequences of the gender difference in age of onset of schizophrenia.

Schizophr Bull 24(1), 99-113 
Hagberg H, Gressens P, Mallard C (2012): Inflammation during fetal and neonatal life: implications for neurologic and neuropsychiatric disease in children and adults.

Ann Neurol 71(4), 444-57

Halim ND, Weickert CS, McClintock BW, Weinberger DR, Lipska BK (2004): Effects of chronic Haloperidol and Clozapine treatment on neurogenesis in the adult rat hippocampus. Neuropsychopharmacology $\underline{29}(6), 1063-9$

Hamm AO, Weike Al, Schupp HT (2001): The effect of neuroleptic medication on prepulse inhibition in schizophrenia patients: current status and future issues. Psychopharmacology (Berl) 156(2-3), 259-65

Hasan A, Falkai P, Wobrock T, Lieberman J, Glenthoj B, Gattaz WF, Thibaut F, Möller HJ; World Federation of Societies of Biological Psychiatry (WFSBP) Task Force on Treatment Guidelines for Schizophrenia (2012): World Federation of Societies of BiologicalPsychiatry (WFSBP) Guidelines for Biological Treatment of Schizophrenia, part 1: update 2012 on the acute treatment of schizophrenia and the management of treatment resistance. World J Biol Psychiatry $\underline{13}(5), 318-78$

Hasan A, Falkai P, Wobrock T, Lieberman J, Glenthoj B, Gattaz WF, Thibaut F, Möller HJ; WFSBP Task force on Treatment Guidelines for Schizophrenia (2013): World Federation of Societies of Biological Psychiatry (WFSBP) guidelines for biological treatment of schizophrenia, part 2: update 2012 on the long-term treatment of schizophrenia and management of antipsychotic-induced side effects. World J Biol Psychiatry 14(1), 2-44

Haukvik UK, Agartz I (2010): Do obstetric complications increase the risk of schizophrenia? Tidsskr Nor Laegeforen $\underline{130}(3)$, 270-2

Heckers S, Konradi C (2002): Hippocampal neurons in schizophrenia. J Neural Transm 109(5-6), 891-905

Heimer L, de Olmos J, Alheid GF, Záborszky L (1991): "Perestroika" in the basal forebrain: opening the border between neurology and psychiatry. Prog Brain Res $\underline{87}, 109-65$

Hokama H, Shenton ME, Nestor PG, Kikinis R, Levitt JJ, Metcalf D, Wible CG, O'Donnell BF, Jolesz FA, McCarley RW (1995): Caudate, putamen, and globus pallidus volume in schizophrenia: a quantitative MRI study. Psychiatry Res 61(4), 209-29 
Hultmann CM, Sparén P, Takei N, Murray RM, Cnattingius S (1999): Prenatal and perinatal risk factors for schizophrenia, affective psychosis, and reactive psychosis of early onset: case control study. BMJ $\underline{318}(7181), 421-6$

Huttenlocher PR (1979): Synaptic density in human in human frontal cortex- developmental changes and effects of aging. Brain Res 163(2), 195-205

Ikeda T (2008): Stem cells and neonatal brain injury. Cell Tissue Res 331(1), 263-9

Ikeda T, Iwai M, Hayashi T, Nagano I, Shogi M, Ikenoue T, Abe K (2005): Limited differentiation to neurons and astroglia from neural stem cells in the cortex and striatum after ischemia/hypoxia in the neonatal rat brain.

Am J Obstet Gynecol 193(3 Pt 1), 849-56

Ikonomidou C, Mosinger JL, Salles KS, Labruyere J, Olney JW (1989): Sensitivity of the developing rat brain to hypobaric/ischemic damage parallels sensitivity to $n$-methyl-aspartate neurotoxicity. J Neurosci $\underline{9}(8), 2809-18$

Impagnatiello F, Guidotti AR, Pesold C, Dwivedi Y, Caruncho H, Pisu MG, Uzunov DP, Smalheiser NR, Davis JM, Pandey GN (1998): A decrease of reelin expression as a putative vulnerability factor in schizophrenia. Proc Natl Acad Sci U S A 95(26), 15718-23

Iwai M, Ikeda T, Havashi T, Sato K, Nagata T, Nagano I, Shoji M, Ikenoue T, Abe K (2006): Temporal profile of neural stem cell proliferation in the subventricular zone after ischemia/hypoxia in the neonatal rat brain. Neurol Res $\underline{28}(4), 461-8$

Janowski M, Gornicka-Pawlak E, Kozlowska H, Domanska-Janik K, Gielecki J, Lukomska B (2008): Structural and functional characteristic of a model for deep-seated lacunar infarct in rats. J Neurol Sci $\underline{273}(1-2), 40-8$

Javitt DC (2007): Glutamate and schizophrenia: phencyclidine, N- methyl- D- aspartate receptors, and dopamine- glutamate interactions. Int Rev Neurobiol 78, 69-108

Jayatissa MN, Henningsen K, Nikolajsen G, West MJ, Wiborg O (2010): A reduced number of hippocampal granule cells does not associate with an anhedonia-like phenotype in a rat chronic mild stress model of depression. Stress $\underline{13}$ (2), 95-105 
Kadam SD, Mulholland JD, McDonald JW, Comi AM (2008): Neurogenesis and neuronal commitment following ischemia in a new mouse model for neonatal stroke.

Brain Res 1208, 35-45

Kalus P, Falkai P, Heinz A (2008): Structural and functional brain changes in schizophrenic disorders. Indications of early neuronal developmental disturbances?

Nervenarzt $\underline{79}(3), 275-87$

Karow T, Roth- Lang R: Allgemeine und spezielle Pharmakologie und Toxikologie.17. Auflage; Selbstverlag Thomas Karow, Köln 2009

Kaspárek T, Prikryl R, Mikl M, Schwarz D, Cesková E, Krupa P (2006): Prefrontal but not temporal grey matter changes in males with first-episode schizophrenia. Prog Neuropsychopharmacol Biol Psychiatry $\underline{31}(1), 151-7$

Keilhoff G, Bernstein HG, Becker A, Grecksch G, Wolf G (2004): Increased neurogenesis in a rat ketamine model of schizophrenia. Biol Psychiatry $\underline{56}(5), 317-22$

Kempermann G, Gast D, Kronenberg G, Yamaguchi M, Gage FH (2003): Early development and long-term persistence of adult-generated new neurons in the hippocampus of mice. Development $\underline{130}(2), 391-9$

Kessler S (1980): The genetics of schizophrenia: A review. Schizophr Bull $\underline{6}(3), 404-16$

Kiessling M, Stumm G, Xie Y, Herdegen T, Aguzzi A, Bravo R, Gass P (1993): Differential transcription and translation of immediate early genes in the gerbil hippocampus after transient global ischemia. J Cereb Blood Flow Metab 13(6), 914-24

Kirch DG (1993): Infection and autoimmunity as etiologic factors in schizophrenia: a review and reappraisal. Schizophr Bull 19(2), 355-70

Koketsu D, Furuichi Y, Maeda M, Matsuoka N, Miyamoto Y, Hisatsune T (2006): Increased number of new neurons in the olfactory bulb and hippocampus of adult non-human primates after focal ischemia. Exp Neurol 199(1), 92-102

Komuro H, Rakic P (1993): Modulation of neuronal migration by NMDA receptors.

Science $\underline{260}(5104), 95-7$ 
Kornhuber J, Wiltfang J, Bleich S (2004): The etiopathogenesis of schizophrenias. Pharmacopsychiatry $\underline{37}$ Suppl2, S103-12

Kotlicka-Antczak M, Gmitrowicz A, Sobów TM, Rabe-Jablonska J (2001): Obstetric complications and apgar score in early- onset schizophrenic patients with prominent positive and prominent negative symptomes. J Psychiatr Res 35(4), 249-57

Krajnc D, Neff NH, Hadjiconstantinou M (1996): Glutamate, glutamine and glutamine synthetase in the neonatal rat brain following hypoxia. Brain Res $\underline{707}(1), 134-7$

Kuhn HG, Dickinson- Anson H, Gage FH (1996): Neurogenesis in the dentate gyrus of the adult rat: age related decrease of neuronal progenitor proliferation.

J Neurosci 16(6), 2027-33

Kuhn HG, Palmer TD, Fuchs E (2001): Adult neurogenesis: a compensatory mechanism for neuronal damage. Eur Arch Psychiatry Clin Neurosci 251(4), 152-8

Laruelle M, Abi-Dargham A, vanDyck CH, Gil R, D'Souza CD, Erdos J, McCane E, Rosenblatt W, Fingado C, Zoghbi SS (1996): Single photon emission computerized tomography imaging of amphetamine- induced dopamine release in drug- free schizophrenic subjects. Proc Nat Acad Sci USA 93(17): 9235-40

Lee YM, Jeong CH, Koo SY, Son MJ, Song HS, Bae SK, Raleigh JA, Chung HY, Yoo MA, Kim KW (2001): Determination of hypoxic region by hypoxia marker in developing mouse embryos in vivo: a possible signal for vessel development. Dev Dyn 220(2), 175-86

Le Strat Y, Ramoz N, Gorwood P (2009): The role of genes involved in neuroplasticity and neurogenesis in the observation of a gene-environment interaction (GxE) in schizophrenia. Curr Mol Med $\underline{9}(4)$, 506-18

Leung A, Chue P (2000): Sex differences in schizophrenia, a review of the literature. Acta Psychiatr Scand Suppl $\underline{401}$, 3-38.

Levison SW, Rothstein RP, Romanko MJ, Snyder MJ, Meyers RL, Vannucci SJ (2001): Hypoxia/ischemia depletes the rat perinatal subventricular zone of oligodendrocyte progenitors and neural stem cells. Dev Neurosci $\underline{23}(3), 234-47$ 
Lewis SW, Murray RM (1987): Obstetric complications, neurodevelopmental deviance, and risk of schizophrenia. J Psychiatr Res 21(4), 413-21

Li YB, Kaur C, Ling EA (1998): Neuronal degeneration and microglial reaction in the fetal and postnatal rat brain after transient maternal hypoxia. Neurosci Res $\underline{32}(2), 137-48$

Lieberman J, Chakos M, Wu H, Alvir J, Hoffman E, Robinson D, Bilder R (2001): Longitudinal study of brain morphology in first episode schizophrenia.

Biol Psychiatry 49 (6), 487-99

Lipska BK, Jaskiw GE, Weinberger DR (1993): Postpubertal emergence of hyperresponsiveness to stress and to amphetamine after neonatal excitotoxic hippocampal damage: a potential animal model of schizophrenia. Neuropsychopharmacology $\underline{9}(1), 67-75$

Liu J, Solway K, Messing RO, Sharp FR (1998): Increased neurogenesis in the dentate gyrus after transient global ischemia in gerbils. J Neurosci 18(19), 7768-78

Lodge D, Anis NA (1982): Effects of phencyclidine on excitatory aminoacid activation of spinal interneurons in the cat. Eur J Pharmacol $\underline{77}(2-3), 203-4$

Lui S, Deng W, Huang X, Jiang L, Ma X, Chen H, Zhang T, Li X, Li D, Zou L (2009):

Association of cerebral deficits with clinical symptoms in antipsychotic-naive first-episode schizophrenia: an optimized voxel-based morphometry and resting state functional connectivity study. Am J Psychiatry 166(2), 196-205

Luzzati F, De Marchis S, Fasolo A, Peretto P (2006): Neurogenesis in the caudate nucleus of the adult rabbit. J Neurosci 26(2), 609-21

Madsen TM, Yeh DD, Valentine GW, Duman RS (2005): Electroconvulsive seizure treatment increases cell proliferation in rat frontal cortex.

Neuropsychopharmacology. $\underline{30}(1), 27-34$

Malberg JE, Eisch AJ, Nestler EJ, Duman RS (2000): Chronic antidepressant treatment increases neurogenesis in adult rat hippocampus. J Neurosci 20(24), 9104-10 
Mallard EC, Rehn A, Rees S, Tolcos M, Copolov D (1999): Ventriculomegaly and reduced hippocampal volume following intrauterine growth-restriction: implications for the aetiology of schizophrenia. Schizophr Res $\underline{40}(1), 11-21$

Mallard C, Loeliger M, Copolov D, Rees S (2000): Reduced number of neurons in the hippocampus and the cerebellum in the postnatal guinea-pig following intrauterine growthrestriction. Neuroscience $\underline{100}(2), 327-33$

Marcotte ER, Pearson DM, Srivastava LK (2001): Animal models of schizophrenia: a critical review. J Psychiatry Neurosci 26 (5), 395-410

Mc Neil TF, Cantor-Graae E, Weinberger DR (2000): Relationship of obstetric complications and differences in size of brain structures in monozygotic twin pairs discordant for schizophrenia. Am J Psychiatry 157(2), 203-12

Mednick SA, Machon RA, Huttunen MO, Bonett D (1988): Adult schizophrenia following prenatal exposure to an influenza epidemic. Arch Gen Psychiatry $\underline{45}(2), 189-92$

Meshul CK, Bunker GL, Mason JN, Allen C, Janowsky A (1996): Effects of subchronic Clozapine and Haloperidol on striatal glutamatergic synapses. J Neurochem $\underline{76}(5), 1965-73$

Meyer U, Feldon J (2010): Epidemiology-driven neurodevelopmental animal models of schizophrenia. Prog Neurobiol 90(3), 285-326

Mishra OP, Delivoria- Papapopoulos M (1999): Cellular mechanism of hypoxic injury in the developing brain. Brain Res Bull $\underline{48}(3)$, 233-38

Mittal VA, Ellman LM, Cannon TD (2008): Gene- environment interaction and covariation in schizophrenia: the role of obstetric complications. Schizophr Bull $\underline{34}(6), 1083-94$

Moghaddam B, Adams B, Verma A, Daly D (1997): Activation of glutamatergic neurotransmission by ketamine: a novel step in the pathway from NMDA receptor blockade to dopamindergic and cognitive disruptions associated with the prefrontal cortex.

J Neurosci 17(8), 2921-7

Möller HJ, Laux G, Deisler A: Duale Reihe Psychiatrie und Psychotherapie. 3. Auflage; Georg Thieme Verlag, Stuttgart 2005 
Morales P, Fiedler JL, Andrés S, Berrios C, Huaiquín P, Bustamante D, Cardenas S, Parra E, Herrera-Marschitz M (2008): Plasticity of hippocampus following perinatal asphyx-

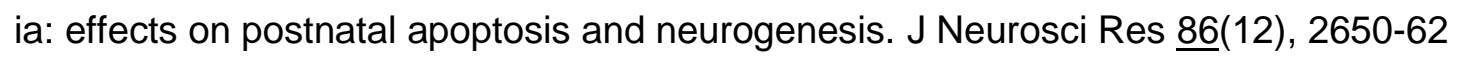

Müller DJ, Barkow K, Kovalenko S, Ohlraum S, Fangerau H, Kölsch H, Lenke MR, Held T, Nöthen MM, Maier W, Heun R, Rietschel M (2005): Suicide attempts in schizophrenia and affective disorders with relation to some specific demographical and clinical characteristics. Eur Psychiatry 20(1), 65-9

Nadri C, Belmaker RH, Agam G (2007): Oxygen restriction of neonate rats elevates neuregulin-1alpha isoform levels: possible relationship to schizophrenia.

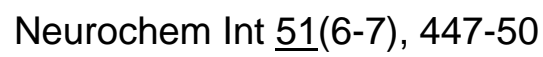

Northington FJ, Ferriero DM, Flock DL, Martin LJ (2001): Delayed neurodegeneration in neonatal rat thalamus after hypoxia-ischemia is apoptosis. J Neurosci 21(6), 1931-8

Nuechterlein KH, Dawson ME, Ventura J, Gitlin M, Subotnik KL, Snyder KS, Mintz J, Bartzokis G (1994): The vulnerability/stressmodel of schizophrenic relapse.

Acta Psychiatr Scand Suppl $\underline{382}$, 58-64

O'Callaghan E, Gibson T, Colohan HA, Buckley P, Walshe DG, Larkin C, Waddington JL (1992): Risk of schizophrenia in adults born after obstetric complications and their association with early onset of illness: a controlled study. BMJ $\underline{305}(6864), 1256-9$

Olney JW, Farber NB (1995a): NMDA antagonists as neurotherapeutic drugs, psychotogens, neurotoxins, and research tolls for studying schizophrenia. Neurophsychopharmacology $\underline{13}(4), 335-45$

Olney JW, Farber NB (1995b): Glutamate receptor dysfunction and schizophrenia.

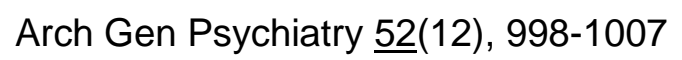

Ong J, Plane JM, Parent JM, Silverstein FS (2005): Hypoxic-ischemic injury stimulates subventricular zone proliferation and neurogenesis in the neonatal rat.

Pediatr Res $\underline{58}(3), 600-6$ 
Osato K, Sato Y, Ochiishi T, Osato A, Zhu C, Sato M, Swanpalmer J, Modjtahedi N, Kroemer G, Kuhn HG (2010): Apoptosis-inducing factor deficiency decreases the proliferation rate and protects the subventricular zone against ionizing radiation. Cell Death Dis $\underline{1}$, e84

Palmer TD, Markakis EA, Willhoite AR, Safar F, Gage FH (1999): Fibroblast growth factor2 activates a latent neurogenic program in neural stem cells from diverse regions of the adult CNS. J Neurosci 19 19 (19), 8487-97

Parent JM, Vexler ZS, Gong C, Derugin N, Ferriero DM (2002): Rat forebrain neurogenesis and striatal neuron replacement after focal stroke. Ann Neurol $\underline{52}(6), 802-13$

Park KI, Himes BT, Stieg PE, Tessler A, Fischer I, Snyder EY (2006): Neural stem cells may be uniquely suited for combined gene therapy and cell replacement: Evidence from engraftment of Neurotrophin-3-expressing stem cells in hypoxic-ischemic brain injury. Exp Neurol $\underline{199}(1), 179-90$

Paxinos G, Watson C: The rat brain in stereotaxic coordinates. 4. Auflage; Academic Press, San Diego 1998

Plane JM, Liu R, Wang TW, Silverstein FS, Parent JM (2004): Neonatal hypoxic-ischemic injury increases forebrain subventricular zone neurogenesis in the mouse. Neurobiol Dis $\underline{16}(3), 585-95$

Porsolt RD, Moser PC, Castagné V (2010): Behavioral indices in antipsychotic drug discovery. J Pharmacol Exp Ther $\underline{333}(3), 632-8$

Pourié G, Blaise S, Trabalon M, Nédélec E, Guéant JL, Daval JL (2006):

Mild, non-lesioning transient hypoxia in the newborn rat induces delayed brain neurogenesis associated with improved memory scores. Neuroscience 140(4), 1369-79

Pschyrembel: Klinisches Wörterbuch. 259. Auflage; Walter de Gruyter, Berlin, New York 2002

Ray J, Peterson DA, Schinstine M, Gage FH (1993): Proliferation, differentiation, and longterm culture of primary hippocampal neurons. Proc Natl Acad Sci U S A 90(8), 3602-6 
Rees S, Inder T (2005): Fetal and neonatal origins of altered brain development. Early Hum Dev 81(9), 753-61

Rees S, Breen S, Loeliger M, McCrabb G, Harding R (1999) Hypoxemia near midgestation has long-term effects on fetal brain development. J Neuropathol Exp Neurol $\underline{58}(9), 932-45$

Rehn AE, Van Den Buuse M, Copolov D, Briscoe T, Lambert G, Rees S (2004): An animal model of chronic placental insufficiency: relevance to neurodevelopmental disorders including schizophrenia. Neuroscience $\underline{129}(2), 381-91$

Reif A, Fritzen S, Finger M, Strobel A, Lauer M, Schmitt A, Lesch KP (2006): Neural stem cell proliferation is decreased in schizophrenia, but not in depression.

Mol Psychiatry 11(5), 514-22

Reif A, Schmitt A, Fritzen S, Lesch KP (2007): Neurogenesis and schizophrenia: dividing neurons in a divided mind? Eur Arch Psychiatry Clin Neurosci 257(5), 290-9

Ripke S, O'Dushlaine C, Chambert K, Moran JL, Kähler AK, Akterin S, Bergen SE, Collins AL, Crowley JJ, Fromer M (2013): Genome-wide association analysis identifies 13 new risk loci for schizophrenia. Nat Genet $\underline{45}(10), 1150-9$

Ripke S, Neale BM, Corvin A, Walters JT, Farh KH, Holmans PA, Lee P, Bulik-Sullivan B, Collier DA, Huang H (2014): Biological insights from 108 schizophrenia-associated genetic loci. Nature $\underline{511}(7510), 421-7$

Romijn HJ, Hofman MA, Gramsbergen A (1991): At what age is the developing cerebral cortex of the rat comparable to that of the full-term newborn human baby?

Early Hum Dev $\underline{26}(1), 61-7$

Rosso IM, Cannon TD, Huttunen T, Huttunen MO, Lönnqvist J, Gasperoni TL (2000): Obstetric risk factors for early- onset schizophrenia in a Finnish birth cohort. Am J Psychiatry 157(5), 801-7

Sams-Dodd F, Lipska BK, Weinberger DR (1997): Neonatal lesions of the rat ventral hippocampus result in hyperlocomotion and deficits in social behaviour in adulthood. Psychopharmacology (Berl) 132(3), 303-10 
Sapolsky RM, Meaney MJ (1986): Maturation of the adrenocortical stress response: Neuroendocrine control mechanisms and the stress hyporesponsive period.

Brain Res 396(1), 64-76

Scheepens A, Wassink G, Piersma MJ, Van de Berg WD, Blanco CE (2003): A delayed increase in hippocampal proliferation following global asphyxia in the neonatal rat. Brain Res Dev Brain Res 142(1), 67-76

Schlett K (2006): Glutamate as a modulator of embryonic and adult neurogenesis.

Curr Top Med Chem $\underline{6}(10)$, 949-60

Schloesser RJ, Lehmann M, Martinowich K, Manji HK, Herkenham M (2010): Environmental enrichment requires adult neurogenesis to facilitate the recovery from psychosocial stress. Mol Psychiatry 15(12), 1152-63

Schmidt-Kastner R, van Os J, W M Steinbusch H, Schmitz C (2006): Gene regulation by hypoxia and the neurodevelopmental origin of schizophrenia. Schizophr Res 84(2-3), 253-71

Schmidt-Kastner R, van Os J, Esquivel G, Steinbusch HW, Rutten BP (2012): An environmental analysis of genes associated with schizophrenia: hypoxia and vascular factors as interacting elements in the neurodevelopmental model. Mol Psychiatry 17(12), 1194-205

Schmitt A, Weber S, Jatzko A, Braus DF, Henn FA (2004): Hippocampal volume and cell proliferation after acute and chronic clozapine or haloperidol treatment.

J Neural Transm 111(1), 91-100

Schmitt A, Fendt M, Zink M, Ebert U, Starke M, Berthold M, Herb A, Petroianu G, Falkai P, Henn FA (2007): Altered NMDA receptor expression and behaviour following postnatal hypoxia: potential relevance to schizophrenia. J Neural Transm 114(2), 239-48

Schmitt A, Parlapani E, Gruber O, Wobrock T, Falkai P (2008): Impact of neuregulin-1 on the pathophysiology of schizophrenia in human post-mortem studies. Eur Arch Psychiatry Clin Neurosci 258 (Suppl 5), 35-9

Schmitt A, Parlapani E, Falkai P (2009a): Ist die Schizophrenie eine Störung der Synaptound oder Neurogenese? J Neurol Neurochir Psychiatr 10(2), 72-6 
Schmitt A, Steyskal C, Bernstein HG, Schneider-Axmann T, Parlapani E, Schaeffer EL, Gattaz WF, Bogerts B, Schmitz C, Falkai P (2009b): Stereologic investigation of the posterior part of the hippocampus in schizophrenia. Acta Neuropathol 117(4), 395-407

Schmitt A, Malchow B, Hasan A, Falkai P (2014): The impact of environmental factors in severe psychiatric disorders. Front Neurosci $\underline{8}, 19$

Schmitz C, Hof PR (2005): Design-based stereology in neuroscience.

Neuroscience $\underline{130}(4), 813-31$

Schwab SG, Wildenauer DB (2013): Genetics of psychiatric disorders in the GWAS era: an update on schizophrenia. Eur Arch Psychiatry Clin Neurosci 263(Suppl 2), 147-54

Seemann P, Chau-Wong M, Tedesco J, Wong K (1975): Brain receptors for antipsychotic drugs and dopamine: Direct binding assays. Proc Nat Acad Sci USA $\underline{72(11), 4376-80}$

Sigma-Aldrich: Handbuch Feinchemikalien 2009/2010.1. Auflage; The SIGMA-ALDRICH Group, Taufkirchen 2009

Simon M, Czéh B, Fuchs E (2005): Age-dependent susceptibility of adult hippocampal cell proliferation to chronic psychosocial stress. Brain Res 1049(2), 244-8

Stibbs HH (1985): Changes in brain concentrations of catecholamines and indoleamines in Toxoplasma gondii infected mice. Ann Trop Med Parasitol $\underline{79}(2), 153-7$

Stroka DM, Burkhardt T, Desbaillets I, Wenger RH, Neil DA, Bauer C, Gassmann M, Candinas D (2001): HIF-1 is expressed in normoxic tissue and displays an organ-specific regulation under systemic hypoxia. FASEB J $\underline{15}(13), 2445-53$

Sullivan PF, Kendler KS, Neale MC (2003): Schizophrenia as a complex trait: evidence from a meta-analysis of twin studies. Arch Gen Psychiatry $\underline{60}(12), 1187-92$

Sun D, Bullock MR, McGinn MJ, Zhou Z, Altememi N, Hagood S, Hamm R, Colello RJ (2009): Basic fibroblast growth factor-enhanced neurogenesis contributes to cognitive recovery in rats following traumatic brain injury. Exp Neurol 216(1), 56-65 
Swanson JW, Swartz MS, Van Dorn RA, Elbogen EB, Wagner HR, Rosenheck RA, Stroup TS, McEvoy JP, Liebermann JA (2006): A national study of violent behaviour in persons with schizophrenia. Arch Gen Psychiatry $\underline{63}(5), 490-9$

Swerdlow NR, Geyer MA; Braff DL (2001): Neural circuit regulation of prepulse inhibition of startle in the rat: current knowledge and future challenges.

Psychopharmacology (Berl) 156(2-3), 194-215

Taj R, Khan S (2005): A study of non- compliance to psychiatric treatment.

J Ayub Med Coll Abbottabad 17(2), 26-8

Takagi Y, Nozaki K, Takahashi J, Yodoi J, Ishikawa M, Hashimoto N (1999): Proliferation of neuronal precursor cells in the dentate gyrus is accelerated after transient forebrain ischemia in mice. Brain Res $\underline{831}(1-2), 283-7$

Takahashi T, Nowakowski RS, Caviness VSJr (1992): BUdR as an S- phase marker for quantitative studies of cytokinetic behaviour in the murine cerebral ventricular zone.

J Neurocytol 21(3), 185-97

Takizawa Y, Takashima S, Itoh M (2006): A histopathological study of premature and mature infants with pontosubicular neuron necrosis: neuronal cell death in perinatal brain damage. Brain Res 1095(1), 200-6

Tashiro A, Sandler VM, Toni N, Zhao C, Gage FH (2006): NMDA-receptor-mediated, cellspecific integration of new neurons in adult dentate gyrus. Nature 442 (7105), 929-33

Taupin P (2007): BrdU immunohistochemistry for studying adult neurogenesis: paradigms, pitfalls, limitations, and validation. Brain Res Rev $\underline{53}(1), 198-214$

Thor DH, Holloway WR (1982): Social memory of the male laboratory rat.

J Comp Physiol Psychol 96(6), 1000-6

TILL JE, MCCULLOCH EA, SIMINOVITCH L (1964): A STOCHASTIC MODEL OF STEM CELL PROLIFERATION, BASED ON THE GROWTH OF SPLEEN COLONY-FORMING CELLS. Proc Natl Acad Sci U S A 51, 29-36 
Tissir F, Goffinet AM (2003): Reelin and brain development.

Nat Rev Neurosci $\underline{4}(6)$, 496-505

Torrey EF, Torrey BB, Peterson MR (1977): Seasonality of schizophrenic births in the United states. Arch Gen Psychiatry $\underline{34}(9), 1065-70$

Trollmann R, Gassmann M (2009): The role of hypoxia-inducible transcription factors in the hypoxic neonatal brain. Brain Dev $\underline{31}(7), 503-9$

Trollmann R, Strasser K, Keller S, Antoniou X, Grenacher B, Ogunshola OO, Dötsch J, Rascher W, Gassmann M (2008): Placental HIFs as markers of cerebral hypoxic distress in fetal mice. Am J Physiol Regul Integr Comp Physiol 295(6), R1973-81

van den Tweel ER, Kavelaars A, Lombardi MS, Nijboer CH, Groenendaal F, van Bel F, Heijnen CJ (2006): Bilateral molecular changes in a neonatal rat model of unilateral hypoxicischemic brain damage. Pediatr Res $\underline{59}(3), 434-9$

Van Erp TG, Saleh PA, Rosso IM, Huttunen M, Lönnqvist J, Pirkola T, Salonen O, Valanne L, Poutanen VP, Standertskjöld-Nordenstam CG (2002): Contributions of genetic risk and fetal hypoxia to hippocampal volume in patients with schizophrenia or schizoaffective disorder, their unaffected siblings, and healthy unrelated volunteers.

Am J Psychiatry 159(9), 1514-20

Vicini S (2008): The role of GABA and glutamate on adult neurogenesis.

J Physiol 568(16), 3737-8

Walker EF, Diforio D (1997): Schizophrenia: a neural diathesis-stress model. Psychol Rev $\underline{104}(4), 667-86$

Watson DR, Anderson JM, Bai F, Barrett SL, McGinnity TM, Mulholland CC, Rushe TM, Cooper SJ (2012): A voxel based morphometry study investigating brain structural changes in first episode psychosis. Behav Brain Res $\underline{227}(1), 91-9$

Weinberger DR (1987): Implications of normal brain development for the pathogenesis of schizophrenia. Arch Gen Psychiatry $\underline{44}(7), 660-9$ 
Weinberger DR (1996): On the plausibilitiy of "the neurodevelopmental hypothesis" of schizophrenia. Neuropsychopharmacology 14 (3 Suppl), 1S-11S

Westerberg E, Monaghan DT, Kalimo H, Cotman CW, Wieloch TW (1989): Dynamic changes of excitatory amino acid receptors in the rat hippocampus following transient cerebral ischemia. J Neurosci $\underline{9}(3), 798-805$

WHO (World Health Organization): Schizophrenia October 2014. http://www.who.int/mediacentre/factsheets/fs397/en/ (letzter Zugriff am 23.11.2014)

Wobrock T, Pajonk FG, Falkai P (2004a): Schizophrenia.

Fortschr Neurol Psychiatr $\underline{72(2), 98-113}$

Wobrock T, Falkai P, Pajonk FG (2004b): Acute treatment of schizophrenia.

Fortschr Neurol Psychiatr $\underline{72}$ (12), 705-23

Won SJ, Kim SH, Xie L, Wang Y, Mao XO, Jin K, Greenberg DA (2006): Reelin-deficient mice show impaired neurogenesis and increased stroke size. Exp Neurol 198(1), 250-9

Yang Z, Levison SW (2007): Perinatal hypoxic/ischemic brain injury induces persistent production of striatal neurons from subventricular zone progenitors. Dev Neurosci 29(4-5), 33140

Yolken RH, Dickerson FB, Fuller Torrey E (2009): Toxoplasma and schizophrenia. Parasite Immunol 31(11), 706-15

Young AH, Blackwood DH, Roxborough H, McQueen JK, Martin MJ, Kean D (1991): A magnetic resonance imaging study of schizophrenia: brain structure and clinical symptoms. Br J Psychiatry $\underline{158}, 158-64$

Yuan J, Yankner BA (2000): Apoptosis in the nervous system. Nature $\underline{407(6805), ~ 802-9}$

Zhang RL, Zhang ZG, Zhang L, Chopp M (2001): Proliferation and differentiation of progenitor cells in the cortex and the subventricular zone in the adult rat after focal cerebral ischemia. Neuroscience $\underline{105}(1), 33-41$ 
Zheng T, Rossignol C, Leibovici A, Anderson KJ, Steindler DA, Weiss MD (2006): Transplantation of multipotent astrocytic stem cells into a rat model of neonatal hypoxicischemic encephalopathy. Brain Res 1112(1), 99-105

Zhu LL, Zhao T, Li HS, Zhao H, Wu LY, Ding AS, Fan WH, Fan M (2005):

Neurogenesis in the adult rat brain after intermittent hypoxia. Brain Res 1055(1-2), 1-6

Zornberg GL, Buka SL, Tsuang MT (2000): Hypoxic-ischemia-related fetal/neonatal complications and risk of schizophrenia and other nonaffective psychoses: a 19-year longitudinal study. Am J Psychiatry 157(2), 196-202 


\section{Danksagung}

Ich bedanke mich bei Prof. Dr. med. Andrea Schmitt für die Vergabe des Dissertationsthemas sowie die intensive Betreuung und das offene Ohr für viele Fragen.

Des Weiteren bedanke ich mich bei Dr. rer. nat. Angelika Schmitt der Universität Würzburg für die freundliche Hilfe beim Erlernen der immunhistochemischen Färbung sowie bei Dr. rer. nat. Evelin Schaeffer für die Unterstützung bei den Tierversuchen.

Ich bedanke mich des Weiteren bei Dr. med. Eleni Parlapani für die Einführung in das Stereologiemikroskop und bei Thomas Schneider-Axmann für die Durchführung der statistischen Auswertung und die Beantwortung meiner Fragen zu ebendieser. 